\title{
Multi-layered chromatin proteomics identifies cell vulnerabilities in DNA repair
}

\author{
Gianluca Sigismondo ${ }^{1}$, Lavinia Arseni ${ }^{2}$, Thomas G Hofmann ${ }^{3}$, Martina Seiffert ${ }^{2}$, Jeroen Krijgsveld ${ }^{1,4,}{ }^{*}$ \\ (1) Division of Proteomics of Stem Cells and Cancer, German Cancer Research Center (DKFZ), \\ Heidelberg, Germany \\ (2) Division of Molecular Genetics, German Cancer Research Center (DKFZ), Heidelberg, Germany. \\ (3) Institute of Toxicology, University Medical Center of the Johannes Gutenberg University Mainz, Mainz, \\ Germany. \\ (4) Heidelberg University, Medical Faculty, Heidelberg, Germany
}

* To whom correspondence should be addressed. Tel: +49 622142 1720, Email: j.krijgsveld@dkfz.de

\section{SUMMARY}

The DNA damage response (DDR) is essential to maintain genome stability, and its deregulation predisposes to carcinogenesis while encompassing attractive targets for cancer therapy. Chromatin governs the DDR via interplay among all chromatin layers including DNA, histones post-translational modifications (hPTMs), and chromatin-associated proteins. Here we employ multi-layered proteomics to characterize chromatin-mediated interactions of repair proteins, signatures of hPTMs, and the DNAbound proteome during DNA double-strand break repair at high temporal resolution. We functionally attribute novel chromatin-associated proteins to repair by non-homologous end-joining or homologous recombination (HR) revealing histone reader ATAD2, microtubule organizer TPX2 and histone methyltransferase G9A as regulators of HR and PARP inhibitor sensitivity. Furthermore, we dynamically profile numerous $\mathrm{hPTMs}$ at $\mathrm{YH} 2 \mathrm{AX}$-mononucleosomes during the DDR. Integration of these complementary data implicated G9A-mediated monomethylation of H3K56 in HR. Collectively, we provide a dynamic chromatin-centered view of DDR, while representing a valuable resource for the use of PARP inhibitors in cancer.

\section{KEYWORDS}

Chromatin dynamics, DSB repair, hPTMs, PARPi, mass spectrometry-based proteomics, pathway choice, HR, NHEJ

\section{INTRODUCTION}

DNA damage represents a major risk for genome stability, and among the different types of lesions, double-strand breaks (DSBs) are the most detrimental if not properly repaired, predisposing to DNA mutations and loss of genomic information. To prevent genome instability, two main repair mechanisms have evolved: the error-prone non-homologous end joining (NHEJ) based on fast ligation of damaged sites, and homologous-directed recombination (HDR or HR) where sister chromatid is used as template for error-free DSB repair (Harper and Elledge, 2007; Huertas, 2010; Jackson and Bartek, 2009; San Filippo et al., 2008). Notably, DNA damage repair (DDR) occurs in the context of chromatin, a higher 
ordered structure composed of DNA wrapped around histone proteins, and stabilized by non-histone components (Probst et al., 2009). Upon DSB formation, chromatin determinants reorganize the structure surrounding the lesion, activate a specific signaling cascade and recruit the repair machinery for an efficient resolution of the DSB via either NHEJ or HR (Green and Almouzni, 2002). In particular, the sensor complex composed of MRE11, RAD50 and NBN (or MRN complex) rapidly accumulates at damaged sites, where it recruits the ATM protein kinase responsible for the phosphorylation of the histone variant $\mathrm{H} 2 \mathrm{~A} . \mathrm{X}$ (referred to as $\mathrm{YH} 2 \mathrm{AX}$ ). This histone post translational modification (hPTM) thus marks damaged sites and recruits MDC1 and TP53BP1/53BP1 that, together with the XRCC6-XRCC5 proteins, promote NHEJ repair. The MRN complex plays a pivotal role as it also promotes extensive endresection, thus creating single-stranded DNA (SSDNA) filaments rapidly stabilized by the replication factor RPA1. The protein RAD51 then replaces RPA1 and, together with BRCA1, promotes sister-chromatid strand invasion and DSB repair via HR (Aymard et al., 2014).

In the past decades, the core components of DSB repair pathways have been intensively studied (Boeing et al., 2016; Gupta et al., 2018; Haahr et al., 2016; Raschle et al., 2015); however it is only partially understood how these machineries are functionally embedded in the broader chromatin context, and, conversely, how chromatin determinants impinge on repair pathway choice (Schep et al., 2021). Beyond $\mathrm{yH} 2 \mathrm{AX}$, the role of other hPTMs in DDR has come into focus (Clouaire et al., 2018), either by regulating DNA accessibility and chromatin stiffness (Downs et al., 2004; Jha et al., 2008; Kusch et al., 2004; Murr et al., 2006), or by acting as docking sites for the recruitment of DSB repair proteins (Botuyan et al., 2006; Pellegrino et al., 2017; Saredi et al., 2016; Simonetta et al., 2018). As a consequence, a conceptual model for DDR is emerging requiring the coordinated action across the different chromatin layers, including DNA, histones, hPTMs, chromatin remodeling complexes and other chromatin-associated proteins, and components of DSB machineries, to collectively ensure successful DNA repair. How these are functionally connected, and how they are temporally regulated upon induction of DSBs, are major questions that remain to be resolved.

Proteins participating in DDR are often de-regulated in different types of cancers. The best studied example is BRCA1 in ovarian and breast cancers, whose loss-of-function results in the accumulation of mutations and predisposes to genomic instability (Lord and Ashworth, 2016). Interestingly, deregulation of BRCA1 presents innovative therapeutic opportunities, since HR-deficient cancer cells acquire extreme sensitivity to inhibitors of Poly-ADP-ribose polymerase (or PARPi). Indeed, in an HR-deficient background (i.e. BRCAness or HRDness) (Pilie et al., 2019), ssDNA breaks that are normally repaired by PARP are instead converted to DSBs during DNA replication, thus promoting catastrophic genome rearrangements and cancer cell death. Genomic screens are therefore broadly employed to identify synthetic lethality with drugs such as PARPi. Nevertheless, patients often develop resistance, thus indicating the need for a deeper characterization of the repair process in order to rationally propose alternative drug targets.

The complexity of DDR suggests that no single approach can capture the regulation of this fundamental biological process. Therefore, we here bring together the unbiased nature of mass spectrometry with three complementary strategies to study DSB-induced chromatin dynamics at different scales of resolution, namely i) chromatin-wide by investigating the DNA-bound proteome (iPOC), ii) targeted at chromatin domains by identifying chromatin-associated interactors of known DDR proteins (ChIP-SICAP) (Rafiee et al., 2016; Rafiee et al., 2020), and iii) at the level of mono-nucleosomes to determine PTM profiles (N-ChroP) (Soldi and Bonaldi, 2013; Soldi et al., 2017). This allowed for characterization of the DDR process from a chromatin-centered perspective in unprecedented detail and with high temporal resolution. In particular, we determine IR-dependent on-chromatin interactions with DDR proteins, we determine time-resolved association of proteins at a chromatin-wide scale, and we dynamically profile dozens of hPTMs at $\mathrm{yH} 2 \mathrm{AX}$-marked mononucleosomes during DDR. We combine this with functional 
assays to assign the role of several newly identified candidates in the regulation of NHEJ, HR or pathway choice, and we show that depletion of novel HR proteins (G9A, ATAD2, TPX2) is synthetic lethal with PARPi. Finally, data integration across chromatin layers allowed the reconstruction of cause-effect mechanisms between DSB-mediated chromatin recruitment and epigenetic regulation during DNA repair. This demonstrated that the G9A substrate H3K56 is rapidly mono-methylated specifically in $\mathrm{yH} 2 \mathrm{AX}$ mononucleosomes, and that downregulation of G9A causes impairment in HR and sensitizes to PARPi. Collectively, our data not only provide mechanistic detail in causal effects of DSB-mediated chromatin dynamics, but also identifies cell vulnerabilities as potential leads for therapeutic intervention.

\section{RESULTS}

\section{Identification of on-chromatin interactors of MDC1 and RPA upon DSB repair}

We employed ChIP-SICAP (Rafiee et al., 2016) in cells subjected to ionizing radiation (IR), an efficient inducer of double-strand breaks (DSBs), to identify novel chromatin-bound proteins that are involved in double-strand break (DSB) repair. In particular, we targeted three core components of the DNA repair machinery: the mediator of checkpoint MDC1, the MRN complex subunit RAD50 and the HR protein RPA. We used a triple-SILAC labeling approach (Hilger and Mann, 2012) to distinguish on-chromatin binders from background in IgG controls, and to accurately quantify DSB-induced changes in protein interactomes [Fig. $1 \mathrm{~A}]$. In each experiment, the bait was among the most enriched proteins, indicating the specificity of ChIP-SICAP, along with histones, reflecting successful chromatin enrichment [Fig.S1A-C]. Moreover, between 40 and $75 \%$ of the interactors were identified exclusively in the on-chromatin fraction, thus providing further evidence of the specificity of the approach [Fig.S1D-F]. When using RPA as bait, known components of the HR pathway (e.g. ATR, RPA2 and ETAA1) were strongly recruited on chromatin, indicating their close proximity to RPA on DNA [Fig.1B]. Moreover, specific interactors of RPA belong to gene ontologies (GOs) associated with regulation of DNA damage repair and replication fork processing [Fig.1C, D]. In the RAD50 experiment, RPA1 showed strong DDR-induced recruitment, and other proteins that co-enriched with RAD50 are involved in telomere maintenance and TP53-mediated signaling [Fig.1B-D]. In contrast, ChIP-SICAP for MDC1 identified different core components of the NHEJ machinery (e.g. 53BP1, XRCC5 and XRCC6), especially in the on-chromatin fraction [Fig.S1G-M]. Our data readily revealed also the dynamic on-chromatin cross-talk between 53BP1 and MDC1, the two $\mathrm{YH} 2 \mathrm{AX}$ readers driving NHEJ repair [Fig.1B, Fig.S1G]. In particular, specific MDC1-interactors enriched GOs terms involved in DNA repair [Fig.1B-D]. When comparing on-chromatin interactors of either RPA or MDC1, we observed that DNA repair components involved in HR and NHEJ machineries were predominantly enriched, respectively; in contrast, the subunits of the MRN complex were particularly associated with RAD50 [Fig.1E]. The comparison between pathways associated with either RPA- or MDC1-specific on-chromatin interactors shows how HR and Fanconi Anemia (FA) are extremely enriched in RPA, while interactors of MDC1 belong to cell cycle and NHEJ [Fig.1F]. These results are in line with the notion on MDC1 as key regulator of the DDR cascade, in contrast with the HR-restricted role of RPA. Moreover, our results highlight the chromatin-meidated association between MDC1 and several components of the NHEJ repair (e.g. 53BP1, XRCC6, XRCC5) Besides known components of the DDR machinery, our analysis identified numerous other proteins functionally interacting with MDC1 or RPA, but not previously associated with a function in the DDR. We therefore selected several novel candidates to functionally assess their potential role in DSB repair through either HR or NHEJ repair pathways. 


\section{On-chromatin interactors of RPA and MDC1 influence DNA repair by regulating HR, NHEJ or DSB repair pathway choice}

From our ChIP-SICAP data, we selected NuMA, TRA2b and PRPF8 as HR candidates, and SMARCE1/BAF57 and HMGA2 among the proteins co-enriched with MDC1. Moreover, we selected SMARCA4/BRG1 in light of its strong enrichment with both RPA and MDC1 [Fig 2A]. To assess their direct involvement in DSB repair, we first evaluated whether their silencing had any impact on the formation and resolution of $\mathrm{yH} 2 \mathrm{AX}$ foci. To this end we used the AID-DIvA system, where the AsiSI enzyme produces a defined number of DSBs upon 4-OHT induction, while the DSB repair is promoted through Auxin-Inducible degradation of the enzyme (Aymard et al., 2014). Although all tested knockdown cells were still partially sensitized to tamoxifen treatment, they all showed a significant reduction in the number of visible $\mathrm{yH} 2 \mathrm{AX}$ foci and lower repair efficiency, thus suggesting that all candidates have an important role in DSB repair or are crucial for $\mathrm{YH} 2 \mathrm{AX}$ spreading upon IR [Fig.2B]. To investigate the functional role of these candidates in DSB repair in more detail, we employed isogenic U2OS-traffic-light reporter (U2OS-TLR) cells (Abu-Zhayia et al., 2017), and used FACS-based quantification to simultaneously evaluate which of the two main DSB repair pathways is impaired upon target knockdown. Cells depleted for 53BP1 and RPA/RAD51 were used as positive controls for the selective impairment of NHEJ and HR, respectively [Fig 2C]. Silencing of HMGA2 resulted in a strong increase in the number of cells repairing DSBs via HR, while the fraction of NHEJ remained unchanged [Fig.2C, Fig.S2A, B]. In contrast, silencing of BRG1, the core component of the BAF complex, decreased the efficiency of HR repair without affecting NHEJ, implicating a role for BRG1 in HR [Fig.2C, Fig.S2A, B] in line with previous evidence (Qi et al., 2015). Moreover, silencing of TRA2b increased the frequency of DSB repair through NHEJ by $20 \%$ [Fig.2C, Fig.S2A, B].

Our results indicate that upon DNA damage BRG1 is recruited at DSB sites to promote a specific chromatin state that facilitates HR; in addition, we determined a direct role for TRA2b during HR, beyond its canonical function in RNA splicing (Tacke et al., 1998). Moreover, our observations clarify the controversial role of HMGA2 in DDR (Palmieri et al., 2011) and indicate that, similar to 53BP1, this transcriptional regulator is recruited at MDC1 sites upon DSB induction and negatively regulates $H R$, thus playing a major role in NHEJ as recently reported for HMGB1 (Cheblal et al., 2020).

Importantly, the frequency of both NHEJ and HR events can be quantified at the same time in the same cell using the U2OS-TLR assay, in contrast with most site-specific DSB repair systems where only one of the two main DSB repair pathways is characterized at a time. As a consequence, we were able to expand our analysis and to identify also protein targets involved in DSB repair pathway choice, where inhibition of such factors is expected to specifically impact on the equilibrium between NHEJ and HR. Interestingly, we showed that NuMA, SMARCE1 and PRPF8 are all important for balancing the ratio between the two main DSB repair pathways, as deletion of one of these targets leads to an increase in NHEJ mirrored by a parallel decrease in HR [Fig.2C, Fig.S2A, B]. This similar behavior thus suggests a common mechanism in preventing genomic instability. Our results corroborate the suggested involvement of NuMA and PRPF8 in DNA damage repair, while assigning a yet unknown but major role in DDR to the BAF/PBAF subunit SMARCE1 (Moreno et al., 2019; Onyango et al., 2017; Vidi et al., 2014).

We then evaluated whether the involvement in either HR or repair pathway choice indicated by the TLR assay can be effectively distinguished. We therefore selected BRG1 and NuMA as representative proteins for HR and repair pathway choice, respectively. After knockdown of either candidate, cells were exposed to increasing amounts of the topoisomerase II inhibitor etoposide for $24 \mathrm{~h}$ before performing colony formation assays (CFA) [Fig.2D, E]. Cells deficient for RPA were used as control for HR impairment in this assay. Our results clearly indicate that, in contrast to NuMA knockdown, silencing of either of the HR regulators (i.e. BRG1 and RPA) significantly sensitizes cells to low doses of etoposide 
[Fig.2D, E]. We next evaluated the potential synthetic lethality between target knockdown and treatment with the PARP inhibitor (PARPi) Olaparib, alone or in combination with $2 \mathrm{~h}$ exposure to $1 \mu \mathrm{M}$ etoposide. As expected, silencing of the HR regulator BRG1 showed synthetic lethality with PARPi, while cells depleted for TRA2b remain more resistant to such treatment, in line with results from the TLR assay, implicating TRA2b in HR by preventing NHEJ repair [Fig.2C, F]. On the contrary, knockdown of NuMA showed a modest synthetic lethality with etoposide (alone or in combination with PARPi), while SMARCE1-depleted cells were only partially sensitized to PARPi [Fig.2F]. These observations strongly suggest that the increase in NHEJ observed upon knockdown of a DSB pathway choice regulator counterbalances the HR deficiency and decreases sensitivity to etoposide [Fig.2D, E]; moreover, our data indicate that NuMA and SMARCE1, recruited at RPA and MDC1 sites, respectively, have a different mechanism of action in regulating DSBs repair pathway choice.

To further investigate the role of candidates participating in HR or DSB repair pathway choice, we monitored in AID-DlvA cells the formation and resolution of RAD51 and BRCA foci, two crucial intermediates in the HR repair cascade [Fig.2G, H]. Interestingly, silencing of BRG1, NuMA or PRPF8 significantly decreased the formation of RAD51 foci upon DSB induction, in line with the common sensitization of BRG1 and NuMA knockdown cells to PARPi upon etoposide treatment [Fig.2F-H]. In contrast, depletion of TRA2b increased the amount of BRCA1 foci during DSB repair. Thus, our results show that TRA2b is enriched at RPA sites where it antagonizes NHEJ, and thereby we characterized a novel role for this target in HR, extending recent evidence on its role in BRCA1 splicing (Raponi et al., 2014). Interestingly, based on our data we determined that SMARCE1 is recruited at MDC1 where it regulates DSBs repair pathway choice. SMARCE1 depletion is associated with a significant increase in RAD51 foci in untreated conditions and causes an accumulation of unrepaired BRCA1 foci [Fig.2G, H], in line with the partial sensitization to PARPi [Fig.2F]. Importantly, none of these results can be explained by a change in cell cycle distribution upon depletion of the target proteins [Fig.S2C, D].

In summary, we clarified the mechanism of regulation of the early events of $\mathrm{HR}$, and identified a role to BRG1, NuMA and PRPF8 in promoting RAD51 foci formation, while TRA2b and SMARCE1 participate in BRCA1 foci repair. In addition, we identified NuMA, SMARCE1 and PRPF8 as important mediators able to alter the balance between NHEJ and HR. Our data also highlight that cellular systems where only HR is monitored might overestimate synthetic lethality for PARPi, while further sub-classification has the potential to increase the efficacy of drugs impacting on DDR signaling pathway.

\section{Dynamic profiling of chromatin-associated interactors of $\mathrm{yH} 2 \mathrm{AX}$}

MDC1 and 53BP1 have been identified as readers of $\mathrm{YH} 2 \mathrm{AX}$ (Kleiner et al., 2015), the first marker of DSB repair upstream of both NHEJ and HR pathways (Rogakou et al., 1998); nevertheless little is known about the identity and dynamics of other chromatin proteins at sites marked by this hPTM during DSB repair. To investigate this process, we enriched for on-chromatin interactors of $\mathrm{YH} 2 \mathrm{AX}$ via ChIP-SICAP, and we profiled their dynamics in a time course experiment upon DSB induction by IR [Fig.3A]. In particular, we employed triple-SILAC labeling to discriminate $\mathrm{YH} 2 \mathrm{AX}$-specific on-chromatin interactors from general histone ( $\mathrm{H} 2 \mathrm{~A})$-associated proteins and from non-specific background (IgG isotype control) [Fig.3A]. Among $283 \mathrm{yH} 2 \mathrm{AX}$-enriched proteins, a core set of 144 proteins was identified at all four time points [Fig.3B]. As expected, this included a strong enrichment of the $\mathrm{yH} 2 \mathrm{AX}$-reader MDC1 illustrating the efficacy of the time-course ChIP-SICAP approach in YH2AX [Fig.3B, Fig.S3A-E]. SUMO E3 ligases were overrepresented among the targets recruited to $\mathrm{YH} 2 \mathrm{AX}$ upon DSB induction [Fig.S3F], in line with the well-established role of SUMOylation in DNA repair (Cremona et al., 2012). In addition, in the same group, we identified proteins involved in RNA splicing [Fig.S3F], thus suggesting a possible stabilization 
of DSB-induced transcripts (Francia et al., 2012). In contrast, proteins evicted from yH2AX-marked sites were more globally involved in ribosome formation and regulation of translation [Fig.3SG]. Moreover, our approach adds a temporal dimension that allows the profiling of dynamic associations of chromatin factors with $\mathrm{yH} 2 \mathrm{AX}$, ranging from stable binding to interactions happening at distinct time points during the DNA repair process.

\section{THRAP3 is rapidly recruited to $\mathrm{YH} 2 \mathrm{AX}$ sites upon DNA damage}

Among the time-specific interactions, we observed that THRAP3 was recruited at $\mathrm{yH} 2 \mathrm{AX}$ sites exclusively at $1 \mathrm{~h}$ after inducing DSB [Fig 3B, C]. This protein was previously reported in an overexpression system to be highly phosphorylated upon DNA repair but to be excluded from micro-irradiated lesions (Beli et al., 2012). Here we therefore tested the co-localization of endogenous THRAP3 with yH2AX in untreated as well as irradiated cells by both immunofluorescence (IF) and proximity ligation assay (PLA). Our results confirmed the significant increase in co-localization between THRAP3 and $\mathrm{yH} 2 \mathrm{AX}$ after $1 \mathrm{~h}$ recovery upon induction of DSBs [Fig.3D]; moreover, silencing of THRAP3 significantly impaired $\mathrm{YH} 2 \mathrm{AX}$ foci formation and repair but without impacting on a specific DSB repair pathway [Fig3E, F]. Taken together, our results suggest the specific enrichment of THRAP3 at $\mathrm{yH} 2 \mathrm{AX}$ upon DSB induction, where this RNA processing factor seems to have a more structural role possibly involved in either promoting splicing of mRNA encoding repair proteins, or in the stabilization of DNA damage-induced RNAs at DSB sites.

\section{ATAD2 and TPX2 stably interact with YH2AX during DNA damage repair and play a key role in HR}

Apart from the rapid and stable recruitment of MDC1 to $\mathrm{YH} 2 \mathrm{AX}$ upon IR, we identified that the topoisomerase II alpha and the helicase DDX21, two enzymes being involved in DNA and R-loop unwinding and regulating genome stability (Song et al., 2017; Tian et al., 2021), follow a similar dynamic recruitment at $\mathrm{yH} 2 \mathrm{AX}$ during DSB repair. Among the proteins with an analogous temporal trend, we also identified candidates not yet or poorly characterized in the context of the DDR, such as the spindle protein TPX2 and the transcriptional co-activator ATAD2 [Fig.3C, Fig.S3A-E]. Upon IR, TPX2 is known to accumulate at DSBs where it binds and negatively regulates 53BP1, thus inhibiting NHEJ (Byrum et al., 2019; Neumayer et al., 2012). ATAD2 is transcriptionally induced by anti-cancer and DNA-damaging agents via ATM and ATR checkpoint kinases, and its silencing sensitizes triple-negative breast cancer cells to carboplatin treatment (Ciro et al., 2009; Duan et al., 2020). Moreover, ATAD2 might bind to hyperacetylated histone $\mathrm{H} 4$ tail through its bromodomain (Koo et al., 2016).

As derived from TCGA data, both TPX2 and ATAD2 are overexpressed or amplified in aggressive tumors [Fig.4A], and high levels of ATAD2 correlate with poor prognosis especially in breast and kidney cancer [Fig.4B]. These observations, together with the fast chromatin recruitment of ATAD2 and TPX2 at YH2AX sites upon DSB induction, prompted us to further investigate the role of these proteins in DSB repair. Our results demonstrate that knockdown of either target resulted in a significant impairment in $\mathrm{yH} 2 \mathrm{AX}$ foci formation and repair [Fig.4C, D]. In particular, while the low number of tamoxifen-induced foci in ATAD2deficient cells remained constant upon auxin treatment, depletion of TPX2 resulted in a progressive accumulation of unrepaired DSBs [Fig.4C]. To further examine the mechanism of action of these two candidates in DNA repair, we adopted the U2OS-TLR cell system and identified a dramatic impairment of over $50 \%$ in HR upon silencing of either ATAD2 or TPX2 [Fig.4D, Fig.S4A, B]. This extend is similar to depletion of the hallmark repair proteins RPA or RAD51 [Fig 2C]. To verify this result, we tested whether knockdown of ATAD2 or TPX2 conferred synthetic lethality in a combined treatment with PARPi. Indeed, 
silencing of either candidate sensitized cells to PARPi [Fig.4E]. Interestingly, the effect was synergistic with etoposide treatment in TPX2- but not in ATAD2-depleted cells [Fig.4E], thus suggesting a different mechanism in the HR pathway. We therefore evaluated the efficiency of formation and resolution of RAD51 and BRCA1 foci in AID-DIvA cells upon selective silencing. Knockdown of ATAD2 or TPX2 affected the formation of induced RAD51 foci [Fig.4F], and TPX2 silencing resulted in a strong increase of BRCA1 foci and pronounced accumulation of cells in G2/M phase [Fig.4G, Fig.S4C, D]. The effect of TPX2 silencing on the cell cycle is in line with previous reports on its interaction with Aurora kinase $A$ (AURKA) (Byrum et al., 2019). In addition, our data highlight that, in contrast with previous reports, TPX2 has a direct role in $\mathrm{HR}$ and might therefore represent a promising drug target. Collectively, our results demonstrated that TPX2 and ATAD2, which are both upregulated in cancer, functionally interact onchromatin with $\mathrm{YH} 2 \mathrm{AX}$ during DSB repair. Furthermore, depletion of either ATAD2 or TPX2 resulted in a direct impairment of $\mathrm{HR}$ and sensitization to PARPi, thus suggesting a potential benefit of combination therapy using PARPi and ATAD2i or TPX2i for the treatment of cancers where these targets are upregulated.

\section{Characterization of DNA repair-induced chromatin dynamics through Isolation of Protein On Chromatin (iPOC)}

The ChIP-SICAP experiments above represent a candidate approach, requiring a priori knowledge for the selective enrichment of chromatin-associated target proteins. We therefore aimed at extending these experiments by developing an innovative and unbiased approach to determine DSB-induced changes in overall chromatin protein composition.

Similar to recent strategies developed to study proteins interacting with nucleic acids (Alabert et al., 2014; Aranda et al., 2019; Bao et al., 2018; Kliszczak et al., 2011; Nakamura et al., 2021; Sirbu et al., 2011), we exploited the use of nucleotide mimetics as a tool to mark the DNA, leaving a chemical trace amenable for selective isolation of protein on chromatin (or iPOC). In particular, we established the conditions for the specific labeling of DNA via full incorporation of 5-Ethynyl-2'-deoxyuridine (EdU) and subsequent capture via copper-catalyzed azide-alkyne cycloaddition (CuAAC) of biotin azide [Fig.5A, Fig.S5A, B]. We combined this methodology with triple SILAC protein labeling to precisely quantify chromatin dynamics during the DDR. Specifically, medium- or heavy-labeled cells were subjected to EdU labeling and then either left untreated or collected at $1 \mathrm{~h}, 4 \mathrm{~h}, 8 \mathrm{~h}$ time points after DSB induction with IR, respectively. LightSILAC cells without EdU labeling served as negative control. At each time point, crosslinked cells from the three differently SILAC-labeled samples were mixed in equal amounts and subjected to click chemistry-based biotin labeling, followed by chromatin shearing and enrichment with protease-resistant streptavidin beads (or prS) (Rafiee et al., 2020). Upon tryptic digestion and mass spectrometry analysis, we characterized the dynamics of chromatin-binding proteins during DSB repair [Fig.5B]. To our knowledge, this represents the first time that a similar approach is employed in a quantitative and timecourse manner to describe global changes in chromatin composition. Protein quantification showed the efficient and highly reproducible enrichment $(\geq 0.85)$ of proteins identified in EdU-treated samples over the negative control [Fig.S5C, D]. High Spearman correlation $(>0.6)$ between protein abundances at different time points during DDR indicates that iPOC captures the highly dynamic nature of chromatin protein composition [Fig.S5E].

To test the sensitivity of the approach, we compared proteins enriched in iPOC with proteins quantified in extensively fractionated chromatin input at different time points during DSB repair [Fig.5C, Fig.S5F, G]. While deregulated proteins observed in the chromatin input were mainly involved in RNA processing and cell cycle [Fig.S5H, I], candidates quantified in iPOC at $1 \mathrm{~h}, 4 \mathrm{~h}$ or $8 \mathrm{~h}$ time points were enriched for gene 
ontology terms associated with DNA repair and chromatin organization [Fig.5D]. Moreover, the vast majority of proteins identified in IPOC were either not detected or not significantly deregulated in the chromatin input [Fig.5E, Fig.S5J], indicating that iPOC shows a higher sensitivity in detecting dynamics of chromatin-associated proteins. In iPOC we identified the DSB-induced chromatin recruitment of different classes of epigenetic regulators ranging from histone modifying enzymes, to structural and core components of molecular machineries regulating the DDR. Examples of DNA repair proteins that associate with chromatin upon IR were MDC1, BRG1, NuMA, but also the topoisomerase II B (TOP2B), the telomeric repeat-binding factor TERF2 and the NHEJ regulator RIF1. Interestingly, upon DSB induction, we observed an overrepresentation of chromatin-modifying enzymes among iPOC-enriched proteins, including subunits of acetyltransferase complexes (e.g. MORF4L1, KAT7 and BRD1), the histone demethylase KDM2A, the hPTM reader and transcriptional regulator PSIP/LEDGF, and the methyltransferases KMT2B/MLL4, WHSC1/NSD2, SETMAR and EHMT2/G9A [Fig.5E, Fig.S5J]. Taken together, these results demonstrate that iPOC is a very sensitive approach to identify chromatinassociated proteins, and to quantify perturbation-induced dynamics in chromatin composition, even for proteins with very fast kinetics such as chromatin remodelers.

Benefiting from the ability of iPOC to investigate the overall histone composition in chromatin, we observed that while in the chromatin input the abundance of most histones declined upon IR, this effect was generally less pronounced for DNA-bound histones identified through iPOC (Fig.S5K). Our data are therefore in line with the recently reported proteasome-mediated depletion of histones (Cheblal et al., 2020), but suggest that soluble histones might strongly contribute to this phenomenon. Even more interestingly, in $\mathrm{PPOC}$ we observed that changes in DNA-bound histones during DSB repair occurred in a time- and histone variant-specific manner, sometimes even leading to a transient increase (e.g. H1.4, H2A.1-3) (Fig.S5K). These results therefore point towards a mechanism to retain, evict or recruit distinct variants to potentially drive the DSB repair process, mirrored by the dynamic chromatin recruitment of histone chaperones observed in iPOC [Fig5E].

From the highly diverse class of proteins that was recruited to chromatin upon DSB [Fig5E], we selected three targets belonging to different functional groups to investigate their role in DNA damage repair. In particular, this included two negative prognostic markers in cancer, ANDP and PHF14 (Karagoz et al., 2019; Zhang et al., 2017), and a chromatin regulator, SMARCA1/SNF2L (Barak et al., 2003). We first evaluated the formation and repair efficiency of $\mathrm{gH} 2 \mathrm{AX}$ foci in cells after knockdown of these targets. We observed that silencing of ADNP increased the number of foci already in untreated conditions, resulting in the accumulation of unrepaired DSBs [Fig.5F]. Recent evidence showed that ADNP forms, together with CHD4 and HP1, the ChAHP remodeling complex involved in the regulation of higher-order chromatin structure (Kaaij et al., 2019). The DSB-induced recruitment of CHD4 observed in iPOC might therefore point towards a possible role of this complex in genome stability, but we cannot exclude a separate function of ADNP during DDR. In agreement with our observation on the role of ADNP in DSB repair, depletion of ADNP in U2OS-TLR cells impacted on NHEJ by negatively regulating DSB repair via HR [Fig.5G, Fig.S6A, B]. Moreover, this effect was not caused by cell cycle deregulation [Fig.S6C, D]. In contrast, similar experiments demonstrate that SMARCA1 and PHF14 are both involved in homologous recombination pathway by preventing NHEJ repair [Fig.5H, Fig.S6A, B]. In line with these results, silencing of neither SMARCA1 nor PHF14 promoted synthetic lethality with PARPi, but depletion of PHF14 sensitized to the chemotherapeutic agent etoposide and caused defective formation of RAD51 foci [Fig. $5 \mathrm{H}, \mathrm{I}]$. In contrast, we did not observe a significant impact of SMARCA1 depletion on either RAD51 or BRCA foci [Fig.5I, J], thus suggesting a more structural role for the core component of the Nucleosome remodeling factor (NuRF) during DSB repair. Collectively, our iPOC data demonstrate that ADNP, SMARCA1, and PHF14 are recruited at chromatin upon IR and that they all play a crucial role in DNA damage response. Moreover, the fast recruitment of nucleosome remodelers (e.g. SMARCA1) and 
DDR regulators (e.g. PHF14) upon DNA damage indicate how they contribute to DSB repair process through the tight interplay between regulators of DNA accessibility and DSB repair machinery.

\section{Dynamics of hPTMs in chromatin and at DSB-sites during DNA damage repair}

The overrepresentation of chromatin-modifying enzymes, in particular methyltransferase observed in iPOC, together with their fundamental function in DNA damage repair (Gong and Miller, 2019), prompted us to investigate histone PTMs as an additional regulatory layer that impinges on chromatin stiffness and accessibility to DSB sites. In particular, we employed Native Chromatin Proteomics (N-ChroP) (Soldi and Bonaldi, 2013; Soldi et al., 2017) in a time-course manner to globally characterize the dynamic changes of hPTMs on single nucleosomes during DDR (hereafter termed DDR-induced hPTMs). In addition, we profiled temporal trends of histone modifications specifically at $\mathrm{YH} 2 \mathrm{AX}$-containing mononuleosomes (hereafter: foci-specific hPTMs).

To achieve this goal, we prepared mononucleosomes from U2OS cells at different time points during IRinduced DSB repair and we profiled the hPTM-dynamics via the ad hoc ArgC-like in-gel digestion prior to mass spectrometry analysis [Fig.S7A, B]. For each hPTM, we described its relative abundance (RA) compared with the amount of concomitant modifications on the same peptide, and the relative enrichment $(R E)$ defined as the fold enrichment between the RA of a certain modification in $\mathrm{YH} 2 \mathrm{AX}$ mononucleosomes and in the chromatin input [Fig.6A]. As a result, we identified 33 different histone modifications on 14 peptides from histone $\mathrm{H} 2 \mathrm{~A}, \mathrm{H} 3$ and $\mathrm{H} 4$, and we quantified their temporal abundance during DSB repair [Fig.S7C-E]. To our knowledge, this represents the first example of unbiased and temporal profiling of histone modifications during DDR with single-nucleosome resolution. Our analyses indicate that $\mathrm{yH} 2 \mathrm{AX}$-mononucleosomes have a distinct hPTM pattern already in untreated conditions, being enriched for hyper-acetylation of histone $\mathrm{H} 4 \mathrm{~N}$-terminal "tale", a modifications associated with a more open chromatin state (Suka et al., 2001), and mono-methylated lysine 20 on histone H4 (H4K20me1) [Fig.6B], a known hPTM with pivotal role in DSB repair (Houston et al., 2008; Oda et al., 2010). These results suggest that nucleosomes containing $\mathrm{yH} 2 \mathrm{AX}$ are enriched in modifications that establish a more relaxed chromatin state, to potentially promote accessibility for the repair machinery and thus "prime" for DNA damage repair signaling. In addition, our analysis allows distinguishing globally induced hPTMs upon DSB (DDR-induced), from modifications acquired exclusively in mononucleosomes in close proximity to the break site and marked by $\mathrm{YH} 2 \mathrm{AX}$ (foci-specific). Among the DDR-induced hPTMs, we identified that dimethylated K79 on histone H3 (H3K79me2) has a bimodal enrichment at $30 \mathrm{~min}$ and $4 \mathrm{~h}$ [Fig.S7D]. This modification is enriched at transcribed regions where its levels correlate with transcript abundance (Huyen et al., 2004). Moreover, 53BP1 can act as a reader of H3K79me2 (Schubeler et al., 2004), thus suggesting an additional role of this hPTM in DDR regulation. Our results therefore suggest that $\mathrm{H} 3 \mathrm{~K} 79 \mathrm{me} 2$ might promote more globally the transcription of DNA repair genes, while at DSB sites it might either act as scaffold for 53BP1 recruitment or stimulate the production of DDR-induced RNAs. Interestingly, we identified that K95 of histone H2A (H2AK95) was globally monomethylated during DNA damage repair, and this hPTM accumulated at late time points upon DSB induction [Fig.6C]. Although little is known about modifications on this core histone residue (Fenley et al., 2018; Tweedie-Cullen et al., 2012), based on our results we propose a possible involvement for H2AK95me1 in global DDR signaling.

Recent efforts have been dedicated to the investigation of foci-specific hPTMs, the most successful advance relying on the intersection between breaks-labeling and sequencing (BLESS) profiles and ChIPsequencing tracks of a priori selected hPTMs (Clouaire et al., 2018; Crosetto et al., 2013). This approach is able to distinguish between hPTMs enriched at NHEJ- and HR-prone DSBs, yet it falls short in 
exploring the dynamics of unpredicted modifications and in studying their combinatorial occurrence. Our time-course proteomic-based approach provides complementary information and allows profiling dynamic changes of foci-specific hPTMs during the DDR. We observed that dimethylated and trimethylated K36 on histone $\mathrm{H} 3$ (H3K36me2 and $\mathrm{H} 3 \mathrm{~K} 36 \mathrm{me}$ ) rapidly accumulate upon DSBs, in line with previous reports on the functional role of these modifications in NHEJ (Fnu et al., 2011), and corroborating the observations from iPOC on the chromatin recruitment of both methyltransferases that catalyze dimethylation on $\mathrm{H} 3 \mathrm{~K} 36$ (NSD2 and SETMAR) and the H3K36me3 reader PSIP/LEDGF [Fig.5E]. Similarly, at YH2AXmononuclesomes we identified a progressive hyper-acetylation of K9/K14 (H3K9Ac/K14Ac) on histone H3 [Fig.6B], which is in line with iPOC results showing the chromatin recruitment of KAT7 and BRD1, two subunits of the HBO1 histone acetyltransferase complex responsible for this modification [Fig.5E]. As expected, among the foci-specific modifications we observed an increase in mono- and di-methylation on K20 of histone $\mathrm{H} 4$ (H4K20me1, H4K20me2) [Fig.6B, D], with the key notion that the degree of methylation at this residue plays a pivotal role in HR versus NHEJ pathway choice (Pellegrino et al., 2017; Saredi et al., 2016; Simonetta et al., 2018). In particular, our time-course analysis showed different kinetics between mono- and di-methylation, where H4K20me1 precedes the dimethylation, enriched at later time points. This effect could either be due to the sequential steps required for achieving a higher methylation degree, or potentially to a different role of H4K2Ome1 and H4K2Ome2 in the DDR cascade.

Interestingly, our unbiased approach identified unexpected trends during DDR. In particular, among the foci-specific hPTMs we observed a progressive increase of monomethylation of K18 and acetylation of K64 on histone $\mathrm{H} 3$ (H3K18me1 and H3K64Ac, respectively) [Fig.S6D, Fig.6D]. Monomethylation of H3K18 has previously been associated with silencing chromatin because of its slow dynamics and the antagonism with acetylation on the same residue (Zee et al., 2010). It is also known that H3K18 needs to be deacetylated through SIRT7 to allow 53BP1 recruitment at DSBs. Our results therefore point towards a possible novel role for $\mathrm{H} 3 \mathrm{~K} 18 \mathrm{me} 1$ in acting as binary switch able to prevent $\mathrm{H} 3 \mathrm{~K} 18$ acetylation and thus promoting NHEJ repair. In contrast, H3K64Ac is enriched at actively transcribed regions (Di Cerbo et al., 2014), therefore our observation of its gradual increase during DDR at $\mathrm{yH} 2 \mathrm{AX}$ mononucleosomes might either represent a signal for DSB repair, or promote chromatin local relaxation and DDR-induced histone exchange [Fig.6B, D].

Interestingly, based on our data we can propose that monomethylation of K56 of histone H3 (H3K56) assumes an important role in the DNA damage response. This residue is located on the lateral surface of histone $\mathrm{H} 3$ close to DNA entry/exit site, and its acetylation seems to contribute to chromatin reassembly after DNA repair, while for H3K56me1 a role in cell cycle progression has been proposed (Chen et al., 2008; Yu et al., 2012). Our data reveal that, upon IR, monomethylation of H3K56 precedes the acetylation of the same residue (1h, 4h) [Fig.6B, E], thus for the first time providing evidence for a role of H3K56me1 in the DDR. This function is further supported by the DSB-induced chromatin recruitment of H3K56me1 methyltransferase G9A observed in our iPOC experiment [Fig.5E]. In our functional investigation on this novel epigenetic crosstalk, we examined and observed that inhibition of G9A with BIX-01294 dramatically decreased the efficiency of HR without perturbing cell cycle regulation [Fig.6F, Fig.S5L-O]. In line with these results, inhibition of G9A sensitized to treatment with PARPi alone or in combination with etoposide [Fig.6G]. In particular, the selective inhibition of G9A did not impact on RAD51 chromatin recruitment but resulted in a significant increase in BRCA1 loading at DSBs and deficient DSB repair at these foci [Fig.6H, I]. Taken together, our results demonstrate that G9A is rapidly recruited to chromatin upon DSB, where it promotes monomethylation of $\mathrm{H} 3 \mathrm{~K} 56$ at $\mathrm{yH} 2 \mathrm{AX}$ mononucleosomes. Since inhibition of G9A causes accumulation of BRCA1 foci and impairs homologous recombination repair, we conclude that H3K56me1 might have a role in HR pathway, presumably by acting as docking site for proteins involved in HR repair downstream of BRCA1. 


\section{DISCUSSION}

Double-strand break repair takes place in the context of chromatin, where a coordinated mechanism engages modulation in histone PTMs and DNA-recruited chromatin regulators to set the stage for the damage response cascade (Green and Almouzni, 2002). To clarify this dynamic and composite picture, here we characterized the response to DSB from a chromatin-centric perspective using three exploratory proteomic approaches studying chromatin organization at different levels of resolution, ranging from a global chromatin composition (studied by iPOC), to a functional interaction map of DDR core components (in ChIP-SICAP, (Rafiee et al., 2016), and hPTMs at monucleosomes flanking the break site (in N-ChroP, (Soldi and Bonaldi, 2013). Moreover, by adding a temporal dimension, we generated complementary data sets that collectively produce a comprehensive and detailed panorama of the chromatin dynamics during the DDR. This rich resource led us to functionally characterize multiple proteins and hPTMs that had not been associated with DDR before, and assigned them a role in HR, NHEJ or pathway choice. In addition, we identified HRDness for several unanticipated HR proteins by showing synthetic lethality with PARPi, thus opening to clinically-relevant opportunities.

iPOC is a novel approach that we developed to capture, identify and quantify proteins recruited to or evicted from chromatin during the DDR. Salient features of IPOC include labeling of DNA by EdU, as in iPOND and iPOTD, (Sirbu et al., 2012) combined with SILAC labeling for robust protein quantification, and capture of biotinylated complexes on protease-resistant streptavidin beads (Rafiee et al., 2020) to increase assay sensitivity. The power of iPOC resides in its ability to determine compositional changes on a chromatin-wide scale, thereby complementing more targeted approaches like ChIP-SICAP. Indeed, beyond identifying core repair proteins also found by ChIP-SICAP, multiple proteins were exclusive to iPOC, notably chromatin-modifying enzymes and transcriptional regulators (Fig.5E). This underscores the simultaneous recruitment of a functionally diverse set of proteins, and suggests that their respective biological activities cannot be seen in isolation. Indeed, we showed cross-regulation among functional processes through the negative effect on HR mediated by the transcriptional regulator ADNP (Fig.5G). Here we applied iPOC to the DDR, however we envision that, in replicating cells, this approach can be used to study the effect of any molecular or cellular perturbation on the chromatin composition.

Another unique aspect of our study is the discrimination between DDR-induced and foci-specific hPTMs by $\mathrm{N}$-ChroP. Applied in a time-course fashion, this allowed us to confirm known PTM profiles, reveal several novel ones, and provide a refined view to published data. For instance, H3K79 acts as one of the docking sites for 53BP1 recruitment (Huyen et al., 2004), however its methylation level has been reported to be unchanged or to decrease upon DSB (Moyal et al., 2011) (Clouaire et al., 2018). Our dynamic data show that H3K79me2 follows a bi-modal increase at 0.5 and $4 \mathrm{~h}$ from DSB induction (Fig.6B), while this modification is partially depleted at foci-specific level upon $8 \mathrm{~h}$ from IR, thus indicating that the time of sampling is crucial to explain these seemingly conflicting observations. Similarly, H3K56Ac has been reported to be either deregulated or unchanged in the DDR (Masumoto et al., 2005). Our results might clarify these conflicting reports as we observed a foci-specific increase at late time points during DSB repair, accompanied by a decrease of this modification at a global scale (Fig.6B).

Since our proteomic approaches characterize complementary chromatin layers, their integration offers a detailed view to better understand the DNA repair process. Cross-correlation of these data may not prove direct causality, however they provide compelling examples of regulatory events between hPTMs and their cognate writers and readers. For instance, the overlay of N-ChroP and IPOC data indicate the crosstalk between the methyltransferases NSD2 and SETMAR and the foci-specific increase in dimethylated $\mathrm{H} 3 \mathrm{~K} 36$, and between the hyper-acetylation of 9-17 peptide of histone $\mathrm{H} 3$ and the chromatin recruitment of 
KAT7 and BRD1, two histone acetyltransferases responsible for H3K14 acetylation. Another example is the chromatin recruitment of the methyltransferase SUV39H1 at late time points during DSB repair (Fig.5E), however without detecting $\mathrm{H} 3 \mathrm{~K} 9 \mathrm{me} / 3$, the heterochromatic mark deposited by this enzyme with a debated role in facilitating resection and HR (Ayrapetov et al., 2014). Similarly, we identified the chromatin recruitment of G9A, another enzyme that can methylate H3K9 and H3K56. In our previous work, we have easily detected H3K9me2/3 (Soldi et al., 2017), therefore we conclude that these modifications occur at undetectable levels or do not correlate particularly with DNA damage, in agreement with recent data showing a lack of association between H3K9me2/3 and DSB repair (Clouaire et al., 2018). Interestingly however, we instead observed a foci-specific increase of monomethylated H3K56, another substrate of G9A, thus suggesting a functional link between G9A recruitment and H3K56me1. Moreover, induction of HRDness upon G9A inhibition (Fig.6F-I) in the absence of H3K9me2/3 suggests that H3K56me1 might have an as-yet unrecognized role in HR downstream of BRCA. This illustrates how the complementary results generated by our multi-layered approach represent a valuable resource to describe the chromatin response to DSBs (Fig.7) and to propose a possible mechanism of action for newly identified DSB-dependent chromatin proteins.

Collectively, from our ChIP-SICAP and iPOC experiments we functionally characterized the role of 12 novel candidates by means of the traffic light reporter assay. This DSB cell system was fundamental to distinguish DDR components regulating both pathways (e.g. NuMA, SMARCE1 and PRPF8) from chromatin proteins belonging to either NHEJ or HR. In addition, we further discriminated targets that negatively regulate NHEJ (e.g. TRA2b and PHF14) from proteins whose depletion affects HR in a BRCA wild-type background (e.g. ATAD2, TPX2, G9A), thus predisposing to synthetic lethality with PARPi. This demonstrates that our multi-layered chromatin approach powerfully complements genetic screens to identify HRDness, while potentially explaining the benefit of PARPi-therapy observed in BRCA wild-type patients (Mirza et al., 2016) (Coleman et al., 2017). In addition, novel chromatin regulators involved in DSB repair identified by our proteomics approach may be nominated as promising drug targets, spurring ongoing efforts to develop epigenetic drugs for targeted therapies or in combination with PARPi (Pfister and Ashworth, 2017).

\section{Limitations of the study}

Our chromatin-directed analysis suffers from limits in common with other proteomic-based strategies. First, these data do not indicate the chromatin conformation and the genomic localization of the described interactions. Second, IPOC and N-ChroP describe associations among chromatin determinants without discriminating between NHEJ- or HR-prone sites. Affinity-based enrichment of candidates coupled with sequencing represents the optimal orthogonal validation. Finally, so far we only explored a few classes of PTM and focused almost exclusively on histones without investigating modifications on non-histone proteins.

\section{Acknowledgments}

The authors thank all members of the division Proteomics of Stem Cells and Cancer, German Cancer Research Center, Heidelberg for their support and advice. The authors thank Dr. Ali Bakr from the Division of Cancer Epigenomics, German Cancer Research Center (DKFZ) for discussion and for providing U2OS ID3-GFP cells. The authors also thank the DKFZ Light Microscopy Facility for its support. G. Legube (University of Toulouse, France) kindly supplied AID-DlvA cells, N Ayoub (Technion, Israel) kindly provided U2OS-TLR cells, and R Syljuåsen (Oslo University Hospital, Norway) for providing the 
U2OS m53BP1-mCherry. TGH is supported by the Deutsche Forschungsgemeinschaft (DFG): SFB 1361 (Project-ID 393547839), project 19.

\section{Author contributions}

JK and GS designed the research. TGH provided scientific expertise to the setup and early phase of the project. LA performed FACS-based experiment with resources and support from MS. GS and LA analyzed the data. GS and JK wrote the manuscript with input from all authors.

\section{Declaration of Interest}

The authors have no conflict of interest to declare.

\section{Additional resources}

A version of the updated ChIP-SICAP protocol is maintained at protocols.io: dx.doi.org/ 10.17504/protocols.io.bcrriv56.

\section{MAIN FIGURE LEGENDS}

\section{Figure 1. On-chromatin functional interactors of DDR core components.}

A) ChIP-SICAP experimental strategy. Crosslinked chromatin preparation from SILAC labeled cells were enriched for target DDR proteins in the absence (UT) or upon DSB (IR) followed by quantification of onchromatin functional interactors. IgG enrichment serves as internal technical control. B) Scatterplots representing modulation of on-chromatin interactors recruited (red) or evicted (blue) from RPA (HR), RAD50 (DSBs), or MDC1 (NHEJ) sites upon DSB (IR) in comparison with untreated condition (UT). Venn diagrams show the number of on-chromatin interactors quantified in each experiment. C) Intersection among the on-chromatin interactors of the three proteins used as baits in ChIP-SICAP. D) Top-6 gene ontology categories associated with on-chromatin interactors quantified in RPA, RAD50 or MDC1 ChIPSICAP experiments. E) Log2 intensity of proteins belonging to HR, MRN complex, or NHEJ and enriched in RPA1 (green), RAD50 (blue), and MDC1 (orange) ChIP-SICAP. F) KEGG pathways of proteins functionally interacting with RPA (green) or MDC1 (orange).

\section{Figure 2. Functional characterization of RPA- and MDC1-specific on-chromatin} interactors.

A) On-chromatin interactors enriched specifically at either RPA- or MDC1-sites upon induction of DSB repair. B) Number of $\mathrm{YH} 2 \mathrm{AX}$ foci per nucleus in AID-DlvA cells left untreated, upon DSB induction, and during DSBs repair (untreated, $+4 \mathrm{OHT}$ and Auxin, respectively) upon knockdown of targets interacting with either RPA or MDC1 in comparison with silencing control (siCtr). Significance over siCtr is shown. C) 
Quantification of HR (green) and NHEJ (red) repair events in traffic-light reporter (U2OS-TLR) cells depleted of protein candidates and normalized to silencing control (siCtr). Green and red asterisks: significant regulation in $\mathrm{HR}$ and NHEJ, respectively, in respect to siCtr. D) CFA assay at increasing amounts of etoposide for $24 \mathrm{~h}$ after knockdown for proteins important for HR repair (BRG1) or pathway choice (NuMA) compared with silencing control. Silencing of RPA is used as positive control. E) Quantification of $D$, indicating mean values normalized on untreated condition (UT) with standard deviations of three replicates. Zoom-in shows survival of cells upon target knockdown compared with silencing control. F) Quantification of colony formation assay in U2OS after target knockdown and subjected to $1 \mu \mathrm{M}$ PARP inhibitor (PARPi) for $2 \mathrm{~h}$ alone or in combination with $1 \mathrm{~h}$ etoposide for $2 \mathrm{~h}$. Mean values normalized on untreated condition (UT) are shown, error bars represent standard deviations of three replicates. Quantification of RAD51 (G) and BRCA1 (H) foci in AID-DIvA cells after target knockdown. ${ }^{*},{ }^{* *}$ and ${ }^{* * *}$ correspond to $p$-value $<0.05,0.01$ and 0.001 , respectively.

\section{Figure 3. Functional interactors of $\mathrm{YH} 2 \mathrm{AX}$ during DNA damage repair.}

A) Time course ChIP-SICAP experimental design; p.i.h.: hours post-irradiation. At each time point cells labeled with light-, medium- or heavy-SILAC amino acids were subjected to ChIP SICAP using IgG control, $\mathrm{H} 2 \mathrm{~A}$ or $\mathrm{YH} 2 \mathrm{AX}$ as bait, respectively. B) Volcano plots represent the fold change difference of $\mathrm{t}$ test statistics for $\mathrm{yH} 2 \mathrm{AX}$ - and $\mathrm{H} 2 \mathrm{~A}$-associated on-chromatin binders (red and blue, respectively), at different time points during DSBs repair. MDC1 is highlighted as positive control. C) Heatmap indicating dynamics of $\mathrm{yH} 2 \mathrm{AX}$-dependent chromatin association during the DDR. At each time point, log2 ratios over untreated sample are shown upon z-score normalization. Red and blue correspond to enriched and evicted $\mathrm{yH} 2 \mathrm{AX}$ interactors during DSBs repair, respectively. D) Immmunoflurescence (top panel) and proximity ligation assay (PLA, bottom panel) validation of DSB-mediated interaction between THRAP3 and $\mathrm{yH} 2 \mathrm{AX}$. Boxplot: quantification of PLA assay in untreated cells (UT) and cells exposed to ionizing radiation (IR). E) Number of $\mathrm{YH} 2 \mathrm{AX}$ foci per nucleus in AID-DlvA cells left untreated, upon DSB induction, and during DSBs repair (untreated, $+4 \mathrm{OHT}$ and Auxin, respectively) upon knockdown for THRAP3 in comparison with silencing control (siCtr). F) Quantification of HR (green) and NHEJ (red) repair events in traffic-light reporter (U2OS-TLR) cells depleted of THRAP3 and normalized on silencing control (siCtr). ${ }^{* * *}$ corresponds to $p$-value $<0.001$.

\section{Figure 4. ATAD2 and TPX2 mediate DSB repair through HR.}

A) Deregulation of ATAD2 or TPX2 RNA level in tumor samples (red) compared to normal tissue (blue) from TCGA expressed as log2 RNAseq by Expectation-Maximization or RSEM. B) Survival probability of patients affected by Kidney renal papillary cell carcinoma (KIRP) with low (green) or high (pink) ATAD2 levels. C) Number of $\mathrm{yH} 2 \mathrm{AX}$ foci per nucleus in AID-DIvA cells left untreated or subjected to DSBs induction and repair (tamoxifen/+4OHT and Auxin, respectively), after knockdown for THRAP3, ATAD2 or TPX2 in comparison with silencing control (siCtr). Significance over siCtr is shown. D) Quantification of HR (green) and NHEJ (red) repair events in U2OS-TLR cells depleted for ATAD2, TPX2 or THRAP3 and normalized on non-targeting silencing control (siCtr). Green and red asterisks reflect significant regulation in HR and NHEJ, respectively, in respect to siCtr. E) Quantification of CFA in U2OS cells depleted of either ATAD2 (light green) or TPX2 (light blue) and subjected to $1 \mu \mathrm{M}$ PARP (PARPi) for $2 \mathrm{~h}$ alone or in combination with $1 \mu \mathrm{M}$ etoposide for $2 \mathrm{~h}$. Mean values of three replicates normalized to untreated (UT); standard deviations are shown. Quantification of RAD51 (F) and BRCA1 (G) foci in AID-DlvA cells after target knockdown. ${ }^{* *}$ and ${ }^{* * *}$ correspond to $p$-value $<0.01$ and 0.001 , respectively. 


\section{Figure 5. Chromatin composition dynamics during DDR investigated by iPOC.}

A) Click chemistry-based immunofluorescence in cells treated with DMSO (left) or the nucleotide analogue EdU (right). B) Schematic representation of iPOC experimental strategy. SILAC labeled U2OS cells exposed to either DMSO (Light, as control) or EdU (Medium and Heavy) and crosslinked in untreated condition or at different time points during DDR. Cells are then subjected to permeabilization, followed by click chemistry-based DNA labeling with biotin azide and enrichment with protease-resistant streptavidin beads (prS) prior to tryptic digestion and MS analysis. C) Venn diagram shows the overlap between proteins quantified in chromatin input and after iPOC. D) Gene ontology (GO) categories associated with proteins identified in iPOC as recruited at chromatin at the different time points upon ionizing radiation (IR) compared with untreated condition. E) Heatmap representation of SILAC log2 ratios for functional categories of DDR- and chromatin-regulators quantified in iPOC at different time points during DSB repair over technical control (Ctr) or untreated sample (UT) relative to chromatin input. Proteins further followed up are highlighted in red. n.d.: not detected. F) Number of $\mathrm{YH} 2 \mathrm{AX}$ foci per nucleus in AID-DIvA cells after target knockdown upon DSB induction and repair (tamoxifen $/+4 \mathrm{OHT}$ and Auxin, respectively) in comparison with silencing control (siCtr). G) Quantification of HR (green) and NHEJ (red) repair events in U2OS-TLR cells depleted for ADNP, SMARCA1, or PHF14 and normalized on non-targeting silencing control (siCtr). Green and red asterisks reflect significant regulation in HR and NHEJ, respectively, from siCtr. H) Quantification of CFA in U2OS cells depleted of PHF14 or SMARCA1 and subjected to $1 \mu \mathrm{M}$ PARP inhibitor (PARPi) for $2 \mathrm{~h}$ alone or in combination with $1 \mu \mathrm{M}$ etoposide for $2 \mathrm{~h}$. Mean values of three replicates normalized to untreated condition (UT), error bars represent standard deviations. Quantification of RAD51 (I) and BRCA1 (J) foci in AID-DlvA cells after target knockdown. * ** and ${ }^{* *}$ correspond to $p$-value $<0.05,0.01$ and 0.001 , respectively.

\section{Figure 6. Profiling of hPTMs during DDR at mononucleosome resolution.}

A) Experimental design of time course N-ChroP. Mononucleosomes from cells at different time points during DDR (hour post irradiation) are enriched for $\mathrm{YH} 2 \mathrm{AX}$ and associated hPTMs are quantified via MS upon chemical acetylation and tryptic digestion (ArgC-like digestion). B) Heatmap representing the log2 relative abundance (RA) of hPTMs in $\mathrm{yH} 2 \mathrm{AX}$-enriched mononucleosomes ( $\mathrm{HH} 2 \mathrm{AX})$ or in chromatin input (Input) calculated over the respective untreated sample. Relative enrichment at steady state (RE UT) highlights combinatorial patterns of hPTMs at $\mathrm{yH} 2 \mathrm{AX}$ mononucleosomes. DDR-induced and foci-specific modifications are highlighted in green and light blue, respectively. Example of hPTMs showing a DDRinduced (green) (C) or foci-specific (light blue) (D) log2 RA dynamics in native chromatin input (Input, left) and $\mathrm{yH} 2 \mathrm{AX}$ mononucleosomes ( $\mathrm{H} \mathrm{H} 2 \mathrm{AX}$ ChIP, right). Mean values are shown. E) Line plot of log2 RA dynamics for hPTMs on H3K56 in native chromatin input (Input, left) and $\mathrm{YH} 2 \mathrm{AX}$ mononucleosomes ( $\mathrm{YH} 2 \mathrm{AX}$ ChIP, right). F) Quantification of HR (green) and NHEJ (red) repair events in U2OS-TLR cells upon inhibition of G9A normalized to silencing control (siCtr). Green asterisk reflects significant regulation in HR compared with siCtr. G) Quantification of CFA in U2OS cells upon G9A inhibition and subjected to $1 \mu \mathrm{M}$ PARP inhibitor (PARPi) alone or in combination with $1 \mu \mathrm{M}$ etoposide treatment for $2 \mathrm{~h}$. Mean values normalized to untreated condition (UT) and standard deviations are shown. Quantification of RAD51 (H) and BRCA1 (I) foci in AID-DlvA cells upon drug-inhibited G9A. ${ }^{* *}$ and ${ }^{* * *}$ correspond to $p$-value $<0.01$ and 0.001 , respectively. n.s. $=$ not significant. 


\section{Figure 7. Multi-layered chromatin-directed proteomics identifies cell vulnerabilities in HR} and NHEJ.

Integration of orthogonal approaches in chromatin-directed proteomics identifies chromatin proteins contributing to HR, NHEJ, and pathway choice, and distinguishes trends of hPTMs induced globally during DNA damage repair (DDR induced) from modifications specifically enriched at $\mathrm{yH} 2 \mathrm{AX}$ mononucleosomes (foci-specific). Orthogonal imaging-based strategies determine the mechanism of action in the early steps of HR repair for chromatin targets involved in either HR or pathway choice, while CFA assays identify targets whose downregulation drives towards synthetic lethality with PARPi epigenetic drug.

\section{SUPPLEMENTAL FIGURE LEGENDS}

\section{Figure S1. Chromatin-mediated interactors quantified in RPA1, RAD50 and MDC1 ChIP- SICAP experiments. Related to Figure 1.}

Log10 intensity-based quantification (iBAQ) rank distribution of on-chromatin functional interactors quantified in RPA (A), RAD50 (B), MDC1 (C) ChIP-SICAP experiment. Light (L), medium (M) and heavy (H) SILAC channels correspond to technical control, untreated condition (UT), and $1 \mathrm{~h}$ upon IR-induced DSBs (IR), respectively. Histone proteins are highlighted in blue, protein used as bait in ChIP is reported in red, examples of core components of HR and NHEJ are shown in black. Venn diagrams show the overlap between proteins quantified in UT and IR condition, while stacked histograms represent the amount of interactors identified exclusively in the on-chromatin fraction (ON-chromatin) or also in the soluble fraction (ON\&OFF) in RPA (D), RAD50 (E), or MDC1 (F) experiment. Tables show on-chromatin functional interactors quantified only in IR condition. ChIP-SICAP experiment performed in UT or IR condition and DSB-induced modulation of on-chromatin interactors of 53BP1 (G) or XRCC6 (H). Scatterplots show the correlation between IR-induced interactors of 53BP1 (I), XRCC6 (L), or MDC1 (M), while the bait proteins are in their OFF- (x-axis) or ON- chromatin (y-axis) fraction. $\mathrm{Ctr}=$ isogenic control experiment. Values into parenthesis correspond to $\log 2 \mathrm{IR} /$ Ctr ratios in the two chromatin fractions. n.d. = protein not identified in that experiment. imp $=$ protein not detected in Ctr, value replaced with mean of log2 ratio distribution.

\section{Figure S2. Functional characterization of targets interacting on-chromatin with HR and NHEJ core components. Related to Figure 2.}

A) Representative flow plots of U2OS-TLR cell lines following transduction with I-Scel-T2A-IFP, GFPdonor-BFP plasmids and silenced for on-chromatin targets related to figure 2. TLR readout is shown following gating on live single cells double positive for IFP and BFP. Cells knockdown for 53BP1 and RPA/RAD51 are shown as positive controls for NHEJ and HR impairment, respectively. (B) Quantification of EGFP (HR) and mCherry (NHEJ) cells as percentage of double positive cells in 3 independent experiments, with standard deviation. C) Plot of PI-based flow cytometry analysis of cell cycle in U2OS cells knockdown for targets related to figure 2. After gating on live cells, the percentage of cells in G1, S and G2-M phases was determined and reported in stacked histogram with standard deviation among replicates $(\mathbf{D})$. 
Figure S3. Dynamics of $\mathrm{yH} 2 \mathrm{AX}$-specific interactors during DNA response. Related to Figure 3.

Density plot of log2 SILAC ratio distribution between $\mathrm{YH} 2 \mathrm{AX}$ and technical lgG isogenic control (left, $\mathrm{H} / \mathrm{L}$ ) or $\mathrm{YH} 2 \mathrm{AX}$ and H2A ChIP-SICAP (right, H/M) in untreated condition (A), or 0.5h (B), 1h (C), 4h (D), 8h (E) upon DSB induction. Scatterplots show the correlation between log2 H/M SILAC ratios in replicates at specified time point. The positive control MDC1 is highlighted in red, while protein targets related to figure 3 (THRAP3, ATAD2 and TPX2) and are reported in black in the scatterplot. Proteins identified as important for HR and NHEJ in figure 2 are shown in green and orange, respectively. Functional protein network visualization and $\mathrm{GO}$ categories associated with proteins rapidly recruited $(\mathbf{F})$ or evicted $(\mathbf{G})$ from $\mathrm{YH} 2 \mathrm{AX}$ shown in figure 3.

\section{Figure S4. Functional characterization of targets interacting with $\mathrm{YH} 2 \mathrm{AX}$ during DNA damage repair. Related to Figure 4.}

A) Representative flow plots of U2OS-TLR cell lines silenced for on-chromatin targets related to figure 3 and 4. Cells knockdown for 53BP1 and RPA/RAD51 are shown as positive controls for NHEJ and HR impairment, respectively. (B) Quantification of EGFP (HR) and mCherry (NHEJ) cells as percentage of double positive cells in 3 independent experiments, with standard deviation. C) Plot of PI-based flow cytometry analysis of cell cycle in U2OS cells knockdown for TPX2 or ATAD2. The percentage of cells in G1, S and G2-M phases is reported in stacked histogram with standard deviation among three biological replicates $(\mathbf{D})$.

\section{Figure S5. Setup of IPOC in DNA damage repair and comparison with fractionated chromatin input. Related to Figure 5.}

EdU-based DNA labeling specificity in cells untreated $(\mathbf{A})$ or upon $1 \mathrm{~h}$ from IR $(\mathbf{B})$ exposed to increasing amounts of EdU for $18 \mathrm{~h}$ and subjected to CuAAC click chemistry with Cy5-azide fluorophore in comparison with cells not treated with EdU (left, NO EdU). Pictures on the right refer to cells exposed to 20uM EdU for 18h, subjected to CuAAC click chemistry-based DNA labeling with biotin-azide and visualized with two differently conjugated anti-biotin antibodies. C) Multi scatterplots showing the correlation of log2 SILAC ratios for proteins quantified in IPOC at untreated condition (medium) over the light negative control (UT/Ctr). Venn diagram shows the overlap of quantified proteins. Pearson correlation coefficient is shown in blue. D) As in C) but for determinants enriched in heavy-labeled samples at $1 \mathrm{~h}, 4 \mathrm{~h}$ and $8 \mathrm{~h}$ time points upon DSB induction over the negative control. E) Correlation between heavy-labeled and medium-labeled untreated sample at different time points during DDR. , Spearman correlation index is reported in red. F) Triple SILAC-based experimental design for chromatin input deep investigation during DDR. Triple SILAC labeled U2OS cells were collected at $0.5 \mathrm{~h}, 1 \mathrm{~h}, 4 \mathrm{~h}$, or 8h upon ionizing radiation-induced DSBs and combined in equal amounts into triple SILAC experiments. Extracted chromatin was sheared, subjected to tryptic digestion and high $\mathrm{pH}$ peptide fractionation prior MS analysis. G) Multi scatterplot shows log2 SILAC ratios for proteins quantified at different time points over untreated (UT) condition. For each pair, Pearson correlation coefficient and number of quantified proteins are reported in blue and red, respectively. H) Top5 gene ontology categories associated with proteins deregulated in the chromatin input at different time points during DDR. I) Heatmap representation of protein abundance changes during DSB repair quantified through fractionated chromatin input analysis. Average log2 SILAC ratios are shown upon z-score normalization. J) Heatmap representation of SILAC 
log2 ratios for proteins quantified in iPOC at different time points during DSB repair over technical control (Ctr) or untreated sample (UT) in comparison with the dynamics quantified in the chromatin input. Red arrows highlight PHF14, G9A, SMARCA1 and ADNP proteins shown in figure 5. K) Average log2 SILAC ratio over untreated control for different histone variants quantified in iPOC (blue scale) and in chromatin input (Chrlnp, orange scale). Histone variants not identified are indicated with nd.

Figure S6. Characterization of the functional role of regulators rapidly recruited at chromatin during DNA damage repair and identified via iPOC. Related to Figure 5 and 6.

A) Representative flow plots of U2OS-TLR cell lines silenced for PHF14, ADNP and SMARCA1 or upon G9A drug inhibition (G9Ai). Cells knockdown for 53BP1 and RPA/RAD51 are shown as positive controls for NHEJ and HR impairment, respectively. B) Quantification of EGFP (HR) and mCherry (NHEJ) cells as percentage of double positive cells in 3 independent experiments, with standard deviation. C) Plot of PIbased flow cytometry analysis of cell cycle in U2OS cells knockdown for PHF14, ADNP and SMARCA1 or upon G9A inhibition. The percentage of cells in G1, S and G2-M phases is reported in stacked histogram with standard deviation among replicates (D).

Figure S7. Setup of native enrichment of $\mathrm{YH} 2 \mathrm{AX}$-marked mononucleosomes and dynamics of co-associated histone modifications during DNA damage response. Related to Figure 6.

A) MNase digested chromatin to mononucleosome preparation from cells in untreated condition or at the indicated time points during DDR. B) Coomassie stained SDS-PAGE of chromatin input and $\mathrm{yH} 2 \mathrm{AX}$ enriched mononucleosomes during DSB repair. Log2 RA dynamics of hPTMs on histone H2A (C), H3 (D) or $\mathrm{H} 4(\mathbf{E})$ in either native chromatin input (Input, up) or in $\mathrm{yH} 2 \mathrm{AX}$-enriched mononucleosomes ( $\mathrm{yH} 2 \mathrm{AX}$ ChIP, down). Mean values are shown. Respective stack histograms represent the percentage of RA $(\mathrm{RA} \%)$ for each $\mathrm{hPTM}$ in either native chromatin input (Inp) or in $\mathrm{\gamma H} 2 \mathrm{AX}$ mononucleosomes $(\mathrm{yH} 2 \mathrm{AX})$ at different time points during DDR.

\title{
STAR Methods
}

\section{Resource availability}

\section{Lead contact}

Further information and requests for resources and reagents should be directed to and will be fulfilled by the lead contact, Prof. Jeroen Krijgsveld (j.krijgsveld@dkfz.de)

\author{
Materials availability \\ This study did not generate new unique reagents
}




\section{Data and code availability}

The mass spectrometry proteomics data have been deposited to the ProteomeXchange Consortium via the PRIDE (https://www.ebi.ac. uk/pride/) (Perez-Riverol et al., 2019) partner repository with the dataset identifier PXD027421

\section{Experimental model and subject details}

U2OS (ATCC) and U2OS-ID3-GFP (kindly provided by Dr. Ali Bakr, DKFZ, Heidelberg) cell lines were cultured in Dulbecco's modified Eagle's medium (DMEM) supplemented with antibiotics, and 10\% FCS (Invitrogen) at $37^{\circ} \mathrm{C}$ under a humidified atmosphere with $5 \% \mathrm{CO}_{2}$. U2OS-TLR cells (kindly provided by Prof. Ayoub N) were cultured as U2OS with puromycin $0.6 \mu \mathrm{g} / \mathrm{mL}$. U2OS pIRES-mCherry-m53BP1 (kindly provided by Prof. Randi Syljuåsen, Oslo University Hospital) and AID-DIvA (MTA with Dr. Gaelle Legube, $\mathrm{CBI}$, Toulouse) were cultured as U2OS with $800 \mu \mathrm{g} / \mathrm{mL}$ G418, Geneticin (Thermo Fisher Scientific, 10131035). DSB were induced in AID-DIvA with 300nM hydroxyl tamoxifen (Sigma Aldrich, T5648) for 4h. Repair was promoted with $500 \mu \mathrm{g} / \mathrm{mL}$ Auxin (Indole-3-acetic acid sodium salt, Sigma Aldrich, 15148) for $1 \mathrm{~h}$.

\section{Method details}

\section{Chromatin-associated interactors investigated through ChIP-SICAP}

ChIP-SICAP experiments were performed as described before (Rafiee et al., 2016) with some modifications. In brief, U2OS cells were metabolically labeled in SILAC (Ong SE et al 2002) DMEM medium containing light (Arg0, Lys0), medium (Arg6, Lys4) or heavy (Arg10, Lys8) amino acids. For experimental design related to figure 1 , U2OS cell pellets corresponding to $24 \times 10^{6}$ cells were crosslinked with formaldehyde ( $1 \%$ final concentration) in the absence (medium) or after $1 \mathrm{~h}$ recovery from $5 \mathrm{~Gy}$ ionizing radiation (heavy) elicited with Gammacell 40 Exactor (Best Theratronics). Control sample labeled in light corresponds to a 1:1 mix of $12 \times 10^{6}$ untreated cells and $12 \times 10^{6}$ irradiated cells as above. Cell pellets were resuspended in $5 \mathrm{~mL}$ of lysis buffer 1 (50mM HEPES-KOH pH 7.5, $140 \mathrm{mM} \mathrm{NaCl}, 1 \mathrm{mM}$ EDTA, $10 \%$ Glycerol, $0.5 \%$ NP-40, $0.25 \%$ Triton X-100), rotated on the wheel at $4^{\circ} \mathrm{C}$ for $10 \mathrm{~min}$ and spun at $400 \mathrm{~g}$ for $5 \mathrm{~min}$ at $4^{\circ} \mathrm{C}$. Pellets were then resuspended in $5 \mathrm{~mL}$ of lysis buffer $2(10 \mathrm{mM} \mathrm{Tris}-\mathrm{HCl} \mathrm{pH} 7.5$, $200 \mathrm{mM} \mathrm{NaCl}, 1 \mathrm{mM}$ EDTA), rotated for $10 \mathrm{~min}$ on the wheel at RT and spun at $400 \mathrm{~g}$ for $5 \mathrm{~min}$ at RT. Pellets were resuspended in $1.8 \mathrm{~mL}$ of lysis buffer $3(10 \mathrm{mM}$ Tris- $\mathrm{HCl}$ pH $7.5,100 \mathrm{mM} \mathrm{NaCl}, 1 \mathrm{mM}$ EDTA) and split in $6 \times 1.5 \mathrm{~mL}$ sonication tubes (Diagenode). Upon 8 cycles of sonication with Pico Bioruptor (Diagenode) (30sec ON/ 30sec OFF), Triton X-100 (1\% final concentration) was added to the samples and the tubes were spun at $400 \mathrm{~g}$. Supernatants from the same SILAC labeling were pooled. The supernatant from medium and heavy samples were combined in equal amounts and subjected to ChIP against target protein (between 5 and $15 \mu \mathrm{g}$ of antibody depending on the target), light-labeled controls were subjected to ChIP with isogenic IgG and used as internal control. After overnight incubation in the cold room, ProteinG magnetic beads previously coated overnight with BSA $0.5 \%$ in PBS1x (100uL per $10 \mu \mathrm{g}$ of antibody) were added. After $3 \mathrm{~h}$ of rotating in the cold room, the beads were cleaned up with Tris$\mathrm{HCl} 10 \mathrm{mM}$. Next, the beads were treated with terminal deoxynucleotidyl transferase (EP0162) and biotinylated nucleotides (Biotin-11-dCTP, Jena Bioscience). The beads were then washed with IP buffer 
(50mM Tris- $\mathrm{HCl} \mathrm{pH} 7.5,1 \%$ Triton X-100, 0.5\% NP-40, 5mM EDTA), and proteins were eluted with elution buffer $(7.5 \%$ SDS, $200 \mathrm{mM} \mathrm{DTT})$ for $15 \mathrm{~min}$ at $37^{\circ} \mathrm{C}$. Eluted samples were diluted in IP buffer and combined. Then, $100 \mu \mathrm{L}$ of protease-resistant streptavidin (or prS (Rafiee et al., 2020)) beads were added for the DNA enrichment. To analyze the soluble interactors, supernatant was concentrated with speedvac, subjected to SP3 protein clean up as previously described (Hughes et al., 2014; Hughes et al., 2019) and eluted in AmBic 50mM prior digestion with 300ng trypsin (Promega V5280). For the onchromatin interactors, prS beads were washed three times with SDS washing buffer $(10 \mathrm{mM}$ Tris- $\mathrm{HCl} \mathrm{pH}$ 8, $1 \%$ SDS, $200 \mathrm{mM} \mathrm{NaCl}, 1 \mathrm{mM}$ EDTA), once with BW2x buffer (10mM Tris-HCl pH 8, 0.1\% Triton X-100, $2 \mathrm{M} \mathrm{NaCl}, 1 \mathrm{mM}$ EDTA), once with isopropanol $20 \%$ in water, and three times with acetonitrile $40 \%$ in water. The beads were transferred to PCR tubes using acetonitrile $40 \%$. The supernatant was removed, and the beads were resuspended in $15 \mu \mathrm{L}$ of $50 \mathrm{mM}$ AmBic-10mM DTT. Then, the samples were incubated at $50^{\circ} \mathrm{C}$ for $15 \mathrm{~min}$ to reduce the disulfide bonds. The cysteines were alkylated with $20 \mathrm{mM} \mathrm{IAA}$ final concentration for $15 \mathrm{~min}$ in the dark. IAA was neutralized by adding $10 \mathrm{mM}$ DTT final concentration. To digest the proteins, 300ng of trypsin (Promega V5280) was added to each tube. The digestion was performed for $18 \mathrm{~h}$ and peptides were cleaned using SP3 beads and eluted in $0.1 \%$ trifluoroacetic acid (TFA) before mass spectrometry analysis.

For the experimental design shown in figure 3, light-, medium- and heavy-labeled cells were collected at untreated conditions or after $30 \mathrm{~min}, 1 \mathrm{~h}, 4 \mathrm{~h}, 8 \mathrm{~h}$ upon $5 \mathrm{~Gy}$ IR. At each time-point, light-labeled sample was used for ChIP with isogenic IgG, while medium- and heavy-labeled samples were subjected to $\mathrm{H} 2 \mathrm{~A}$ and

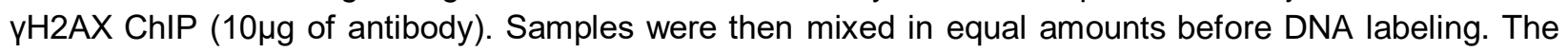
rest of the procedure was carried out as described above.

\section{Isolation of Protein on Chromatin (or iPOC) during double-strand break repair}

Per each experiment, 40x $10^{6}$ U2OS cells were metabolically labeled in SILAC (Ong SE et al 2002) DMEM medium containing light (Arg0, Lys0), medium (Arg6, Lys4) or heavy (Arg10, Lys8) amino acids. Medium- and heavy-labeled samples were also treated with 5-ethynyl-2'-deoxyuridine (or EdU) for 18h at a final concentration of $20 \mu \mathrm{M}$. Light- and medium-labeled samples were collected in untreated conditions, while heavy labeled cells were harvested at $1 \mathrm{~h}, 4 \mathrm{~h}$ or $8 \mathrm{~h}$ upon $5 \mathrm{~Gy}$ ionizing radiations. Each cell pellet was resuspended in $4 \mathrm{~mL}$ of permeabilization buffer (0.25\% Triton X-100 in PBS1x), incubated for 30min at $\mathrm{RT}$ and spun at $4^{\circ} \mathrm{C}$ for $5 \mathrm{~min}$ at $900 \mathrm{~g}$. Pellets were washed once with cold $0.5 \%$ BSA in PBS $1 \mathrm{x}$ and once with PBS $1 \mathrm{x}$. Upon centrifugation as above, each pellet was resuspended in $5 \mathrm{~mL}$ of click reaction mix (10 $\mu \mathrm{M}$ biotin azide, Jena Bioscience CLK-047), $10 \mathrm{mM}$ sodium ascorbate, $2 \mathrm{mM} \mathrm{CuSO}_{4}$ in PBS 1x) and rotated on the wheel, at RT, in the dark for $3 \mathrm{~h}$. Samples were then spun and washed once with $0.5 \%$ BSA in PBS1x and once with PBS $1 x$ as above. The pellet was resuspended in $400 \mu \mathrm{L}$ of lysis buffer $(1 \%$ SDS, 50mM Tris- $\mathrm{HCl} \mathrm{pH} \mathrm{7.5)} \mathrm{and} \mathrm{sonicated} \mathrm{with} \mathrm{the} \mathrm{Pico} \mathrm{Bioruptor} \mathrm{(Diagenode)} \mathrm{for} 20$ cycles (30sec ON/ $30 \mathrm{sec}$ OFF) or until a chromatin input focused around 600-700bp. Differently labeled samples were then spun at RT for $10 \mathrm{~min}$ at $16000 \mathrm{~g}$, and supernatants were combined in equal amount before adding $200 \mu \mathrm{L}$ of magnetic prS beads (Rafiee et al., 2020) pre-conditioned with lysis buffer. Samples were rotated overnight on the wheel. Supernatant was discarded and prS beads-chromatin sample complexes were recovered on the magnet, washed once with lysis buffer and once with $1 \mathrm{M} \mathrm{NaCl}$. PrS beads-chromatin sample complexes where conditioned in AmBic $50 \mathrm{mM}$, then resuspended in $30 \mathrm{uL}$ of $50 \mathrm{mM}$ AmBic- $10 \mathrm{mM}$ DTT. Then, the samples were incubated at $50^{\circ} \mathrm{C}$ for $15 \mathrm{~min}$ to reduce disulfide bonds, followed by cysteines alkylation with $20 \mathrm{mM}$ IAA for $15 \mathrm{~min}$ in the dark. IAA was neutralized by adding $10 \mathrm{mM}$ DTT final concentration and proteins were digested with 300ng of trypsin (Promega V5280) for 18h. Peptides were cleaned using SP3 protocol as previously described (Hughes et al., 2014; Hughes et al., 2019), and peptides were then eluted in $0.1 \%$ trifluoroacetic acid (TFA). Ammonium formate $20 \mathrm{mM}$ final 
concentration was added to each sample before subjecting them to fractionation using high-pH reversephase chromatography. Peptides were fractionated on an Agilent 1200 Infinity HPLC system with a Gemini C18 column $(3 \mu \mathrm{m}, 110 \AA$ A $100 \times 1.0 \mathrm{~mm}$, Phenomenex) using a linear $60 \mathrm{~min}$ gradient from $0 \%$ to $35 \%(\mathrm{v} / \mathrm{v})$ acetonitrile in $20 \mathrm{mM}$ ammonium formate $(\mathrm{pH} \mathrm{10})$ at a flow rate of $0.1 \mathrm{ml} / \mathrm{min}$. Elution of peptides was detected with a variable-wavelength UV detector set to $254 \mathrm{~nm}$. Thirty-two 1-min fractions were collected and subsequently pooled into four fractions per sample.

\section{Chromatin preparation and fractionation to study the global dynamics of determinants during DNA repair}

U2OS cells were metabolically labeled in SILAC (Ong SE et al 2002) DMEM medium containing light (Arg0, Lys0), medium (Arg6, Lys4) or heavy (Arg10, Lys8) amino acids. Each cell pellet corresponded to $24 \times 10^{6}$ cells cross-linked with formaldehyde $1 \%$ final concentration. Medium-labeled samples were collected after either $30 \mathrm{~min}$ or $4 \mathrm{~h}$ from DSB induction with $5 \mathrm{~Gy}$ ionizing radiations (IR) with Gammacell 40 Exactor (Best Theratronics), while heavy-labeled cells were harvested after either $1 \mathrm{~h}$ or $8 \mathrm{~h}$ from IR. Cells labeled with light amino acids were collected in untreated conditions and used as common reference channel between the two triple SILAC experiments. The first SILAC experiment contained cells untreated, $30 \mathrm{~min}$ and $1 \mathrm{~h}$ upon IR, labeled in light, medium and heavy channel, respectively. In the second experiment cells untreated, $4 \mathrm{~h}$ and $8 \mathrm{~h}$ upon IR were labeled in light, medium and heavy, respectively. Cell pellets from the same experiment were resuspended in lysis buffer $1(50 \mathrm{mM} \mathrm{HEPES}-\mathrm{KOH} \mathrm{pH} \mathrm{7.5,}$ $140 \mathrm{mM} \mathrm{NaCl}, 1 \mathrm{mM}$ EDTA, $10 \%$ Glycerol, $0.5 \%$ NP-40, 0.25\% Triton X-100) and mixed in equal amounts into the two triple SILAC experiments. Cells were then rotated on the wheel at $4^{\circ} \mathrm{C}$ for $10 \mathrm{~min}$ and spun at $400 \mathrm{~g}$ for $5 \mathrm{~min}$ at $4^{\circ} \mathrm{C}$, ultimately resuspended in lysis buffer $2(10 \mathrm{mM}$ Tris- $\mathrm{HCl} \mathrm{pH} 7.5,200 \mathrm{mM} \mathrm{NaCl}, 1 \mathrm{mM}$ EDTA). Upon rotation for $10 \mathrm{~min}$ on the wheel at RT and centrifugation at $400 \mathrm{~g}$ for $5 \mathrm{~min}$ at RT, the pellets were resuspended in lysis buffer $3(10 \mathrm{mM}$ Tris- $\mathrm{HCl} \mathrm{pH} \mathrm{7.5,100mM} \mathrm{NaCl}, 1 \mathrm{mM}$ EDTA) and subjected to 8 cycles of sonication with Pico Bioruptor (Diagenode) (30sec ON/ 30sec OFF). Triton X-100 1\% final concentration was added to the samples and the tubes were spun at $400 \mathrm{~g}$. Per each experiment, $20 \mu \mathrm{g}$ of chromatin was subjected to buffer exchange through SP3 protein clean up protocol (Hughes et al., 2014) and resuspended in AmBic-10mM DTT before proteins digestion with 1:50 trypsin (Promega V5280) for 18h. Peptides were cleaned using SP3 beads and eluted in $0.1 \%$ trifluoroacetic acid (TFA) plus $20 \mathrm{mM}$ ammonium formate $\mathrm{pH} 10$ final concentration before high $\mathrm{pH}$ reverse-phase chromatography fractionation. Peptides were fractionated on an Agilent 1200 Infinity HPLC system with a Gemini C18 column ( $3 \mu \mathrm{m}$, $110 \AA$, $100 \times 1.0 \mathrm{~mm}$, Phenomenex) using a linear $60 \mathrm{~min}$ gradient from $0 \%$ to $35 \%(\mathrm{v} / \mathrm{v})$ acetonitrile in $20 \mathrm{mM}$ ammonium formate $(\mathrm{pH} \mathrm{10})$ at a flow rate of $0.1 \mathrm{ml} / \mathrm{min}$. Elution of peptides was detected with a variable wavelength UV detector set to $254 \mathrm{~nm}$. Forty 1 -min fractions were collected and subsequently pooled into 8 fractions per sample experiment.

\section{Profiling of histone post-translational modifications during DNA repair in native conditions and at mononucleosome resolution}

Native Chromatin Proteomic (or N-ChroP) protocol was performed as described before (Soldi and Bonaldi, 2013; Soldi et al., 2017) with some modifications. Fifty million U2OS cells were collected in untreated conditions or $30 \mathrm{~min}, 1 \mathrm{~h}, 4 \mathrm{~h}, 8 \mathrm{~h}$ recovery from $5 \mathrm{~Gy}$ ionizing radiations elicited with Gammacell 40 Exactor (Best Theratronics) and resuspended in Native lysis buffer (10\% sucrose, $0.5 \mathrm{mM}$ EGTA pH 8.0, $15 \mathrm{mM} \mathrm{NaCl}, 60 \mathrm{mM} \mathrm{KCl}, 15 \mathrm{mM}$ HEPES, $0.5 \%$ Triton, 0.5mM PMSF, $1 \mathrm{mM}$ DTT, $5 \mathrm{mM}$ NAF, $5 \mathrm{mM}$ $\mathrm{Na}_{3} \mathrm{VO}_{4}, 5 \mathrm{mM}$ NaButyrate), supplemented with Triton X-100 $0.5 \%$ final concentration and incubated for 
$10 \mathrm{~min}$ on the wheel at $4^{\circ} \mathrm{C}$. Nuclei were isolated via centrifugation on a sucrose cushion (Native lysis buffer with $20 \%$ sucrose) at $2800 \mathrm{~g}$ for $30 \mathrm{~min}$, at $4^{\circ} \mathrm{C}$. Pelleted nuclei were washed twice with PBS $1 \mathrm{x}$ at $\mathrm{RT}$ and resuspended in MNase digestion buffer $\left(0.32 \mathrm{M}\right.$ sucrose, $50 \mathrm{mM}$ Tris- $\mathrm{HCl} \mathrm{pH} 7.5,4 \mathrm{mM} \mathrm{MgCl}_{2}$, $1 \mathrm{mM} \mathrm{CaCl}_{2}, 0.1 \mathrm{mM}$ PMSF) digested to mononucleosomes with $0.01 \mathrm{U} / \mu \mathrm{L}$ micrococcal nuclease (New England Biolabs, MO247S) at $37^{\circ} \mathrm{C}$ and spun at $2800 \mathrm{~g}$ for $10 \mathrm{~min}$ at $4^{\circ} \mathrm{C}$. After saving $30 \mu \mathrm{g}$ as input, the supernatant was used for ChIP with $\mathrm{YH} 2 \mathrm{AX}$ overnight, at $4^{\circ} \mathrm{C}$ on the wheel. ProteinG magnetic beads, pre-conditioned with BSA $0.5 \%$ in PBS1x (100uL per 10 $\mathrm{\mu g}$ of antibody), were then added and left rotating for $3 \mathrm{~h}$ at $4^{\circ} \mathrm{C}$. Beads were then recovered on the magnet and washed twice with native washing buffer $A$ (or WBA: $50 \mathrm{mM}$ Tris- $\mathrm{HCl} \mathrm{pH} 7.5,75 \mathrm{mM} \mathrm{NaCl}, 10 \mathrm{mM}$ EDTA), once with native washing buffer B (WBA with $125 \mathrm{mM} \mathrm{NaCl}$ ) and once with native washing buffer $\mathrm{C}$ (WBA with $175 \mathrm{mM} \mathrm{NaCl}$ ). Immunopurified material and respective input were separated by SDS-PAGE. After Coomassie staining, histone bands were excised from the gel, and de-stained with 6 washes of alternate $0,50 \%, 100 \%$ acetonitrile. Histones were then chemically alkylated with D6-acetic anhydride (Sigma 175641) in $1 \mathrm{M} \mathrm{AmBic}$ for $3 \mathrm{~h}$ at $37^{\circ} \mathrm{C}$, followed by acetonitrile washes as above and in-gel tryptic digestion. Peptides were extracted from the gel with $3 \times 100 \%$ acetonitrile, $1 \times 5 \%$ formic acid, $2 \times 100 \%$ acetonitrile washes. Supernatants containing peptides were pooled, concentrated with speedvac and desalted with self-made StageTips (Rappsilber et al., 2003) with $\mathrm{C}_{18}$ resin. Eluted peptides were lyophilized, resuspended in $0.1 \%$ TFA and analyzed with Q-Exactive HF (Thermo Scientific) mass spectrometer. Acquisition details under "Mass spectrometry data acquisition".

\section{Mass spectrometry data acquisition}

Peptides were loaded on a trap column (PepMap100 C18 Nano-Trap 100 $\mu \mathrm{m} \times 20 \mathrm{~mm}$ ) and separated over a $25 \mathrm{~cm}$ analytical column (Waters nanoEase $\mathrm{BEH}, 75 \mu \mathrm{m} \times 250 \mathrm{~mm}, \mathrm{C} 18,1.7 \mu \mathrm{m}, 130 \AA$ ) using the Thermo Easy nLC 1200 nanospray source (Thermo Easy nLC 1200, Thermo Fisher Scientific). Solvent A was water with $0.1 \%$ formic acid and solvent $B$ was $80 \%$ acetonitrile, $0.1 \%$ formic acid. During the elution step, the percentage of solvent B increased in a linear fashion from 3 to $8 \%$ in $4 \mathrm{~min}$, then increased to $10 \%$ in $2 \mathrm{~min}$, to $32 \%$ in $68 \mathrm{~min}$, to $50 \%$ in $12 \mathrm{~min}$ and finally to $100 \%$ in a further $1 \mathrm{~min}$ and went down to $3 \%$ for the last $11 \mathrm{~min}$. Peptides were analyzed on a Tri-Hybrid Orbitrap Fusion mass spectrometer (Thermo Fisher Scientific) operated in positive $(+2.5 \mathrm{kV})$ data dependent acquisition mode with HCD fragmentation. The MS1 and MS2 scans were acquired in the Orbitrap and ion trap, respectively, with a total cycle time of 3s. MS1 detection occurred at 120,000 resolution, AGC target 1E6, maximal injection time $50 \mathrm{~ms}$ and a scan range of $375-1500 \mathrm{~m} / \mathrm{z}$. Peptides with charge states 2-4 were selected for fragmentation with an exclusion duration of 40s. MS2 occurred with NCE 33\%, detection in topN mode and scan rate was set to Rapid. AGC target was $1 \mathrm{E} 4$ and maximal injection time allowed of $50 \mathrm{~ms}$. Data were recorded in centroid mode.

For histone samples, peptides were loaded and separated on same trap and analytical columns as above, but the percentage of solvent B increased in a linear fashion from 8 to $40 \%$ in $100 \mathrm{~min}$, then increased to $60 \%$ in $3 \mathrm{~min}$, to $95 \%$ in $5 \mathrm{~min}$ and remained $95 \%$ for $3 \mathrm{~min}$ before going back to $8 \%$ for $5 \mathrm{~min}$. Peptides were analyzed on a Q-Exactive HF Orbitrap mass spectrometer (ThermoFisher Scientific) operated in positive $(+2.5 \mathrm{kV})$ data dependent acquisition mode with HCD fragmentation. MS1 detection occurred at 60,000 resolution, AGC target 3E6 maximal injection time $150 \mathrm{~ms}$ and a scan range of $300-$ $1500 \mathrm{~m} / \mathrm{z}$. Peptides with charge states $2-5$ were selected for fragmentation with an exclusion duration of 60 s. MS2 occurred with NCE 30\%, detection in top20 mode. AGC target was 5E4 and maximal injection time allowed of $250 \mathrm{~ms}$. Data were recorded in centroid mode. 


\section{MS data processing, analysis and data visualization}

Mass spectrometry data were processed with MaxQuant software (1.5.2.8, 1.6.2.6) (Cox and Mann, 2008; Tyanova et al., 2016) using default settings. MSMS spectra were searched against the Human UniProt database concatenated to a database containing protein sequences of contaminants. Enzyme specificity was set to trypsin/ $\mathrm{P}$, allowing a maximum of two missed cleavages. Cysteine carbamidomethylation was set as fixed modification, while methionine oxidation and protein $\mathrm{N}$-terminal acetylation were used as variable modifications. Global false discovery rate for both protein and peptides was set to $1 \%$. The match-between-runs and re-quantify options were enabled. Intensity-based quantification options (iBAQ and LFQ) were calculated. Perseus software was used for data visualization (Tyanova et al, 2016); after canonical filtering (reverse, potential contaminants, and proteins only identified by site), only proteins with at least 1 unique peptide in all the replicates were considered as identified while only proteins with LFQ or SILAC ratio in all the replicates were defined as quantified. Pathway enrichment analysis was performed using the Metascape web software (Zhou et al., 2019).

Survival probability plot was generated with UCSC Xena (http://xena.ucsc.edu), while log2 RNA seq data visualization was performed with firebrowse (http://firebrowse.org). Boxplot were generated with $\mathrm{R}$ studio, R (https://rstudio.com) or boxplotr web software (http://shiny.chemgrid.org/boxplotr/). STRING web software (https://string-db.org/) was adopted for functional protein association network visualization.

\section{Immunofluorescence in AID-DIvA cells}

For immunofluorescence, around $1 \times 10^{4}$ AID-DlvA cells (Aymard et al., 2014) were seeded in 24-well plates on glass coverslips in DMEM medium without antibiotics for $10 \mathrm{~h}$. Cells were then transfected with 10nM final concentration of control or target siRNAs using Lipofectamine ${ }^{\mathrm{TM}}$ RNAiMAX (Thermo Fisher Scientific), according to the manufacturer's instructions, medium was then replaced with complete medium after $8 \mathrm{~h}$. $72 \mathrm{~h}$ post-transfection, DSBs were induced with $300 \mathrm{nM}$ hydroxyl tamoxifen (4-OHT Sigma Aldrich T5648) for $4 \mathrm{~h}$. Repair was promoted via adding $500 \mu \mathrm{g} / \mathrm{mL}$ Auxin (Indole-3-acetic acid sodium salt, Sigma Aldrich 15148) for 1h, triggering degradation of the AsiSI enzyme. Cells were fixed with $4 \%$ formaldehyde for 10 min and permeabilized with $0.2 \%$ Triton X-100 for 10 min while on shaking. For figure S5A, B, cells were subjected to click-chemistry reaction with $20 \mathrm{mM}$ of Cy5- or Biotin-azide (Jena Bioscience) for 30min. Biotin-azide samples were incubated afterwards with DNA hydrolysis buffer $(1.5 \mathrm{M} \mathrm{HCl})$ for $30 \mathrm{~min}$, followed by three washes with PBS 1x. For figure 3D, U2OS cells were used in immunofluorescence and DSB were induced with 5Gy ionizing radiations with a Gammacell 40 Exactor (Best Theratronics) and cells were fixed and permeabilized $1 \mathrm{~h}$ upon IR. All cells were incubated with blocking solution (1\%BSA, 22.52mg/mL Glycine in PBS-Tween20 $0.1 \%$ ) for $1 \mathrm{~h}$ while shaking. Immunostaining was performed overnight in a humidified chamber with antibody diluted in blocking solution. Antibodies against yH2AX (Millipore, 05-636), THRAP3 (Novus Biologicals, NB100-40848) were used at 1:1000 dilution, antibody anti-RAD51 (Millipore, PC-130) and anti-BRCA1 (Santa Cruz Biotechnology, sc6954) were incubated at 1:100 and 1:50, respectively. After washes, secondary antibodies were added at 1:500 dilution for $1 \mathrm{~h}$, followed by washes with PBS1x. In the second wash, Hoechst at 1:1000 was added. Upon coverslip mounting, images were acquired with a Zeiss Cell Observer inverted microscope (Zeiss) with an oil objective at 63x magnification. Images were analyzed with ImageJ software (imagej.nih.gov/ij), where Hoechst or DAPI was used to count the number of cells and define nuclei boundaries as ROIs. RAD51-, BRCA- and YH2AX-foci were counted within each nucleus with an in-house developed Java Macro after background subtraction with rolling ball radius of 50pixels. Minimum size restrictions were adopted and only foci with at least 0.2 and 0.15 micron^ 2 were counted for RAD51, BRCA and $\mathrm{yH} 2 \mathrm{AX}$, respectively. In all conditions, at least 50 cells were imaged and the number of foci was represented as boxplot in comparison with non-targeting silencing control. 
Significance was calculated with One-way ANOVA statistics and ${ }^{*},{ }^{* *}$ and ${ }^{* * *}$ correspond to $p$-value lower than $0.05,0.001$, and 0.0001 , respectively. For co-localization between $\mathrm{\gamma H} 2 \mathrm{AX}$ and THRAP3 in figure 3D upper panel, "Colocalization threshold" ImageJ plug-in in was used adopting default settings.

\section{Proximity ligation assay}

Proximity ligation assay was performed with Duolink® Proximity Ligation Assay (Sigma Aldrich-Merck, DUO92102) according to manufacturer's instructions. In brief, $1 \times 10^{4}$ U2OS cells where seeded on glass coverslip and after $12 \mathrm{~h}$ were either left untreated, or DSBs were induced with 5 Gy ionizing radiation with a Gammacell 40 Exactor (Best Theratronics). Cells were then fixed, permeabilized as in the immunofluorescence protocol above. Blocking and incubation with primary antibodies against $\mathrm{yH} 2 \mathrm{AX}$ (Millipore, 05-636), THRAP3 (Novus Biologicals, NB100-40848) was performed overnight in a humidified chamber. PLA mouse and rabbit probes were added and ligated, before rolling circle amplification according to the manufacturer's instructions. Slide preparation and imaging acquisition were performed as in the immufluorescence protocol above. DAPI staining was used to count nuclei and for defining nuclei boundaries as ROIs. PLA products per nucleus were counted with ImageJ using in-house developed Java Macro after background subtraction with rolling ball radius of 10pixels. Number of colocalization events are reported in boxplot for untreated and IR condition. Significance was calculated with One-way ANOVA statistics and ${ }^{* * *}$ correspond to $p$-value lower than 0.0001 .

\section{Cell cycle analysis by flow cytometry}

Flow cytometric analysis was performed as previously described (Khoury-Haddad et al., 2014). Briefly, cells were transfected with $10 \mathrm{nM}$ final concentration of control or target siRNAs using Lipofectamine ${ }^{\mathrm{TM}}$ RNAiMAX (Thermo Fisher Scientific), according to the manufacturer's instructions. After $72 \mathrm{~h}$ cells were fixed overnight with ice-cold $70 \%$ ethanol, and then permeabilized in phosphate buffer solution (PBS) containing $0.25 \%$ Triton X-100 (Sigma). DNA was stained with $50 \mu \mathrm{g} / \mathrm{ml}$ propidium iodide (PI, SigmaAldrich) in PBS containing $0.1 \%$ Triton-X-100 and $200 \mu \mathrm{g} / \mathrm{ml}$ DNase free RNase A (Sigma-Aldrich). Measurements were performed on a BD LSRFortessa flow cytometer (BD Biosciences) with FACSDiva software version 8.0.1 (BD Biosciences). 100.000 PI+ events were recorded for each condition from three independent experiments. Data analysis was performed using FlowJo X 10.0.7 software (FlowJo).

\section{Traffic light reporter (TLR) assay}

TLR assay was performed as previously described (Abu-Zhayia et al., 2017; Certo et al., 2011). In brief, U2OS-TLR cells were transfected with $10 \mathrm{nM}$ final concentration of control or target siRNAs using Lipofectamine ${ }^{\mathrm{TM}}$ RNAiMAX (Thermo Fisher Scientific), according to the manufacturer's instructions. After $10 \mathrm{~h}$, cells were co-transfected with plasmids expressing I-Scel nuclease fused to infrared fluorescent protein (IFP) and donor plasmid expressing GFP donor sequence fused to blue fluorescent protein (BFP), using Polyjet ${ }^{\mathrm{TM}}$ in vitro transfection reagent (SignaGen Laboratories) according to the manufacturer's instructions. Seventy-two hours after siRNA transfection, cells were harvested, and GFP and mCherry signals (reflecting HDR and NHEJ, respectively) were measured by four-color fluorescent flow-cytometry using a BD LSRFortessa flow cytometer (BD Biosciences). A minimum of 10.000 double-positive (IFP+/ $\mathrm{BFP}+$ ) cells were recorded for each condition from three independent experiments. Data analysis was performed using FlowJo X 10.0.7 software (FlowJo). Results of siRNA-transfected cells were normalized 
to control siRNA-transfected cells. U2OS ID3-GFP (kindly provided by Dr. Ali Bakr, DKFZ) and U2OS m53BP1-mCherry cells (Lund-Andersen et al., 2014) (kindly provided by Prof. Randi Syljuåsen, Oslo University Hospital) were used for compensation in flow cytometry.

\section{Colony formation assay, PARP inhibition and etoposide treatment}

Colonigenic assays were performed as previously described (Franken et al., 2006) with some modifications. In brief, U2OS cells were plated overnight in complete medium without antibiotics at 20$25 \%$ density. Cells were then subjected to siRNA transfection with $10 \mathrm{nM}$ final concentration of control or target siRNAs using Lipofectamine ${ }^{\mathrm{TM}}$ RNAiMAX (Thermo Fisher Scientific), according with manufacturer's instructions. After $24 \mathrm{~h}$ post transfection, cells were collected, counted and seeded in a 6 -well plate at a density of 1000 cells per well. 48h post transfection, cells were incubated for $2 \mathrm{~h}$ with $1 \mu \mathrm{M}$ PARP inhibitor or solvent control; followed by DSB induction via $1 \mu \mathrm{M}$ etoposide treatment for $2 \mathrm{~h}$ or solvent control. For figure $2 \mathrm{E}$, cells were treated for $24 \mathrm{~h}$ with etoposide at $0.1,0.5,1$ or $10 \mu \mathrm{M}$. For G9A colony formation assay, cells were exposed for $4 \mathrm{~h}$ to $5 \mu \mathrm{M}$ G9Ai before incubation with PARPi. After 10-14 days, colonies were fixed for $10 \mathrm{~min}$ in $70 \%$ ethanol, stained with crystal violet, destained in water and visualized. Colonies were counted with ImageJ software (imagej.nih.gov/ij) with an in-house developed Java Macro upon setting the image threshold and defining well boundary as ROI. Number of colonies or superficial area (normalized on reference) was normalized on non-targeting silencing control. Values from three biological replicates were averaged and displayed as mean \pm standard deviation.

\section{Quantification and statistical analysis}

SigmaPlot software was used to create graphs, perform statistical test and calculate $p$-values among at least three biological replicates. Unless stated otherwise, one-way ANOVA statistics was used for multiple comparison analysis. Each figure legend and respective method sections indicate both statistical significance and reference used for calculation of the p-value. For DDR-induced protein modulation, targets were classified as recruited or evicted if they fall in $\pm 5 \%$, respectively, of the 90 percentile log2 ratio distribution. Ratios of identified proteins with an intensity value (LFQ or iBAQ) only in either DDRtreated or untreated SILAC channel were replaced by a fixed value corresponding to \pm 6.67 in $\log 2$, respectively. Volcano plots were generated with Perseus software via a two-side t-test statistics, FDR> 0.05 , S0 equal to 0.1 . When reported, $z$-score normalization was performed per experiment (or column $z$ score normalization) with Perseus software. For the analysis of hPTM, the extracted ion chromatography (or XIC) was used as a measure of abundance of each modification. The relative abundance (or RA) is calculated as the XIC of a modified peak over the sum of all the XICs of all peaks for the same peptide multiplied by 100. In the heatmap RA over untreated time point are reported. The relative enrichment of a particular modification is calculated as the ratio of its RA in the ChIP over its RA in the chromatin input. Histone modifications with a log2 ratio higher or lower than 1 where considered as enriched or depleted, respectively. 


\section{SUPPLEMENTAL ITEMS}

\section{Supplemental item 1: SI_1_ChIP-SICAP_Results_DDR_core_components.}

On-chromatin proteins quantified in ChIP-SICAP experiments using RPA, RAD50, MDC1 or gamma$\mathrm{H} 2 \mathrm{AX}$ as functional bait protein in untreated as well as upon induced DSB.

\section{Supplemental item 2: SI_2_iPOC_Results_chromatin_regulation_during_DSB_repair}

Dynamics of chromatin-interacting proteins during DSB repair quantified in iPOC.

\section{Supplemental item 3: SI_3_N-ChroP_Results_dynamics_hPTM_during_DDR}

Quantification of histone PTMs profiled during DSB repair in global chromatin input and at $\mathrm{YH} 2 \mathrm{AX}$ mononucleosomes.

\section{REFERENCES}

Abu-Zhayia, E.R., Khoury-Haddad, H., Guttmann-Raviv, N., Serruya, R., Jarrous, N., and Ayoub, N. (2017). A role of human RNase P subunits, Rpp29 and Rpp21, in homology directed-repair of double-strand breaks. Sci Rep 7, 1002.

Alabert, C., Bukowski-Wills, J.C., Lee, S.B., Kustatscher, G., Nakamura, K., de Lima Alves, F., Menard, P., Mejlvang, J., Rappsilber, J., and Groth, A. (2014). Nascent chromatin capture proteomics determines chromatin dynamics during DNA replication and identifies unknown fork components. Nat Cell Biol 16, 281-293.

Aranda, S., Alcaine-Colet, A., Blanco, E., Borras, E., Caillot, C., Sabido, E., and Di Croce, L. (2019). Chromatin capture links the metabolic enzyme AHCY to stem cell proliferation. Sci Adv 5, eaav2448.

Aymard, F., Bugler, B., Schmidt, C.K., Guillou, E., Caron, P., Briois, S., lacovoni, J.S., Daburon, V., Miller, K.M., Jackson, S.P., et al. (2014). Transcriptionally active chromatin recruits homologous recombination at DNA double-strand breaks. Nat Struct Mol Biol 21, 366-374.

Ayrapetov, M.K., Gursoy-Yuzugullu, O., Xu, C., Xu, Y., and Price, B.D. (2014). DNA double-strand breaks promote methylation of histone $\mathrm{H} 3$ on lysine 9 and transient formation of repressive chromatin. Proc Natl Acad Sci U S A 111, 9169-9174.

Bao, X., Guo, X., Yin, M., Tariq, M., Lai, Y., Kanwal, S., Zhou, J., Li, N., Lv, Y., Pulido-Quetglas, C., et al. (2018). Capturing the interactome of newly transcribed RNA. Nat Methods 15, 213-220.

Barak, O., Lazzaro, M.A., Lane, W.S., Speicher, D.W., Picketts, D.J., and Shiekhattar, R. (2003). Isolation of human NURF: a regulator of Engrailed gene expression. EMBO J 22, 6089-6100.

Beli, P., Lukashchuk, N., Wagner, S.A., Weinert, B.T., Olsen, J.V., Baskcomb, L., Mann, M., Jackson, S.P., and Choudhary, C. (2012). Proteomic investigations reveal a role for RNA processing factor THRAP3 in the DNA damage response. Mol Cell 46, 212-225.

Boeing, S., Williamson, L., Encheva, V., Gori, I., Saunders, R.E., Instrell, R., Aygun, O., Rodriguez-Martinez, M., Weems, J.C., Kelly, G.P., et al. (2016). Multiomic Analysis of the UV-Induced DNA Damage Response. Cell Rep 15, 1597-1610. 
Botuyan, M.V., Lee, J., Ward, I.M., Kim, J.E., Thompson, J.R., Chen, J., and Mer, G. (2006). Structural basis for the methylation state-specific recognition of histone H4-K20 by 53BP1 and Crb2 in DNA repair. Cell 127, 1361-1373.

Byrum, A.K., Carvajal-Maldonado, D., Mudge, M.C., Valle-Garcia, D., Majid, M.C., Patel, R., Sowa, M.E., Gygi, S.P., Harper, J.W., Shi, Y., et al. (2019). Mitotic regulators TPX2 and Aurora A protect DNA forks during replication stress by counteracting 53BP1 function. J Cell Biol 218, 422-432.

Certo, M.T., Ryu, B.Y., Annis, J.E., Garibov, M., Jarjour, J., Rawlings, D.J., and Scharenberg, A.M. (2011). Tracking genome engineering outcome at individual DNA breakpoints. Nat Methods 8, 671-676.

Cheblal, A., Challa, K., Seeber, A., Shimada, K., Yoshida, H., Ferreira, H.C., Amitai, A., and Gasser, S.M. (2020). DNA Damage-Induced Nucleosome Depletion Enhances Homology Search Independently of Local Break Movement. Mol Cell 80, 311-326 e314.

Chen, C.C., Carson, J.J., Feser, J., Tamburini, B., Zabaronick, S., Linger, J., and Tyler, J.K. (2008). Acetylated lysine 56 on histone $\mathrm{H} 3$ drives chromatin assembly after repair and signals for the completion of repair. Cell 134, 231-243.

Ciro, M., Prosperini, E., Quarto, M., Grazini, U., Walfridsson, J., McBlane, F., Nucifero, P., Pacchiana, G., Capra, M., Christensen, J., et al. (2009). ATAD2 is a novel cofactor for MYC, overexpressed and amplified in aggressive tumors. Cancer Res 69, 8491-8498.

Clouaire, T., Rocher, V., Lashgari, A., Arnould, C., Aguirrebengoa, M., Biernacka, A., Skrzypczak, M., Aymard, F., Fongang, B., Dojer, N., et al. (2018). Comprehensive Mapping of Histone Modifications at DNA Double-Strand Breaks Deciphers Repair Pathway Chromatin Signatures. Mol Cell 72, 250-262 e256.

Coleman, R.L., Oza, A.M., Lorusso, D., Aghajanian, C., Oaknin, A., Dean, A., Colombo, N., Weberpals, J.I., Clamp, A., Scambia, G., et al. (2017). Rucaparib maintenance treatment for recurrent ovarian carcinoma after response to platinum therapy (ARIEL3): a randomised, double-blind, placebo-controlled, phase 3 trial. Lancet 390, 1949-1961.

Cox, J., and Mann, M. (2008). MaxQuant enables high peptide identification rates, individualized p.p.b.range mass accuracies and proteome-wide protein quantification. Nat Biotechnol 26, 1367-1372.

Cremona, C.A., Sarangi, P., Yang, Y., Hang, L.E., Rahman, S., and Zhao, X. (2012). Extensive DNA damageinduced sumoylation contributes to replication and repair and acts in addition to the mec1 checkpoint. Mol Cell 45, 422-432.

Crosetto, N., Mitra, A., Silva, M.J., Bienko, M., Dojer, N., Wang, Q., Karaca, E., Chiarle, R., Skrzypczak, M., Ginalski, K., et al. (2013). Nucleotide-resolution DNA double-strand break mapping by next-generation sequencing. Nat Methods 10, 361-365.

Di Cerbo, V., Mohn, F., Ryan, D.P., Montellier, E., Kacem, S., Tropberger, P., Kallis, E., Holzner, M., Hoerner, L., Feldmann, A., et al. (2014). Acetylation of histone H3 at lysine 64 regulates nucleosome dynamics and facilitates transcription. Elife 3, e01632.

Downs, J.A., Allard, S., Jobin-Robitaille, O., Javaheri, A., Auger, A., Bouchard, N., Kron, S.J., Jackson, S.P., and Cote, J. (2004). Binding of chromatin-modifying activities to phosphorylated histone H2A at DNA damage sites. Mol Cell 16, 979-990.

Duan, Z., Andrews, N.P., Chen, C.Z., Fan, M., Wang, J., Shen, J., Li, J.J., and Chen, H.W. (2020). Targeting bromodomain protein ANCCA/ATAD2 enhances the efficacy of DNAdamaging chemotherapy agents and radiation. Oncol Rep 43, 318-327.

Fenley, A.T., Anandakrishnan, R., Kidane, Y.H., and Onufriev, A.V. (2018). Modulation of nucleosomal DNA accessibility via charge-altering post-translational modifications in histone core. Epigenetics Chromatin 11, 11.

Fnu, S., Williamson, E.A., De Haro, L.P., Brenneman, M., Wray, J., Shaheen, M., Radhakrishnan, K., Lee, S.H., Nickoloff, J.A., and Hromas, R. (2011). Methylation of histone H3 lysine 36 enhances DNA repair by nonhomologous end-joining. Proc Natl Acad Sci U S A 108, 540-545. 
Francia, S., Michelini, F., Saxena, A., Tang, D., de Hoon, M., Anelli, V., Mione, M., Carninci, P., and d'Adda di Fagagna, F. (2012). Site-specific DICER and DROSHA RNA products control the DNA-damage response. Nature 488, 231-235.

Franken, N.A., Rodermond, H.M., Stap, J., Haveman, J., and van Bree, C. (2006). Clonogenic assay of cells in vitro. Nat Protoc 1, 2315-2319.

Gong, F., and Miller, K.M. (2019). Histone methylation and the DNA damage response. Mutat Res 780, 37-47.

Green, C.M., and Almouzni, G. (2002). When repair meets chromatin. First in series on chromatin dynamics. EMBO Rep 3, 28-33.

Gupta, R., Somyajit, K., Narita, T., Maskey, E., Stanlie, A., Kremer, M., Typas, D., Lammers, M., Mailand, N., Nussenzweig, A., et al. (2018). DNA Repair Network Analysis Reveals Shieldin as a Key Regulator of NHEJ and PARP Inhibitor Sensitivity. Cell 173, 972-988 e923.

Haahr, P., Hoffmann, S., Tollenaere, M.A., Ho, T., Toledo, L.I., Mann, M., Bekker-Jensen, S., Raschle, M., and Mailand, N. (2016). Activation of the ATR kinase by the RPA-binding protein ETAA1. Nat Cell Biol 18, 1196-1207.

Harper, J.W., and Elledge, S.J. (2007). The DNA damage response: ten years after. Mol Cell 28, 739-745. Hilger, M., and Mann, M. (2012). Triple SILAC to determine stimulus specific interactions in the Wnt pathway. J Proteome Res 11, 982-994.

Houston, S.I., McManus, K.J., Adams, M.M., Sims, J.K., Carpenter, P.B., Hendzel, M.J., and Rice, J.C. (2008). Catalytic function of the PR-Set7 histone H4 lysine 20 monomethyltransferase is essential for mitotic entry and genomic stability. J Biol Chem 283, 19478-19488.

Huertas, P. (2010). DNA resection in eukaryotes: deciding how to fix the break. Nat Struct Mol Biol 17, 11-16.

Hughes, C.S., Foehr, S., Garfield, D.A., Furlong, E.E., Steinmetz, L.M., and Krijgsveld, J. (2014). Ultrasensitive proteome analysis using paramagnetic bead technology. Mol Syst Biol 10, 757.

Hughes, C.S., Moggridge, S., Muller, T., Sorensen, P.H., Morin, G.B., and Krijgsveld, J. (2019). Single-pot, solid-phase-enhanced sample preparation for proteomics experiments. Nat Protoc 14, 68-85.

Huyen, Y., Zgheib, O., Ditullio, R.A., Jr., Gorgoulis, V.G., Zacharatos, P., Petty, T.J., Sheston, E.A., Mellert, H.S., Stavridi, E.S., and Halazonetis, T.D. (2004). Methylated lysine 79 of histone H3 targets $53 B P 1$ to DNA double-strand breaks. Nature 432, 406-411.

Jackson, S.P., and Bartek, J. (2009). The DNA-damage response in human biology and disease. Nature 461, 1071-1078.

Jha, S., Shibata, E., and Dutta, A. (2008). Human Rvb1/Tip49 is required for the histone acetyltransferase activity of Tip60/NuA4 and for the downregulation of phosphorylation on H2AX after DNA damage. Mol Cell Biol 28, 2690-2700.

Kaaij, L.J.T., Mohn, F., van der Weide, R.H., de Wit, E., and Buhler, M. (2019). The ChAHP Complex Counteracts Chromatin Looping at CTCF Sites that Emerged from SINE Expansions in Mouse. Cell 178, 1437-1451 e1414.

Karagoz, K., Mehta, G.A., Khella, C.A., Khanna, P., and Gatza, M.L. (2019). Integrative proteogenomic analyses of human tumours identifies ADNP as a novel oncogenic mediator of cell cycle progression in high-grade serous ovarian cancer with poor prognosis. EBioMedicine 50, 191-202.

Khoury-Haddad, H., Guttmann-Raviv, N., Ipenberg, I., Huggins, D., Jeyasekharan, A.D., and Ayoub, N. (2014). PARP1-dependent recruitment of KDM4D histone demethylase to DNA damage sites promotes double-strand break repair. Proc Natl Acad Sci U S A 111, E728-737.

Kleiner, R.E., Verma, P., Molloy, K.R., Chait, B.T., and Kapoor, T.M. (2015). Chemical proteomics reveals a gammaH2AX-53BP1 interaction in the DNA damage response. Nat Chem Biol 11, 807-814.

Kliszczak, A.E., Rainey, M.D., Harhen, B., Boisvert, F.M., and Santocanale, C. (2011). DNA mediated chromatin pull-down for the study of chromatin replication. Sci Rep 1, 95. 
Koo, S.J., Fernandez-Montalvan, A.E., Badock, V., Ott, C.J., Holton, S.J., von Ahsen, O., Toedling, J., Vittori, S., Bradner, J.E., and Gorjanacz, M. (2016). ATAD2 is an epigenetic reader of newly synthesized histone marks during DNA replication. Oncotarget 7, 70323-70335.

Kusch, T., Florens, L., Macdonald, W.H., Swanson, S.K., Glaser, R.L., Yates, J.R., 3rd, Abmayr, S.M., Washburn, M.P., and Workman, J.L. (2004). Acetylation by Tip60 is required for selective histone variant exchange at DNA lesions. Science 306, 2084-2087.

Lord, C.J., and Ashworth, A. (2016). BRCAness revisited. Nat Rev Cancer 16, 110-120.

Lund-Andersen, C., Patzke, S., Nahse-Kumpf, V., and Syljuasen, R.G. (2014). PLK1-inhibition can cause radiosensitization or radioresistance dependent on the treatment schedule. Radiother Oncol 110, 355361.

Masumoto, H., Hawke, D., Kobayashi, R., and Verreault, A. (2005). A role for cell-cycle-regulated histone H3 lysine 56 acetylation in the DNA damage response. Nature 436, 294-298.

Mirza, M.R., Monk, B.J., Herrstedt, J., Oza, A.M., Mahner, S., Redondo, A., Fabbro, M., Ledermann, J.A., Lorusso, D., Vergote, I., et al. (2016). Niraparib Maintenance Therapy in Platinum-Sensitive, Recurrent Ovarian Cancer. N Engl J Med 375, 2154-2164.

Moreno, N.S., Liu, J., Haas, K.M., Parker, L.L., Chakraborty, C., Kron, S.J., Hodges, K., Miller, L.D., Langefeld, C., Robinson, P.J., et al. (2019). The nuclear structural protein NuMA is a negative regulator of 53BP1 in DNA double-strand break repair. Nucleic Acids Res 47, 10475.

Moyal, L., Lerenthal, Y., Gana-Weisz, M., Mass, G., So, S., Wang, S.Y., Eppink, B., Chung, Y.M., Shalev, G., Shema, E., et al. (2011). Requirement of ATM-dependent monoubiquitylation of histone H2B for timely repair of DNA double-strand breaks. Mol Cell 41, 529-542.

Murr, R., Loizou, J.I., Yang, Y.G., Cuenin, C., Li, H., Wang, Z.Q., and Herceg, Z. (2006). Histone acetylation by Trrap-Tip60 modulates loading of repair proteins and repair of DNA double-strand breaks. Nat Cell Biol 8, 91-99.

Nakamura, K., Kustatscher, G., Alabert, C., Hodl, M., Forne, I., Volker-Albert, M., Satpathy, S., Beyer, T.E., Mailand, N., Choudhary, C., et al. (2021). Proteome dynamics at broken replication forks reveal a distinct ATM-directed repair response suppressing DNA double-strand break ubiquitination. Mol Cell 81, 10841099 e1086.

Neumayer, G., Helfricht, A., Shim, S.Y., Le, H.T., Lundin, C., Belzil, C., Chansard, M., Yu, Y., Lees-Miller, S.P., Gruss, O.J., et al. (2012). Targeting protein for xenopus kinesin-like protein 2 (TPX2) regulates gamma-histone 2AX (gamma-H2AX) levels upon ionizing radiation. J Biol Chem 287, 42206-42222.

Oda, H., Hubner, M.R., Beck, D.B., Vermeulen, M., Hurwitz, J., Spector, D.L., and Reinberg, D. (2010). Regulation of the histone $\mathrm{H} 4$ monomethylase PR-Set7 by CRL4(Cdt2)-mediated PCNA-dependent degradation during DNA damage. Mol Cell 40, 364-376.

Onyango, D.O., Lee, G., and Stark, J.M. (2017). PRPF8 is important for BRCA1-mediated homologous recombination. Oncotarget 8, 93319-93337.

Palmieri, D., Valentino, T., D'Angelo, D., De Martino, I., Postiglione, I., Pacelli, R., Croce, C.M., Fedele, M., and Fusco, A. (2011). HMGA proteins promote ATM expression and enhance cancer cell resistance to genotoxic agents. Oncogene 30, 3024-3035.

Pellegrino, S., Michelena, J., Teloni, F., Imhof, R., and Altmeyer, M. (2017). Replication-Coupled Dilution of H4K20me2 Guides 53BP1 to Pre-replicative Chromatin. Cell Rep 19, 1819-1831.

Perez-Riverol, Y., Csordas, A., Bai, J., Bernal-Llinares, M., Hewapathirana, S., Kundu, D.J., Inuganti, A., Griss, J., Mayer, G., Eisenacher, M., et al. (2019). The PRIDE database and related tools and resources in 2019: improving support for quantification data. Nucleic Acids Res 47, D442-D450.

Pfister, S.X., and Ashworth, A. (2017). Marked for death: targeting epigenetic changes in cancer. Nat Rev Drug Discov 16, 241-263.

Pilie, P.G., Tang, C., Mills, G.B., and Yap, T.A. (2019). State-of-the-art strategies for targeting the DNA damage response in cancer. Nat Rev Clin Oncol 16, 81-104. 
Probst, A.V., Dunleavy, E., and Almouzni, G. (2009). Epigenetic inheritance during the cell cycle. Nat Rev Mol Cell Biol 10, 192-206.

Qi, W., Wang, R., Chen, H., Wang, X., Xiao, T., Boldogh, I., Ba, X., Han, L., and Zeng, X. (2015). BRG1 promotes the repair of DNA double-strand breaks by facilitating the replacement of RPA with RAD51. J Cell Sci 128, 317-330.

Rafiee, M.R., Girardot, C., Sigismondo, G., and Krijgsveld, J. (2016). Expanding the Circuitry of Pluripotency by Selective Isolation of Chromatin-Associated Proteins. Mol Cell 64, 624-635.

Rafiee, M.R., Sigismondo, G., Kalxdorf, M., Forster, L., Brugger, B., Bethune, J., and Krijgsveld, J. (2020). Protease-resistant streptavidin for interaction proteomics. Mol Syst Biol 16, e9370.

Raponi, M., Smith, L.D., Silipo, M., Stuani, C., Buratti, E., and Baralle, D. (2014). BRCA1 exon 11 a model of long exon splicing regulation. RNA Biol 11, 351-359.

Rappsilber, J., Ishihama, Y., and Mann, M. (2003). Stop and go extraction tips for matrix-assisted laser desorption/ionization, nanoelectrospray, and LC/MS sample pretreatment in proteomics. Anal Chem 75, 663-670.

Raschle, M., Smeenk, G., Hansen, R.K., Temu, T., Oka, Y., Hein, M.Y., Nagaraj, N., Long, D.T., Walter, J.C., Hofmann, K., et al. (2015). DNA repair. Proteomics reveals dynamic assembly of repair complexes during bypass of DNA cross-links. Science $348,1253671$.

Rogakou, E.P., Pilch, D.R., Orr, A.H., Ivanova, V.S., and Bonner, W.M. (1998). DNA double-stranded breaks induce histone H2AX phosphorylation on serine 139. J Biol Chem 273, 5858-5868.

San Filippo, J., Sung, P., and Klein, H. (2008). Mechanism of eukaryotic homologous recombination. Annu Rev Biochem 77, 229-257.

Saredi, G., Huang, H., Hammond, C.M., Alabert, C., Bekker-Jensen, S., Forne, I., Reveron-Gomez, N., Foster, B.M., Mlejnkova, L., Bartke, T., et al. (2016). H4K20me0 marks post-replicative chromatin and recruits the TONSL-MMS22L DNA repair complex. Nature 534, 714-718.

Schep, R., Brinkman, E.K., Leemans, C., Vergara, X., van der Weide, R.H., Morris, B., van Schaik, T., Manzo, S.G., Peric-Hupkes, D., van den Berg, J., et al. (2021). Impact of chromatin context on Cas9induced DNA double-strand break repair pathway balance. Mol Cell 81, 2216-2230 e2210.

Schubeler, D., MacAlpine, D.M., Scalzo, D., Wirbelauer, C., Kooperberg, C., van Leeuwen, F., Gottschling, D.E., O'Neill, L.P., Turner, B.M., Delrow, J., et al. (2004). The histone modification pattern of active genes revealed through genome-wide chromatin analysis of a higher eukaryote. Genes Dev 18, 1263-1271.

Simonetta, M., de Krijger, I., Serrat, J., Moatti, N., Fortunato, D., Hoekman, L., Bleijerveld, O.B., Altelaar, A.F.M., and Jacobs, J.J.L. (2018). H4K20me2 distinguishes pre-replicative from post-replicative chromatin to appropriately direct DNA repair pathway choice by 53BP1-RIF1-MAD2L2. Cell Cycle 17, 124-136.

Sirbu, B.M., Couch, F.B., and Cortez, D. (2012). Monitoring the spatiotemporal dynamics of proteins at replication forks and in assembled chromatin using isolation of proteins on nascent DNA. Nat Protoc 7, 594-605.

Sirbu, B.M., Couch, F.B., Feigerle, J.T., Bhaskara, S., Hiebert, S.W., and Cortez, D. (2011). Analysis of protein dynamics at active, stalled, and collapsed replication forks. Genes Dev 25, 1320-1327.

Soldi, M., and Bonaldi, T. (2013). The proteomic investigation of chromatin functional domains reveals novel synergisms among distinct heterochromatin components. Mol Cell Proteomics 12, 764-780.

Soldi, M., Mari, T., Nicosia, L., Musiani, D., Sigismondo, G., Cuomo, A., Pavesi, G., and Bonaldi, T. (2017). Chromatin proteomics reveals novel combinatorial histone modification signatures that mark distinct subpopulations of macrophage enhancers. Nucleic Acids Res 45, 12195-12213.

Song, C., Hotz-Wagenblatt, A., Voit, R., and Grummt, I. (2017). SIRT7 and the DEAD-box helicase DDX21 cooperate to resolve genomic $R$ loops and safeguard genome stability. Genes Dev 31, 1370-1381.

Suka, N., Suka, Y., Carmen, A.A., Wu, J., and Grunstein, M. (2001). Highly specific antibodies determine histone acetylation site usage in yeast heterochromatin and euchromatin. Mol Cell 8, 473-479. 
Tacke, R., Tohyama, M., Ogawa, S., and Manley, J.L. (1998). Human Tra2 proteins are sequence-specific activators of pre-mRNA splicing. Cell 93, 139-148.

Tian, T., Bu, M., Chen, X., Ding, L., Yang, Y., Han, J., Feng, X.H., Xu, P., Liu, T., Ying, S., et al. (2021). The ZATT-TOP2A-PICH Axis Drives Extensive Replication Fork Reversal to Promote Genome Stability. Mol Cell 81, 198-211 e196.

Tweedie-Cullen, R.Y., Brunner, A.M., Grossmann, J., Mohanna, S., Sichau, D., Nanni, P., Panse, C., and Mansuy, I.M. (2012). Identification of combinatorial patterns of post-translational modifications on individual histones in the mouse brain. PLoS One 7, e36980.

Tyanova, S., Temu, T., and Cox, J. (2016). The MaxQuant computational platform for mass spectrometrybased shotgun proteomics. Nat Protoc 11, 2301-2319.

Vidi, P.A., Liu, J., Salles, D., Jayaraman, S., Dorfman, G., Gray, M., Abad, P., Moghe, P.V., Irudayaraj, J.M., Wiesmuller, L., et al. (2014). NuMA promotes homologous recombination repair by regulating the accumulation of the ISWI ATPase SNF2h at DNA breaks. Nucleic Acids Res 42, 6365-6379.

Yu, Y., Song, C., Zhang, Q., DiMaggio, P.A., Garcia, B.A., York, A., Carey, M.F., and Grunstein, M. (2012). Histone H3 lysine 56 methylation regulates DNA replication through its interaction with PCNA. Mol Cell 46, 7-17.

Zee, B.M., Levin, R.S., Xu, B., LeRoy, G., Wingreen, N.S., and Garcia, B.A. (2010). In vivo residue-specific histone methylation dynamics. J Biol Chem 285, 3341-3350.

Zhang, L., Huang, Q., Lou, J., Zou, L., Wang, Y., Zhang, P., Yang, G., Zhang, J., Yu, L., Yan, D., et al. (2017). A novel PHD-finger protein 14/KIF4A complex overexpressed in lung cancer is involved in cell mitosis regulation and tumorigenesis. Oncotarget 8, 19684-19698.

Zhou, Y., Zhou, B., Pache, L., Chang, M., Khodabakhshi, A.H., Tanaseichuk, O., Benner, C., and Chanda, S.K. (2019). Metascape provides a biologist-oriented resource for the analysis of systems-level datasets. Nat Commun 10, 1523. 
bioRxiv preprint doi: https://doi.org/10.1101/2021.08.05.455226; this version posted August 5, 2021. The copyright holder for this preprint (which was not certified by peer review) is the author/funder. All rights reserved. No reuse allowed without permission.

\section{Sigismondo et al. Figure 1}

A) SILAC cell labeling,

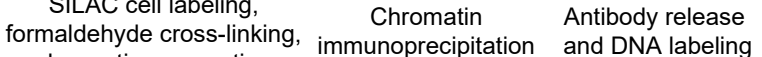
chromatin preparation

Reverse cross-linking,

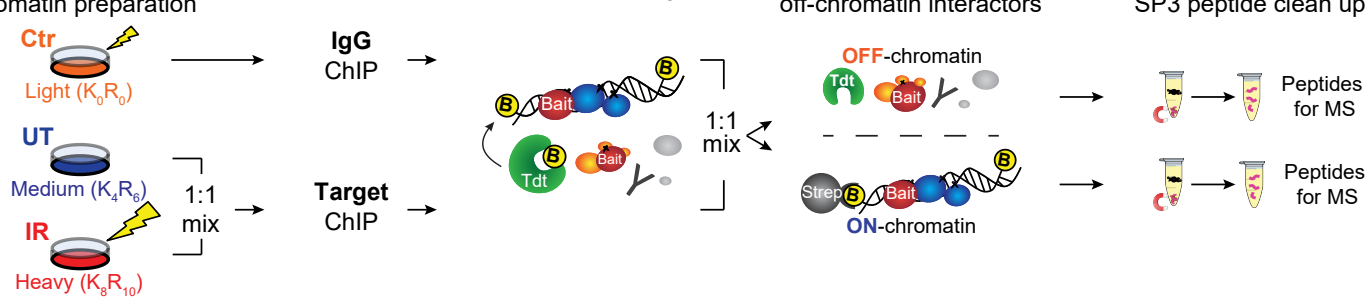
Ctr $=$ UT:IR 1 to 1 subjected to IgG ChIP UT= untreated IR= irradiated 5Gy, $1 \mathrm{~h}$ recovery Target= RPA, MDC1, RAD50,

B)

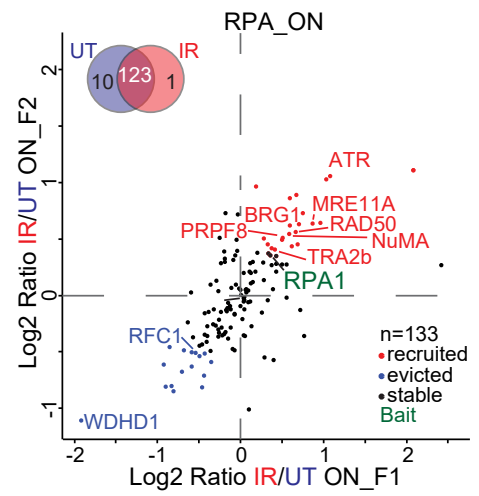

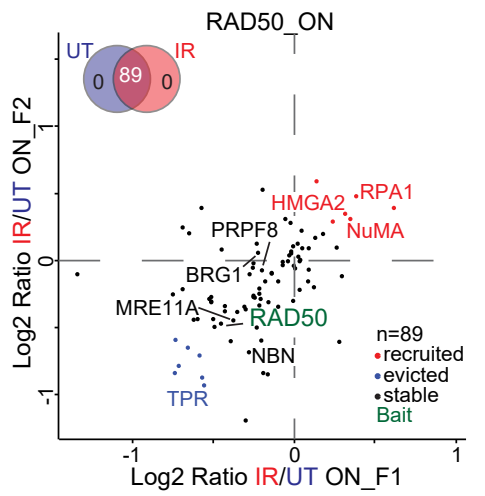

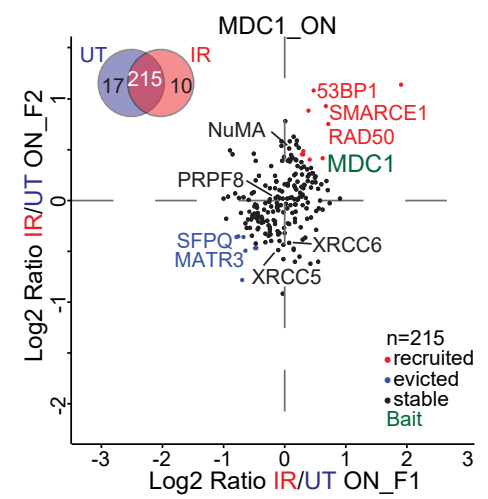

C)

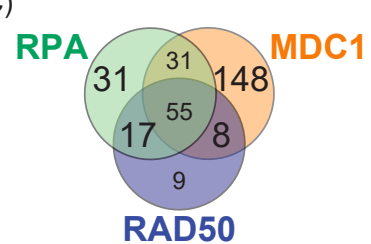

E)

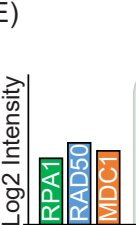

D) $\widehat{Ð} 20-$
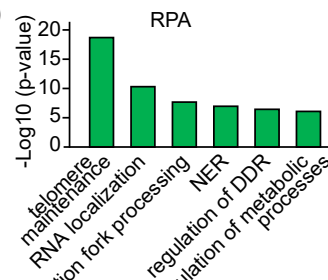<smiles>C1CCCCC1</smiles>
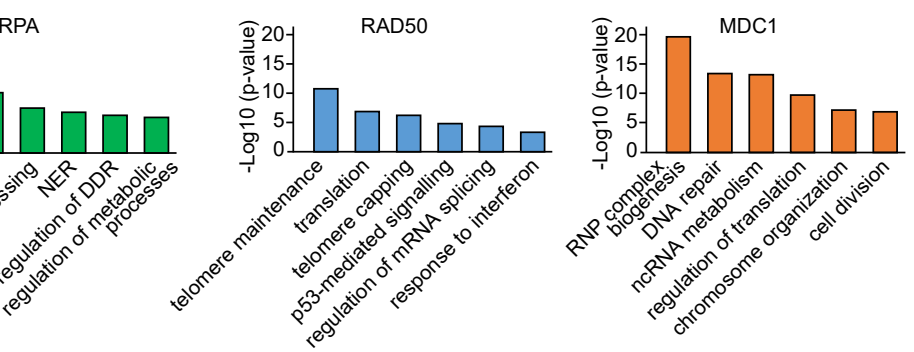

Homologous recombination

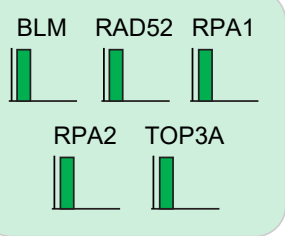

MRN complex

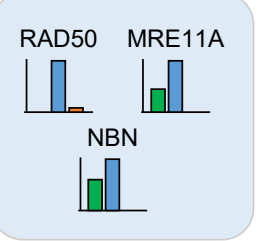

Non-homologous end-joining

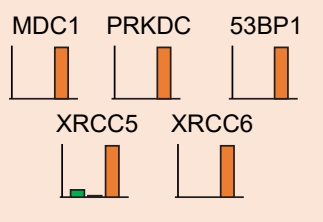

F)

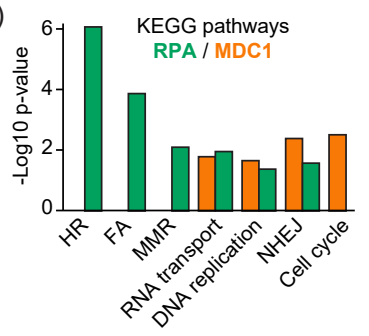


bioRxiv preprint doi: https://doi.org/10.1101/2021.08.05.455226; this version posted August 5, 2021. The copyright holder for this preprint (which was not certified by peer review) is the author/funder. All rights reserved. No reuse allowed without permission.

Sigismondo et al. Figure 2

A)

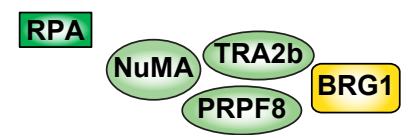

MDC1
B)

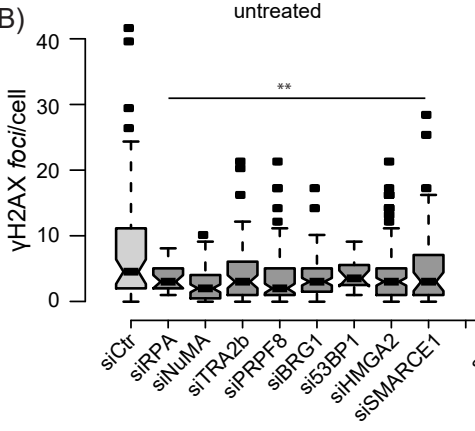

C)

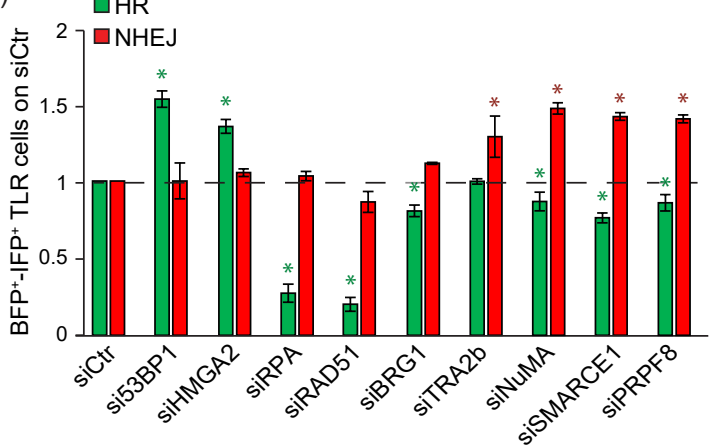

F)

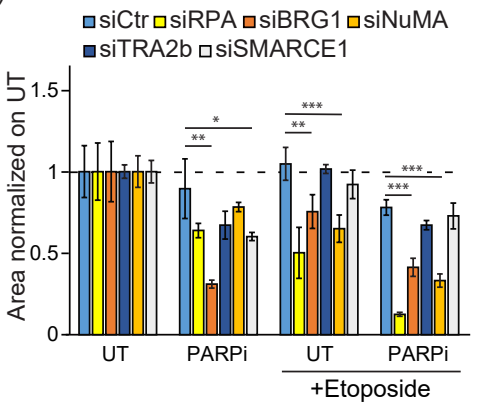

G)

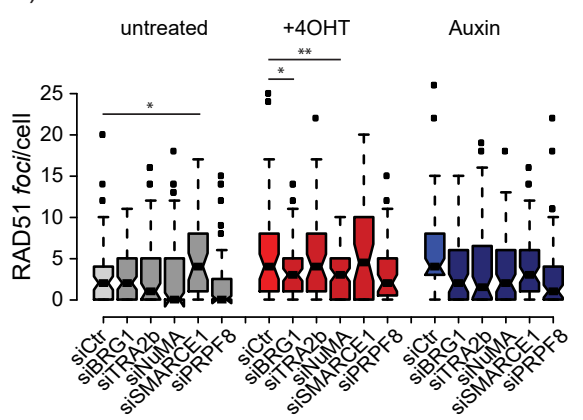

D)
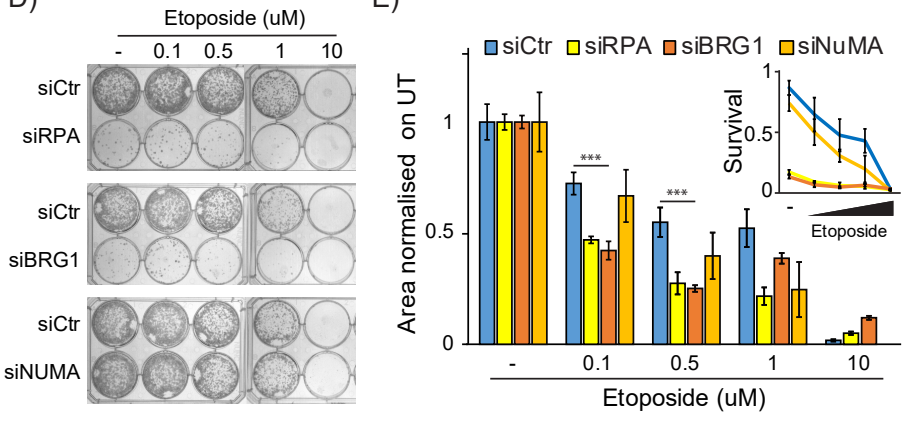

H)

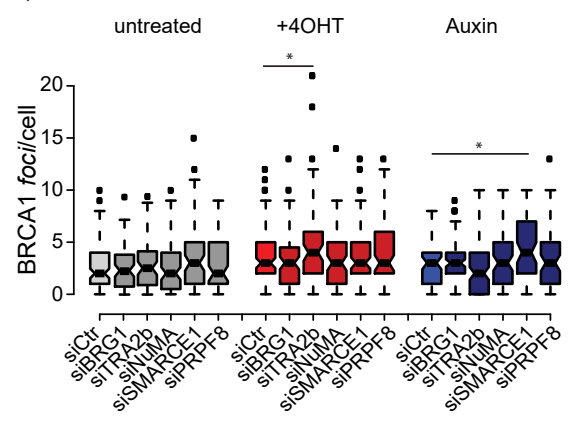




\section{Sigismondo et al. Figure 3}

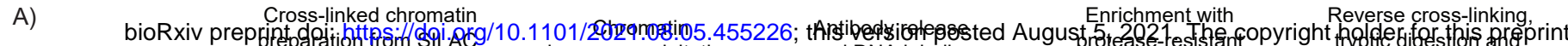

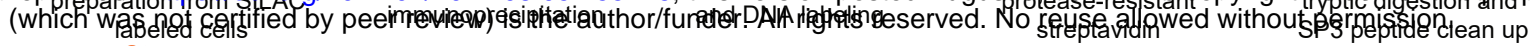

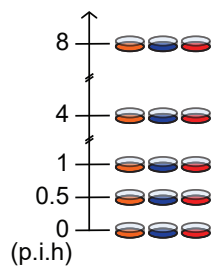

B)
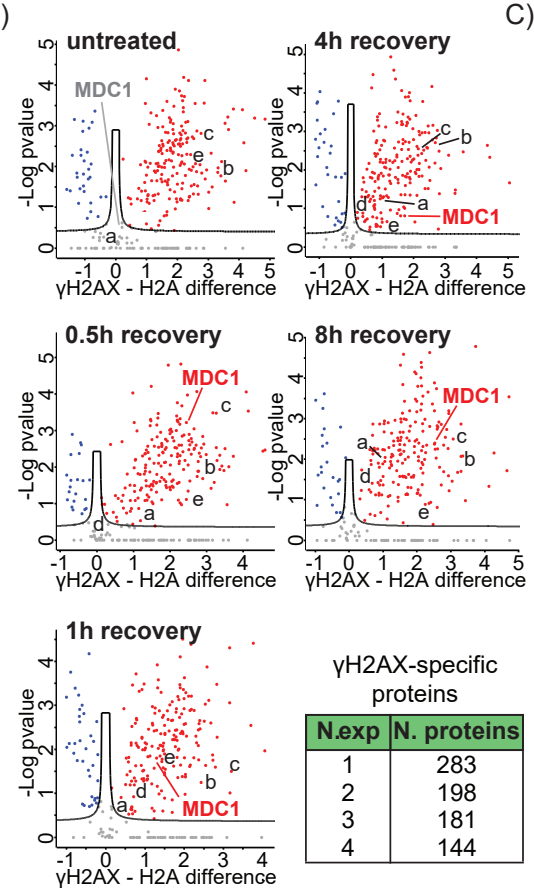

a) ATAD2 b) PRPF8 c) THRAP3 d) TPX2 e) TRA2b

C)
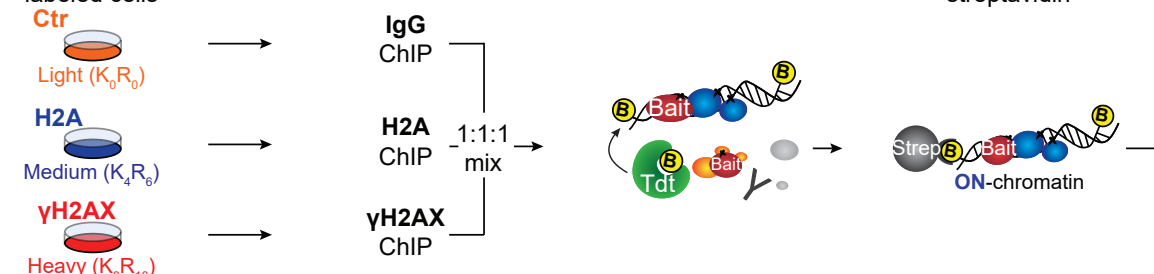

C $\begin{aligned} & \text { Peptides } \\ & \text { for MS }\end{aligned}$

D)
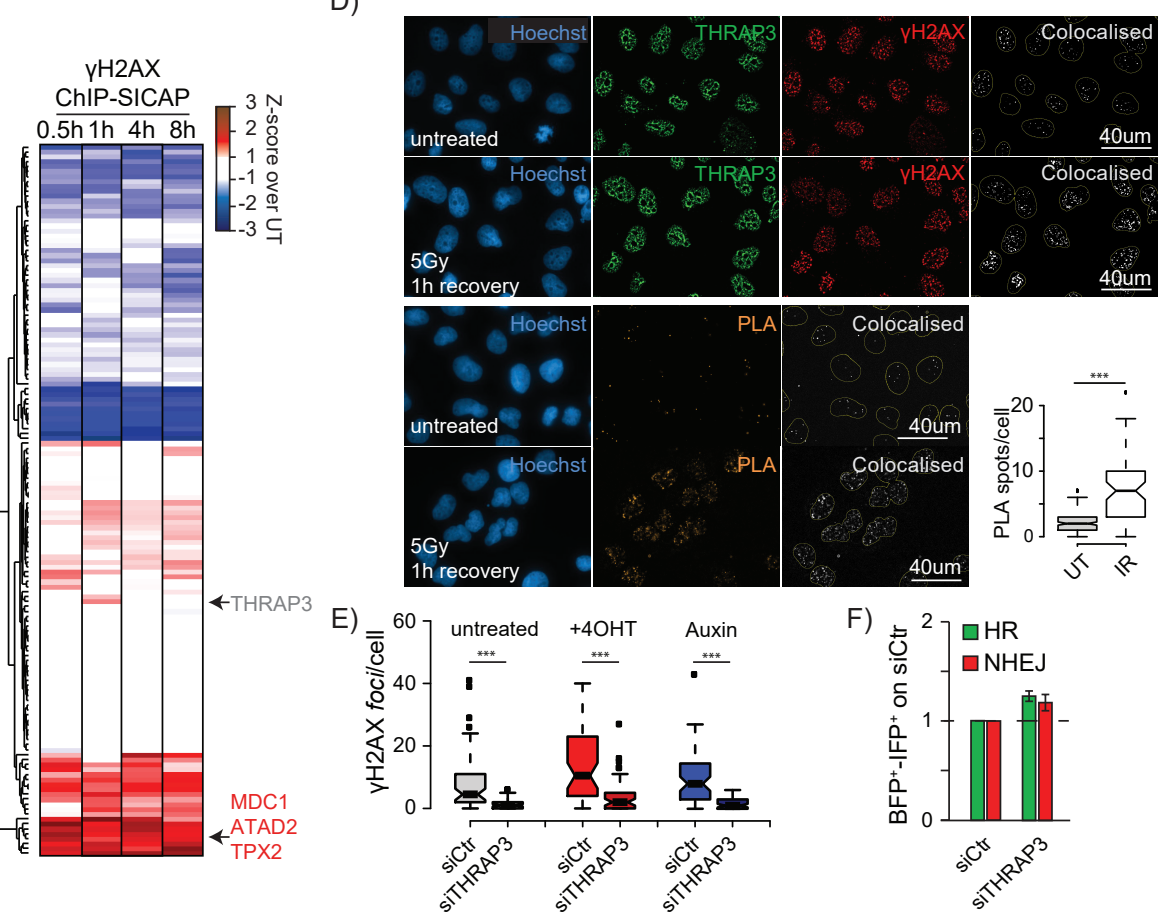

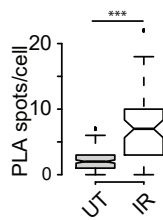

F) $=2$

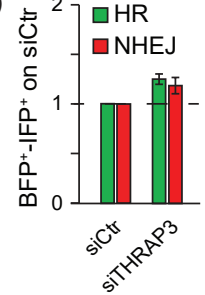


Sigismondo et al. Figure 4

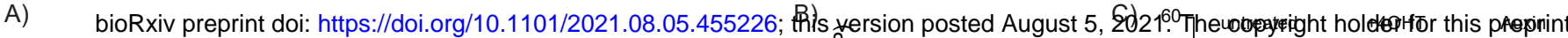
(which was not certified by peer review) is the author/funde fall fights reserved. No reuse allowed without permission.
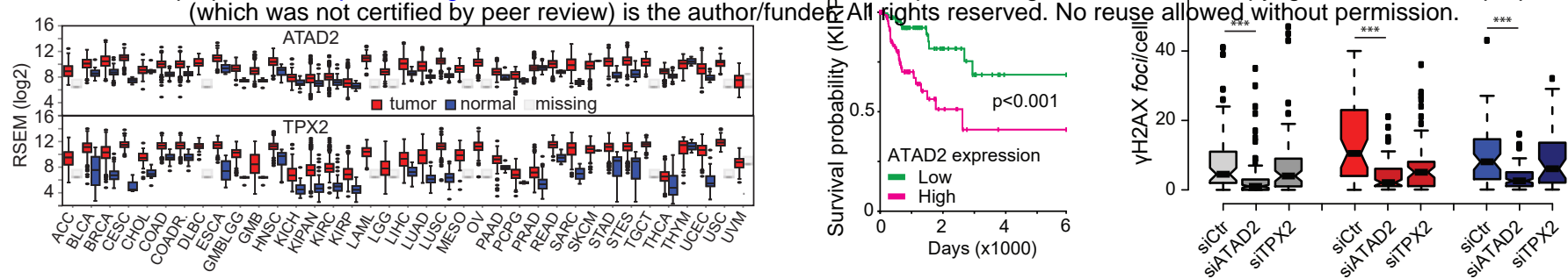

D)

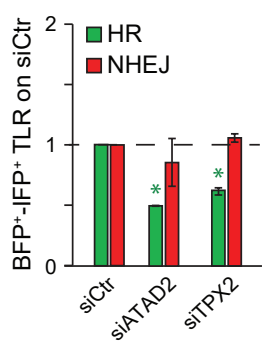

E)

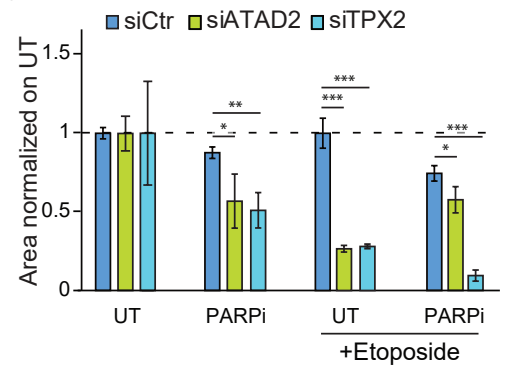

F)

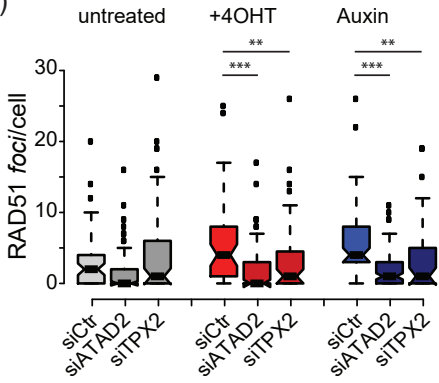

G)

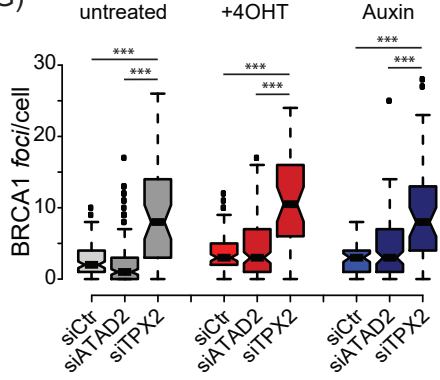




\section{Sigismondo et al. Figure 5}

A) bioRxiv preprint doi: https://dojorg/10.1101/2021.08.05.455226; this version posted August 5, 2021. The copyright holder for this preprint A) (which was not certified by peer review) is the author/funder. All rights reserved. No reuse allowed without permission.

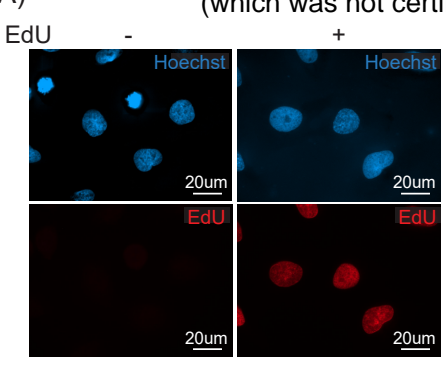

C)

Chromatin input

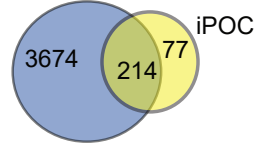

D)

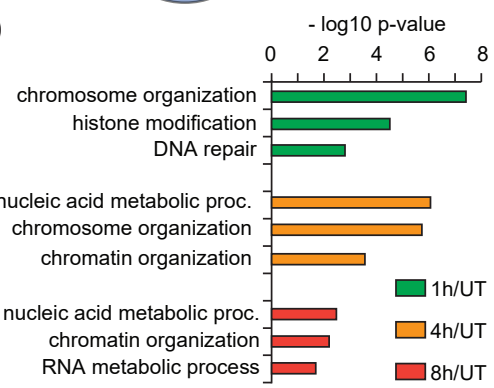

F)

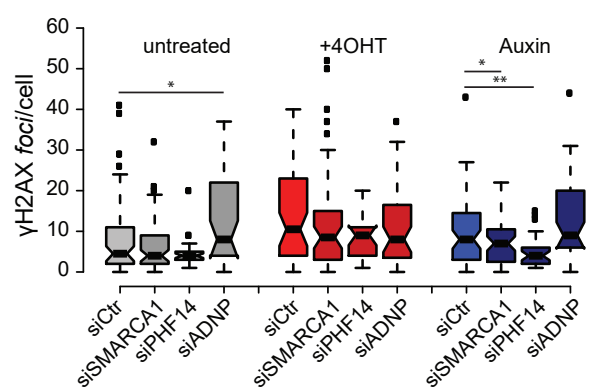

G)

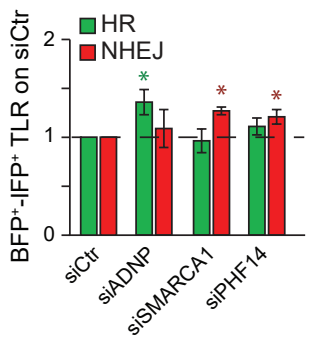

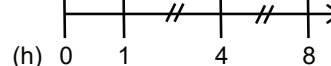

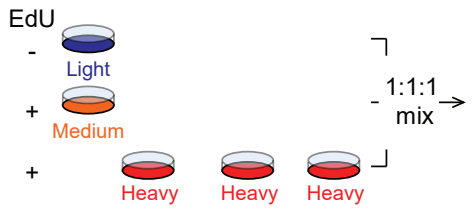

Biotin azide click

Streptavidin pull-down and chromatin shearing washed and tryptic digestion

Peptide clean up and MS analysis
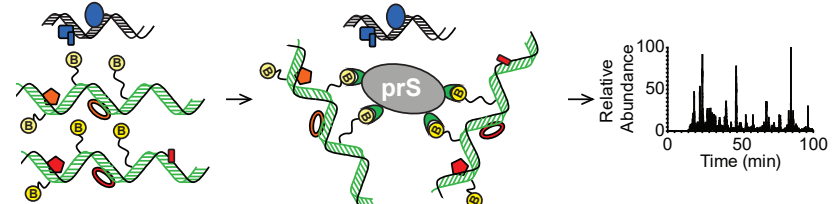

E)

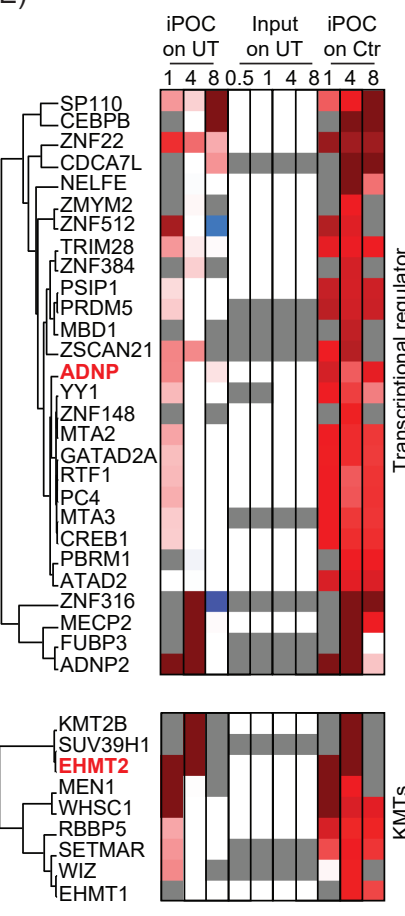

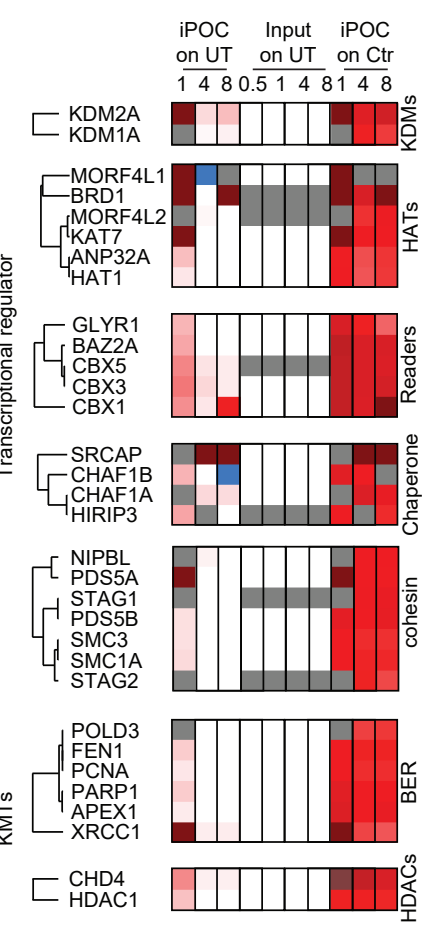

IPOC Input IPOC on UT on UT on $\mathrm{Ct}$

KDM2A
KDM1A $\overline{1480.51481 \overline{48}}$ on UT on UT on Ctr 
Sigismondo et al. Figure 6

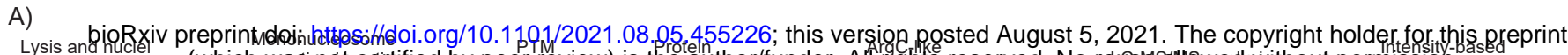

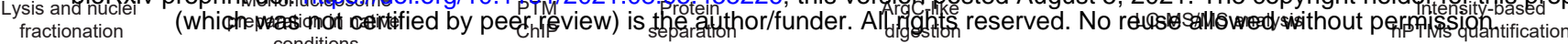

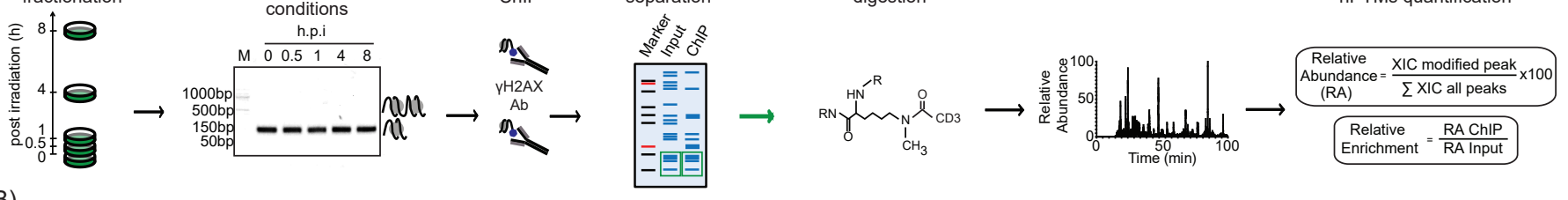

B)

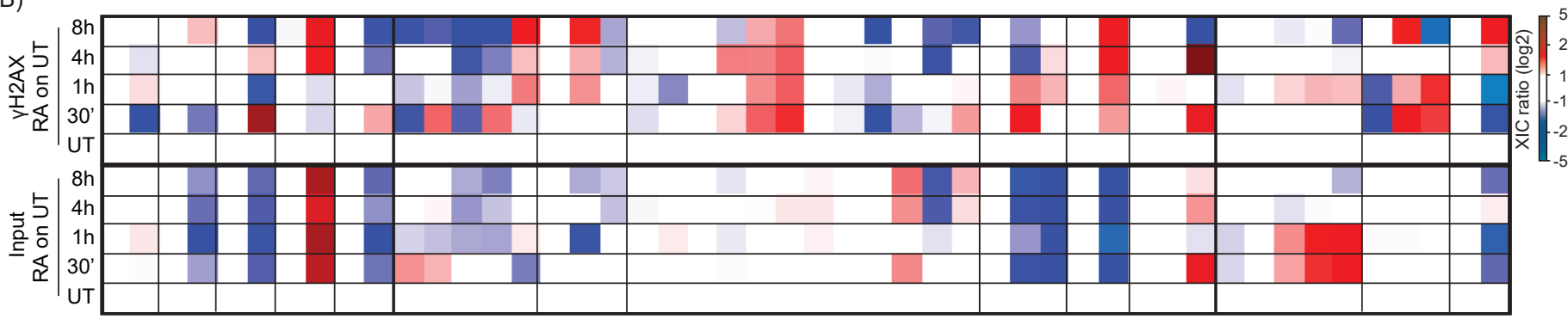

RE UT \begin{tabular}{|l|l|l|l|l|l|l|l|l|l|l|l|l|l|l|l|l|l|l|}
\hline \\
\hline
\end{tabular}

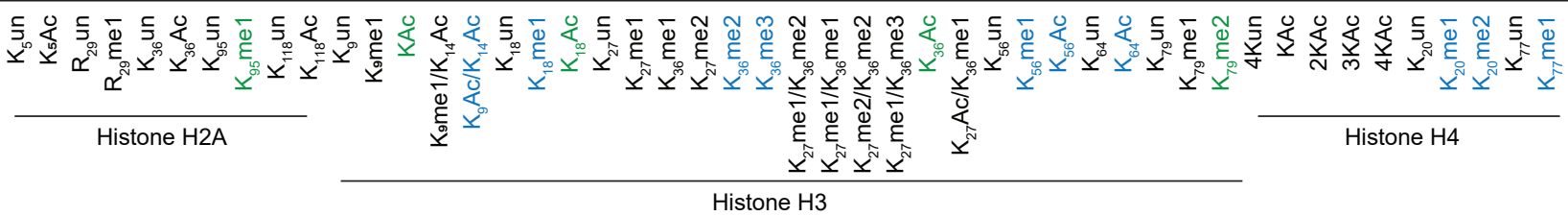

C)

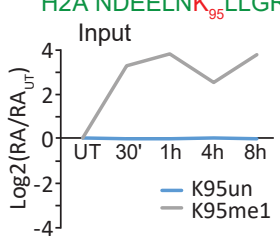

E) ${ }_{H} 3$ YQK ${ }_{56}$ STELLIR
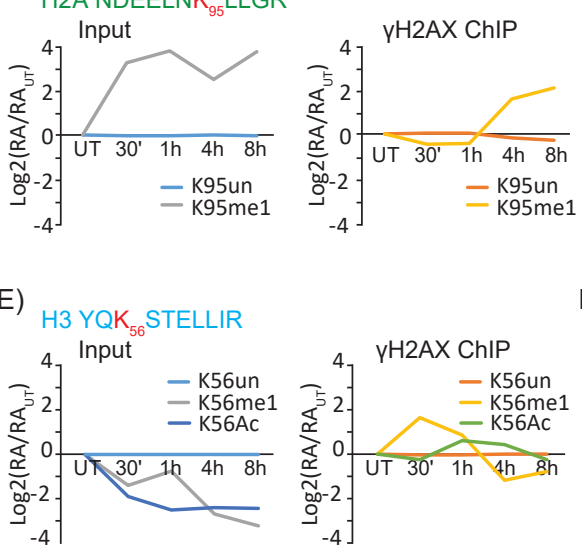

D)

F)
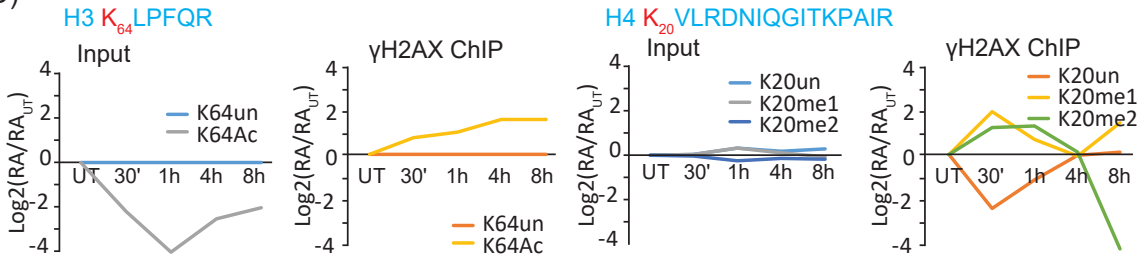

)

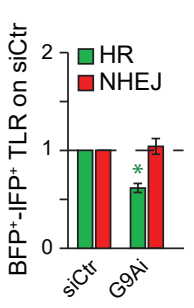

G)

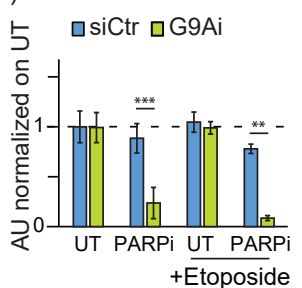

H)

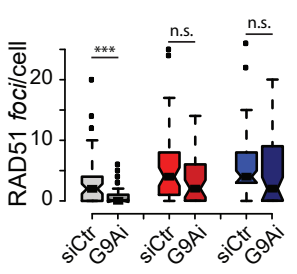

I) untreated $+4 \mathrm{OHT}$ Auxin

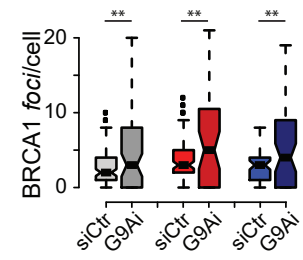


Sigismondo et al. Figure 7

bioRxiv preprint doi: https://dolorg/10.1101/2021 08.05.455226; ; this yersion posted August 5, 2021. The copyright holder for this preprint (which was not Certifiealfy peer review) is the authorffunder. Anll rights reserved. No reuse allowed without permission.

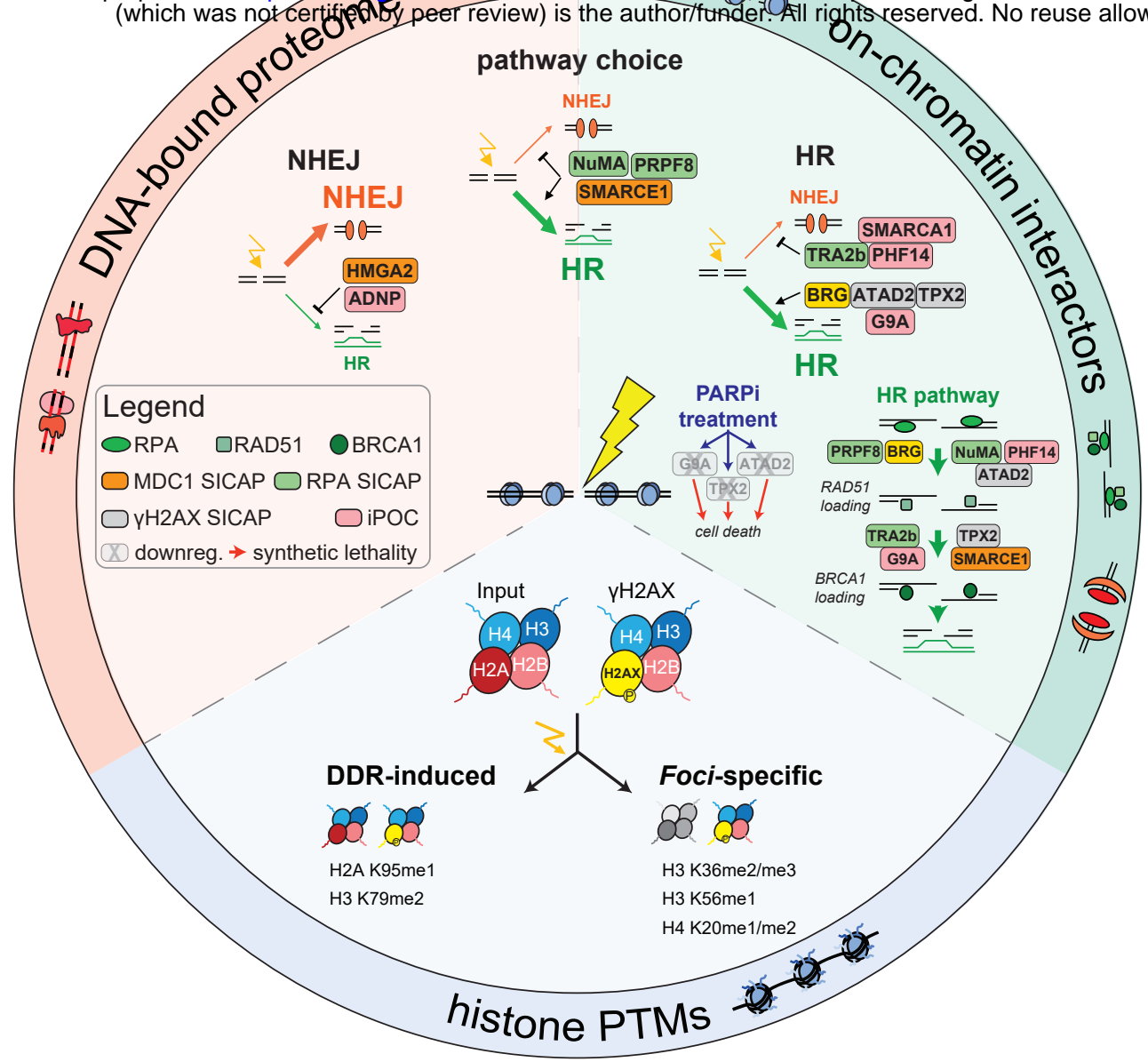


Sigismondo et al. Graphical abstract

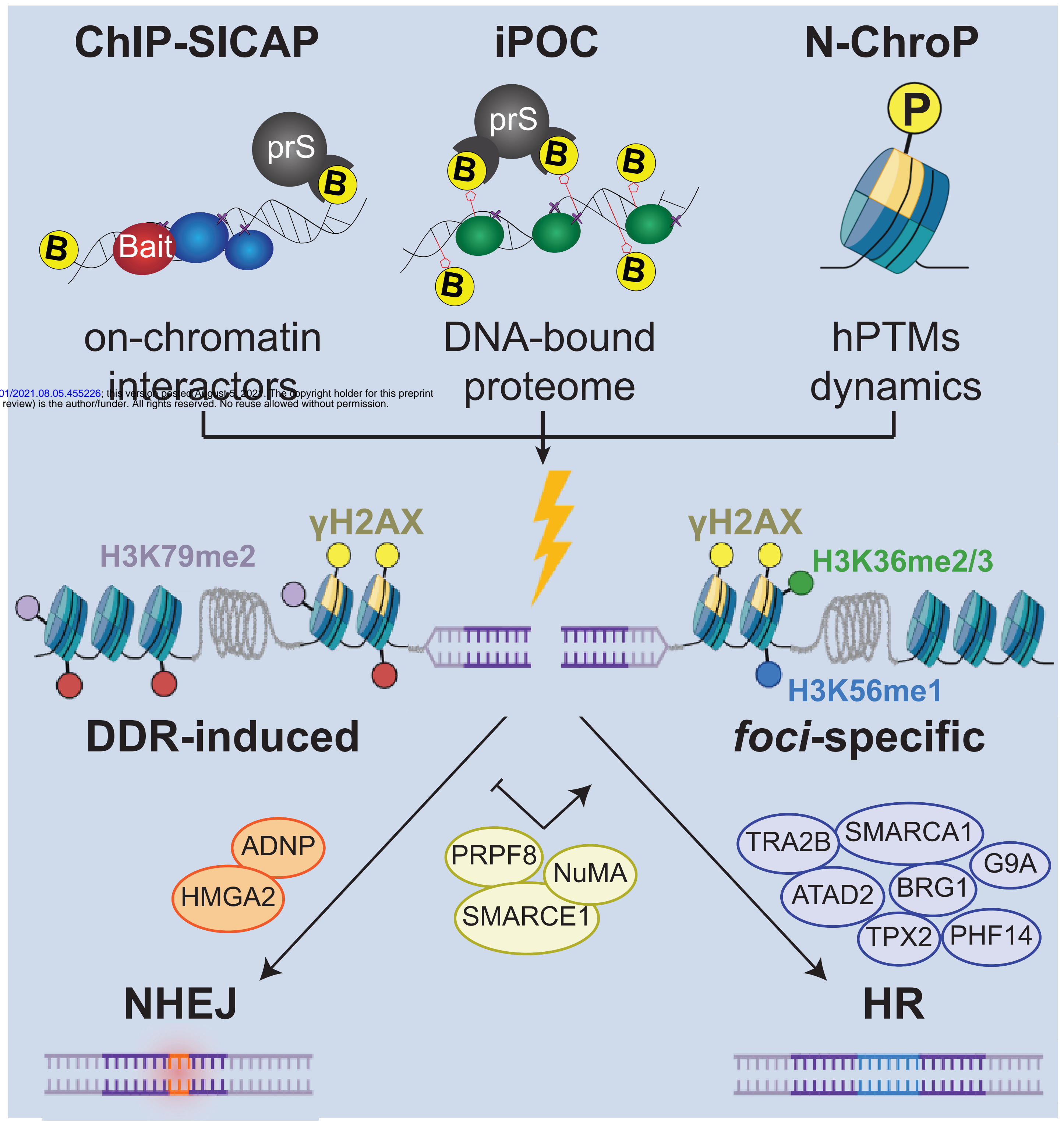


bioRxiv preprint doi: https://doi.org/10.1101/2021.08.05.455226; this version posted August 5, 2021. The copyright holder for this preprint

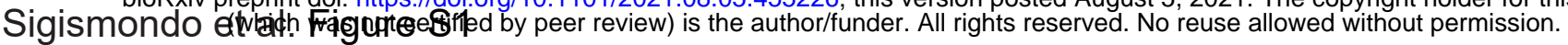
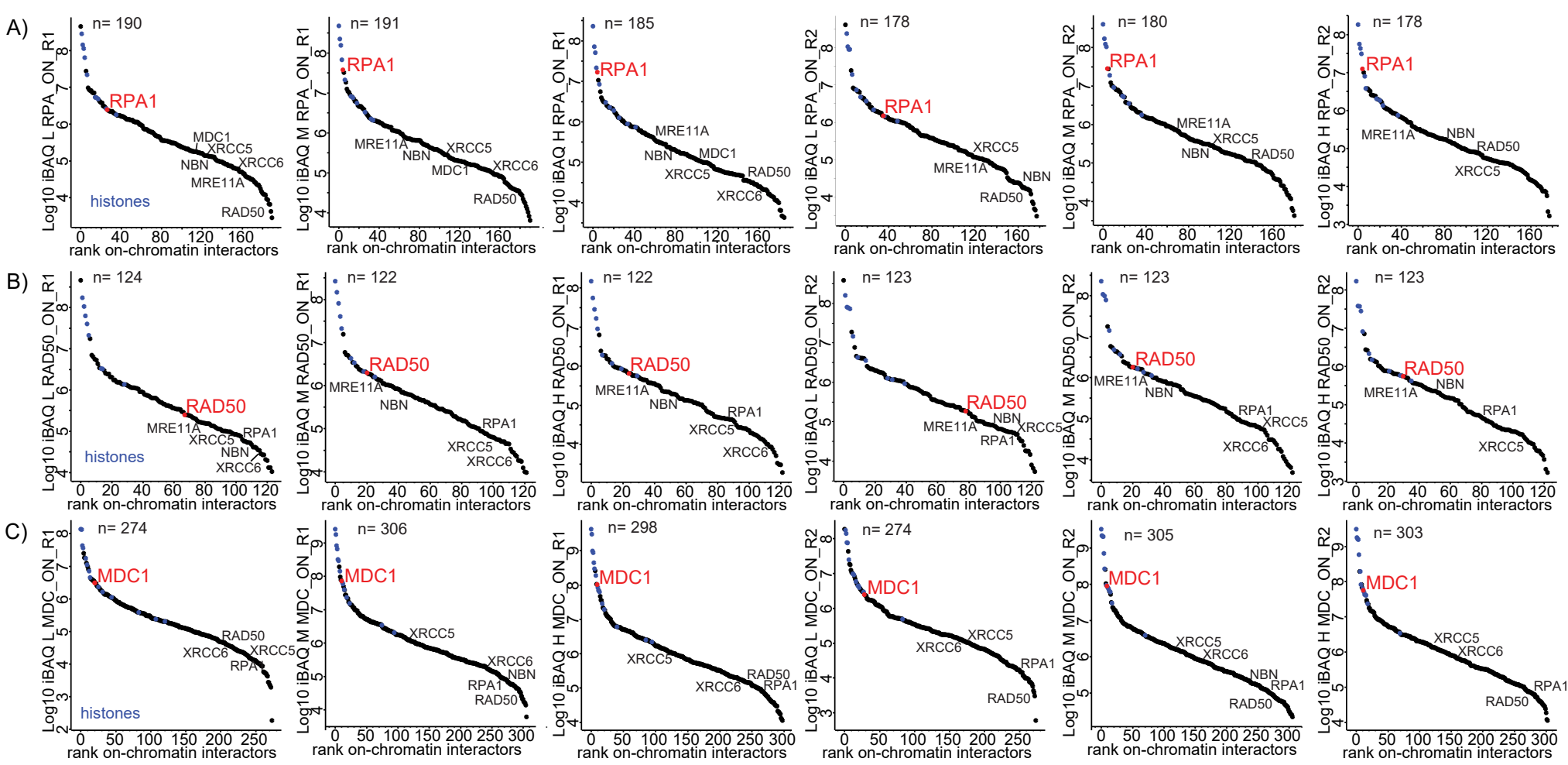

D) RPA ON-chromatin

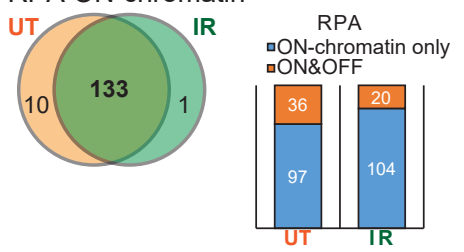

RPA_ON-chromatin_lonizing radiations-only \begin{tabular}{|c|c|c|}
\hline Protein IDs & Protein names & Gene names \\
\hline & Peptidyl-prolyl cis-trans & PPIA \\
\hline
\end{tabular} \begin{tabular}{l|l|l|} 
V9HWF5 & $\begin{array}{l}\text { Peptidyl-prolyl cis-trans } \\
\text { isomerase A }\end{array}$ & PPIA \\
\hline
\end{tabular}

E) RAD50 ON-chromatin

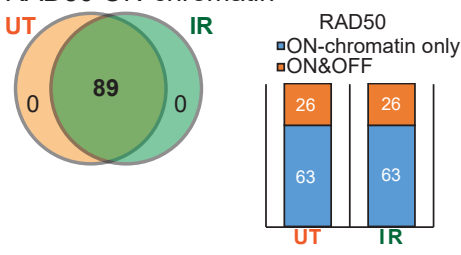

F) MDC1 ON-chromatin
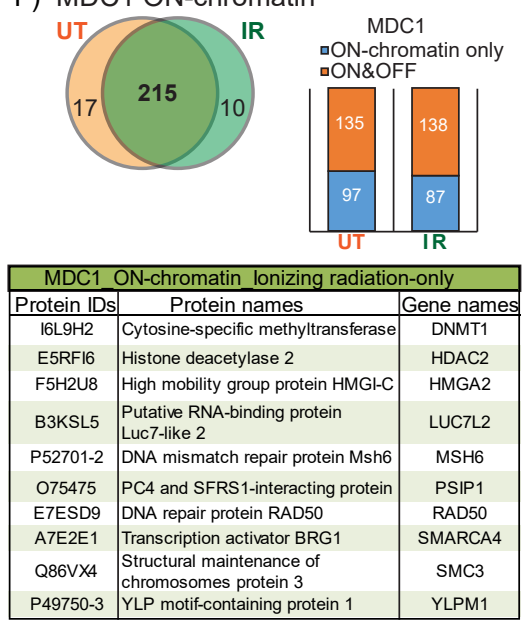

G)

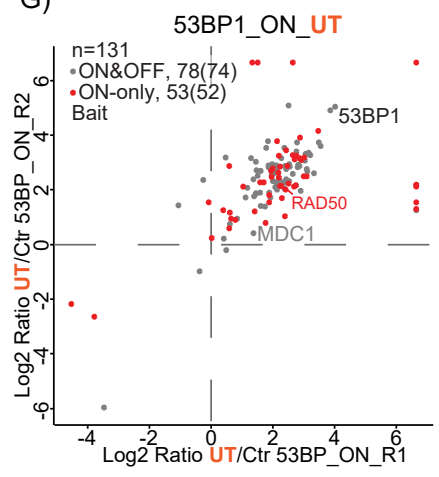

53BP1_ON_IR
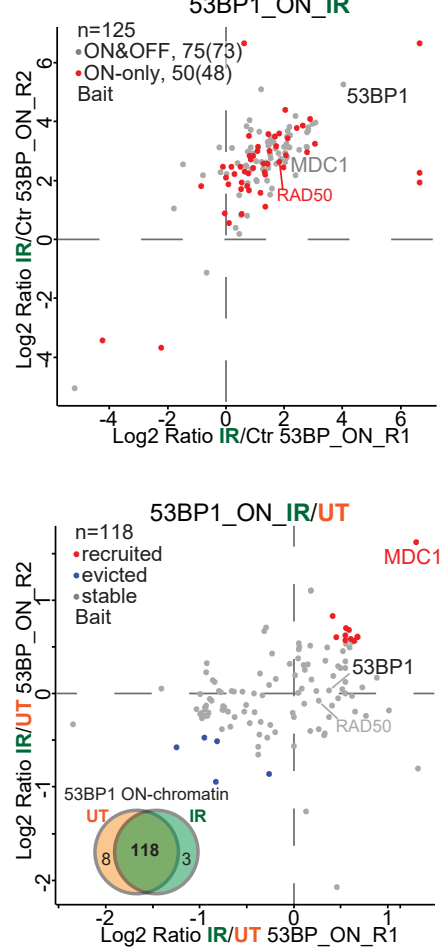

H)

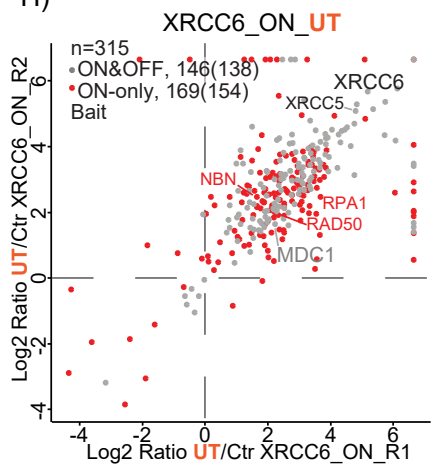

XRCC6_ON_IR
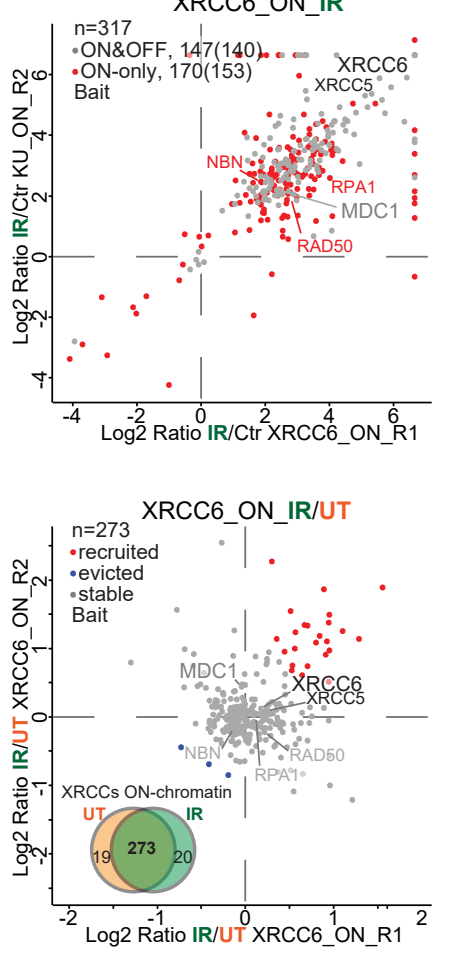

I)

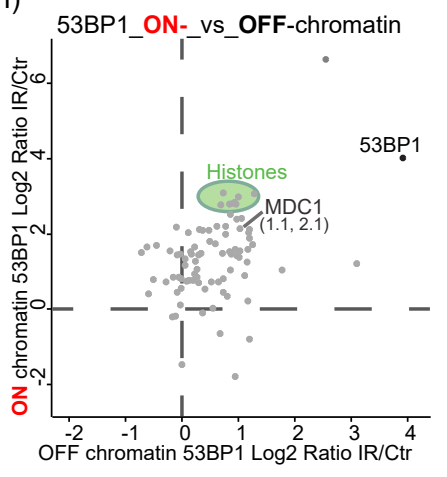

L) XRCC6 ON-vs_OFF-chromatin

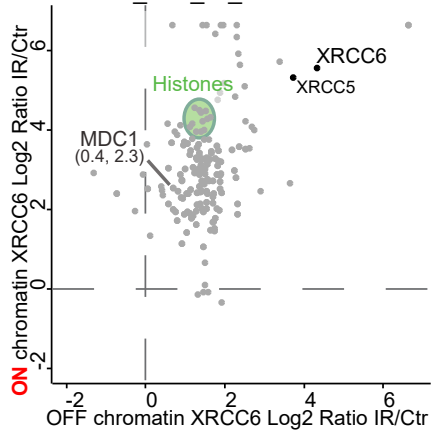

M) MDC1_ON-_vs_OFF-chromatin

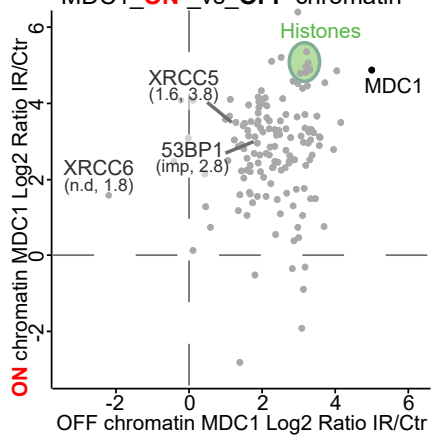


A)
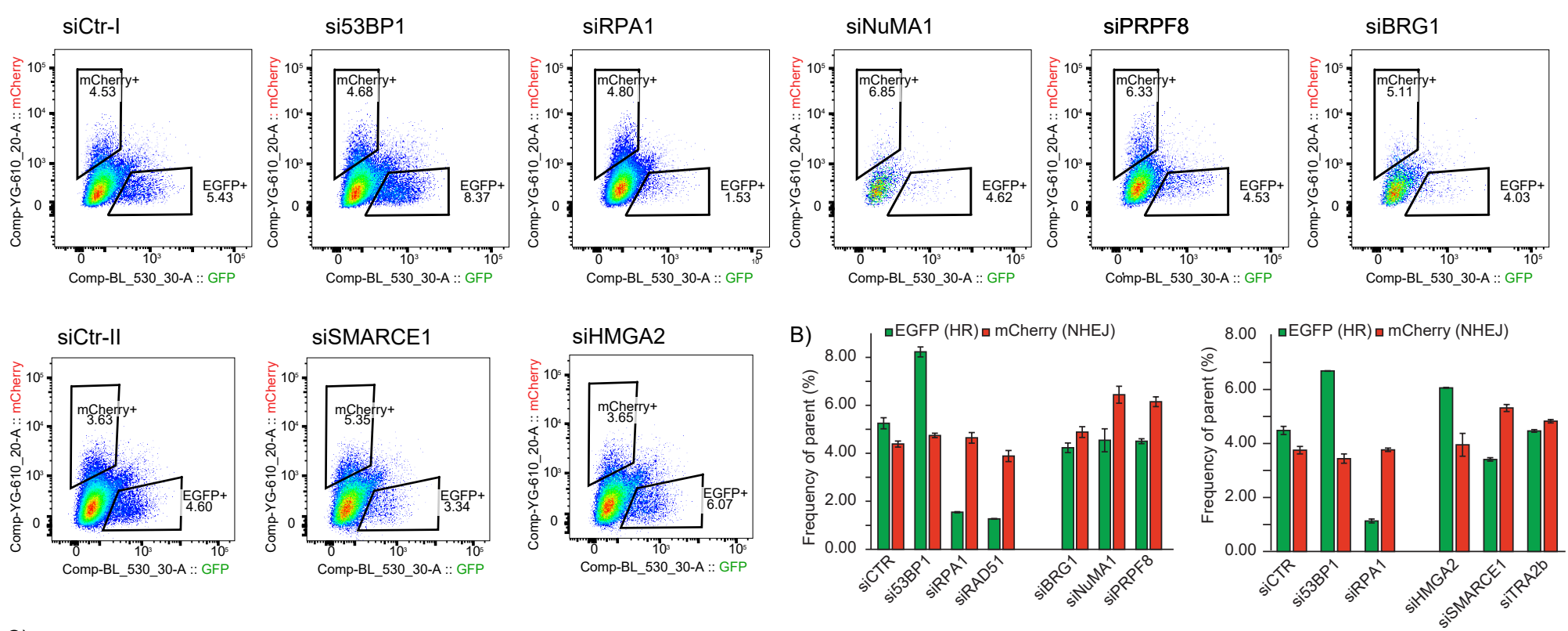

C)
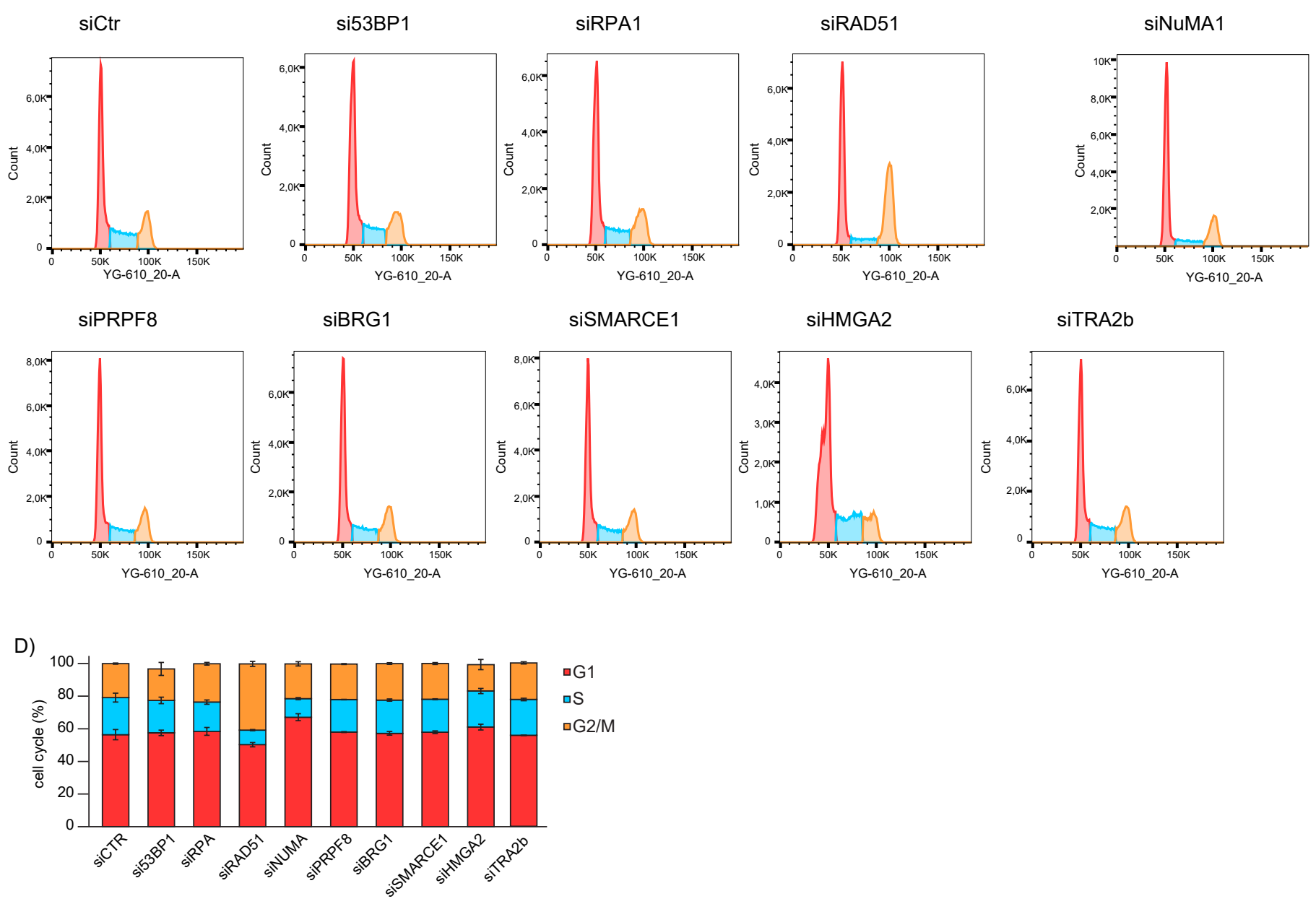
bioRxiv preprint_doi: https://doi.org/10.1101/2021.08.05.455226; this version posted August 5, 2021. The copyright holder for this preprint

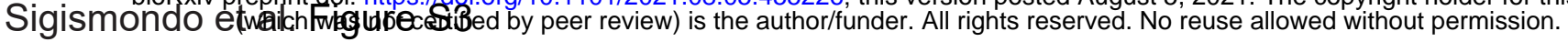

A)
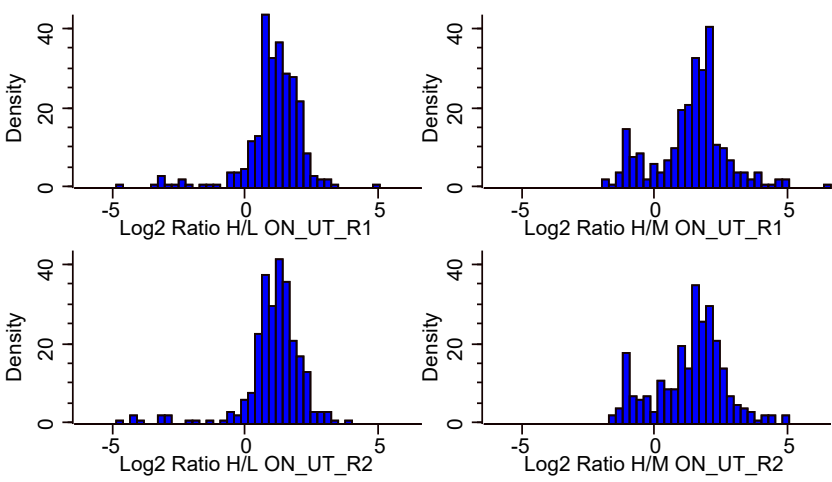

B)
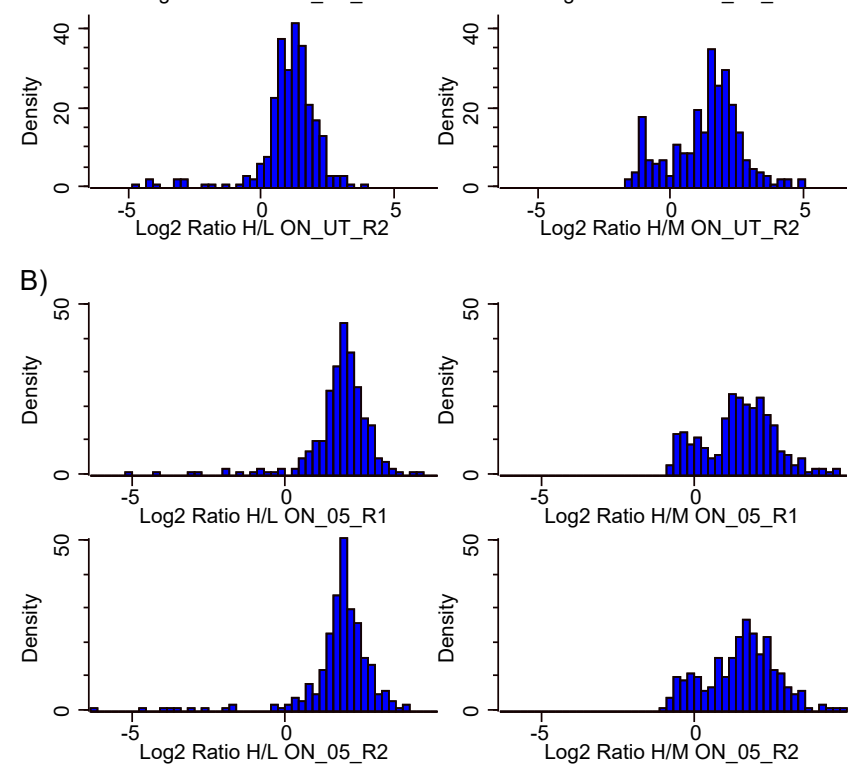

C)
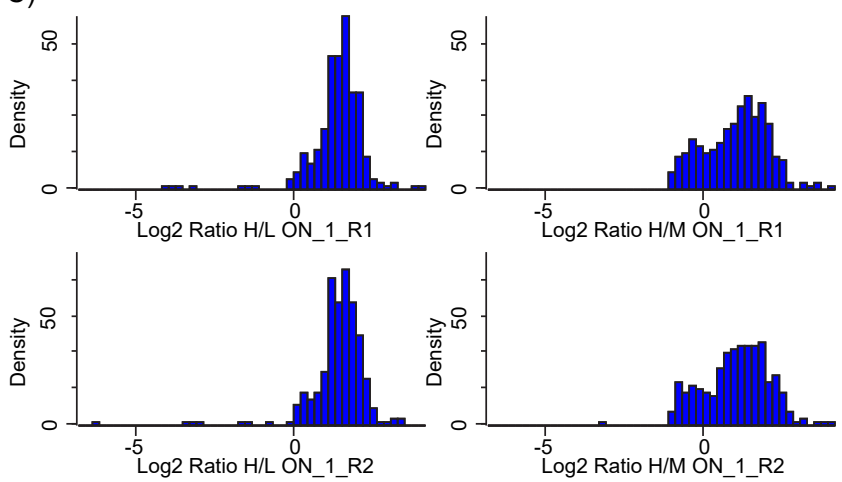

D)
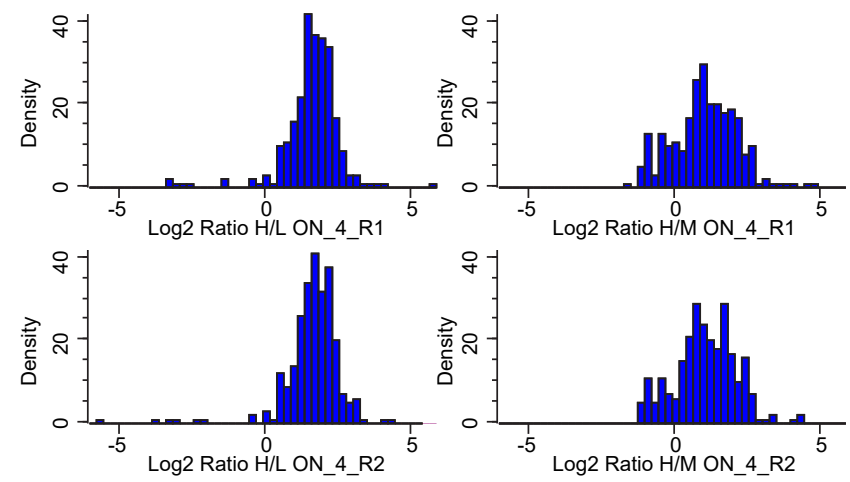

E)
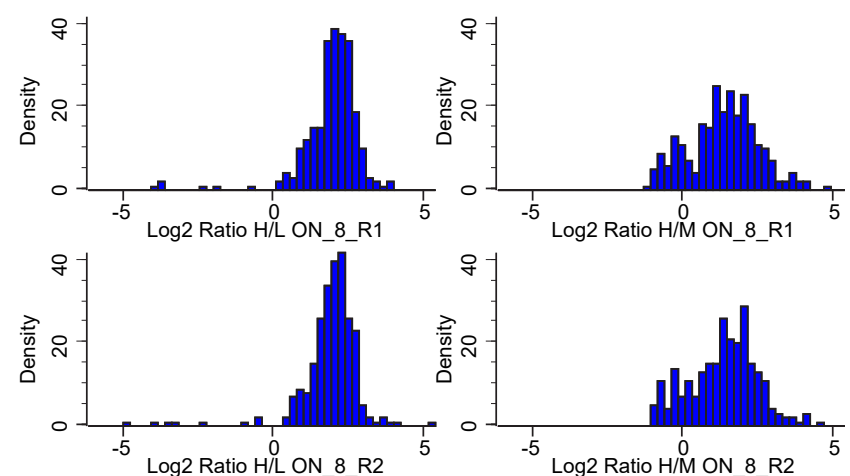
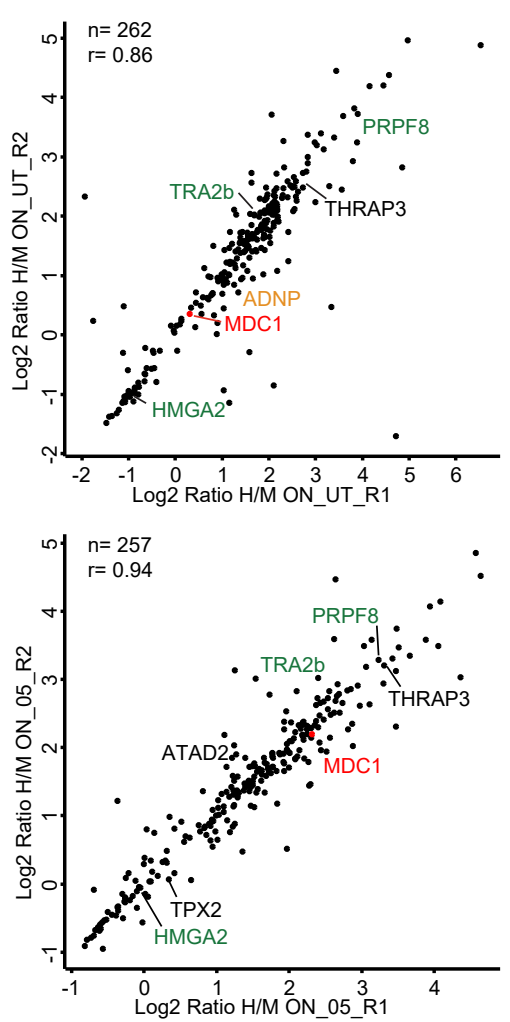

F)
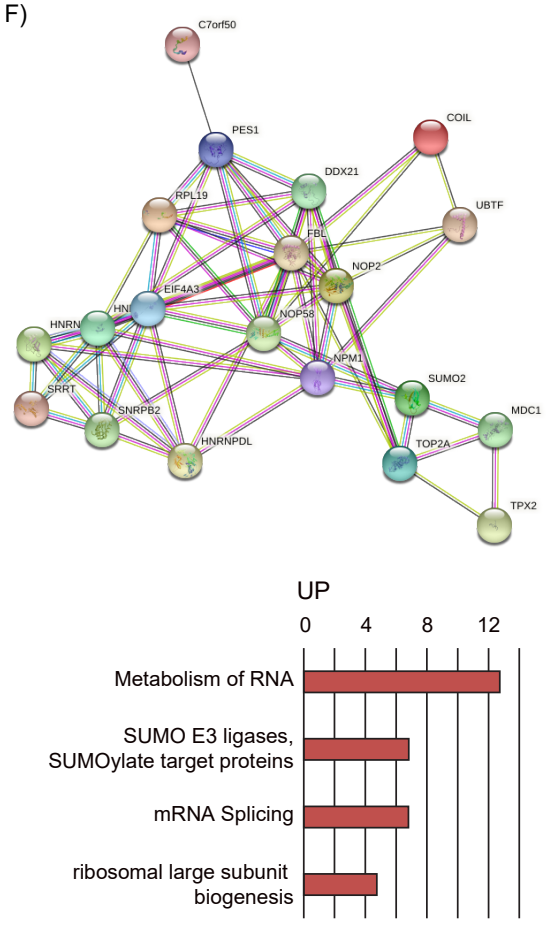

G)
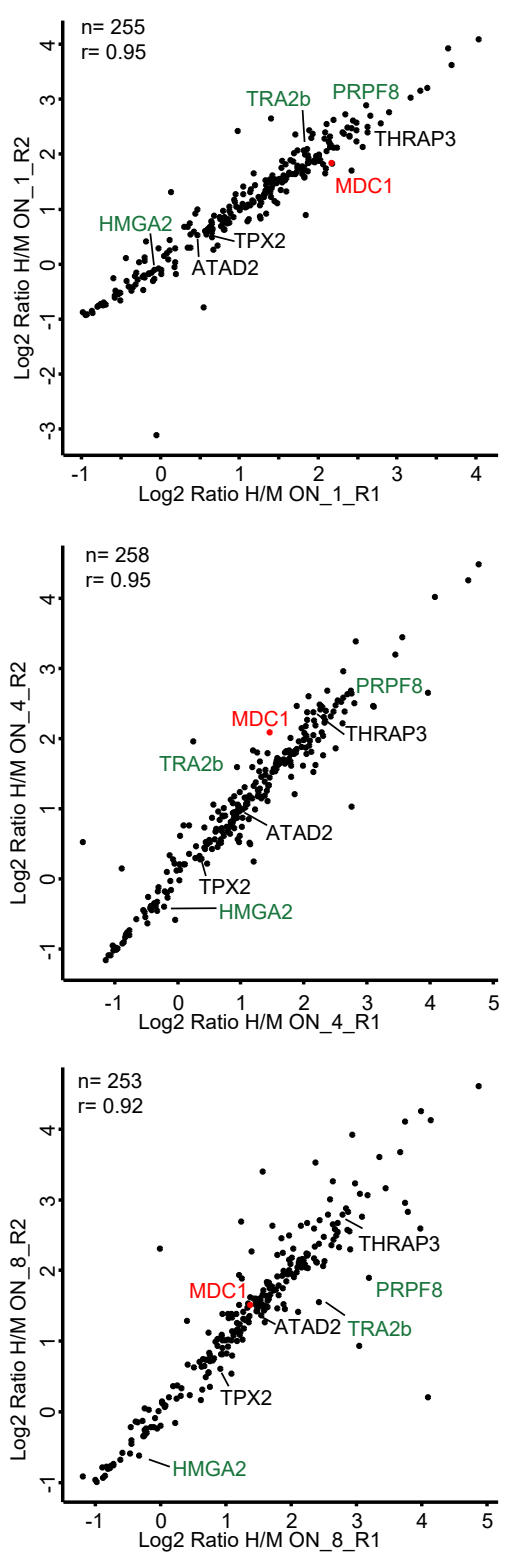

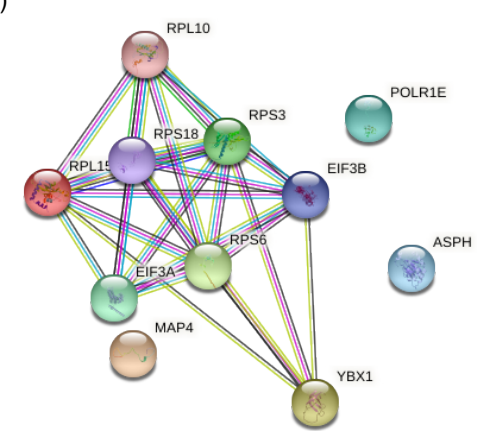

DOWN

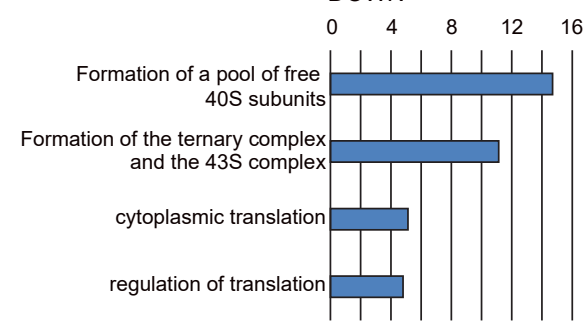


bioRxiv preprint doi: https://doi.org/10.1101/2021.08.05.455226; this version posted August 5, 2021. The copyright holder for this preprint (which was not certified by peer review) is the author/funder. All rights reserved. No reuse allowed without permission.

\section{Sigismondo et al. Figure S4}

A)
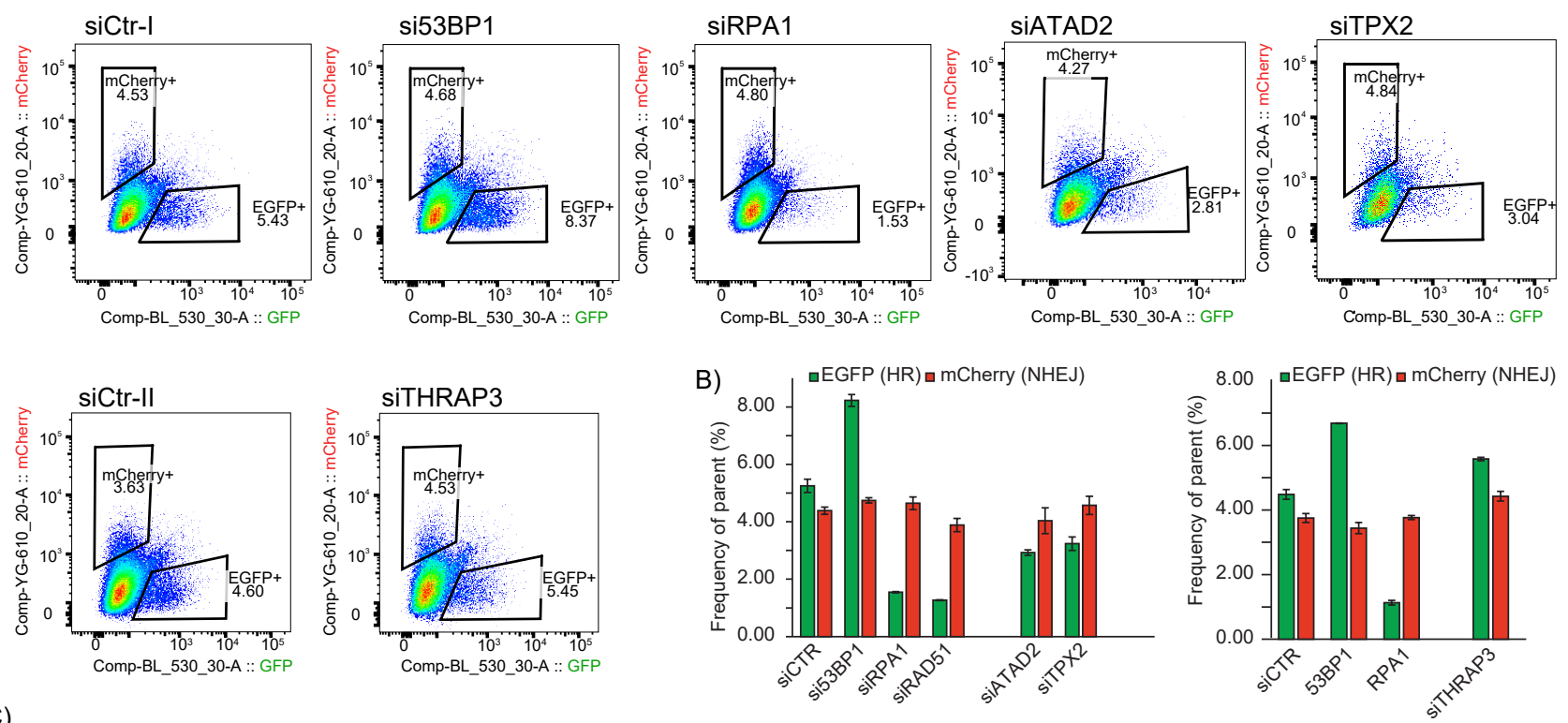

C)
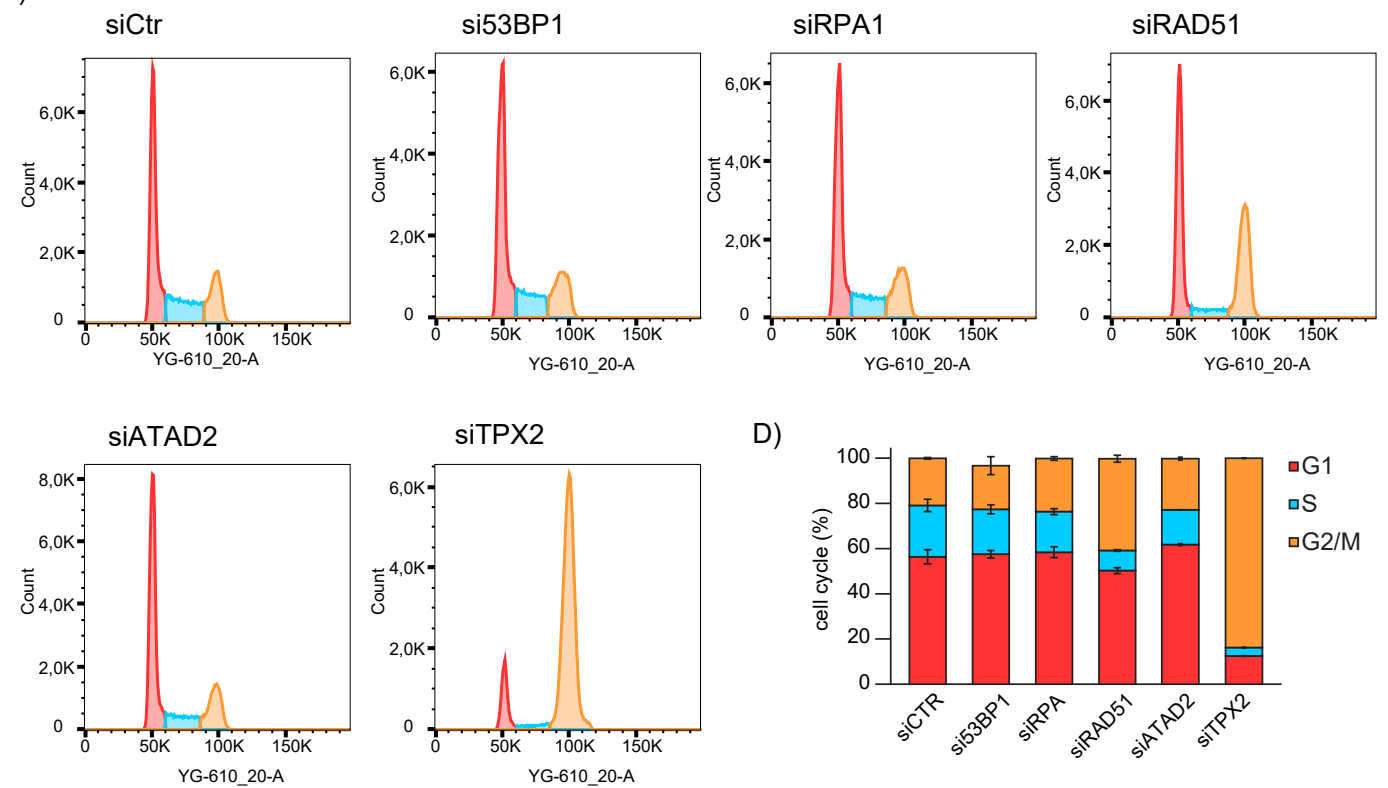

D)

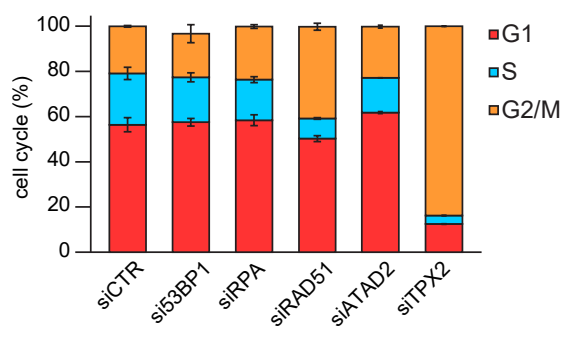


Sigismondo et al. Figure S5

A) untreated

B) 5 Gy ionizing radiations (IR), $1 \mathrm{~h}$ recovery

Cy5-azide Cy5-azide

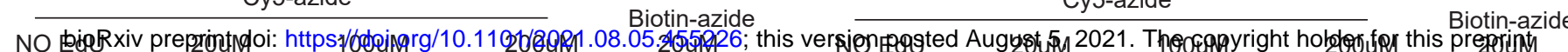

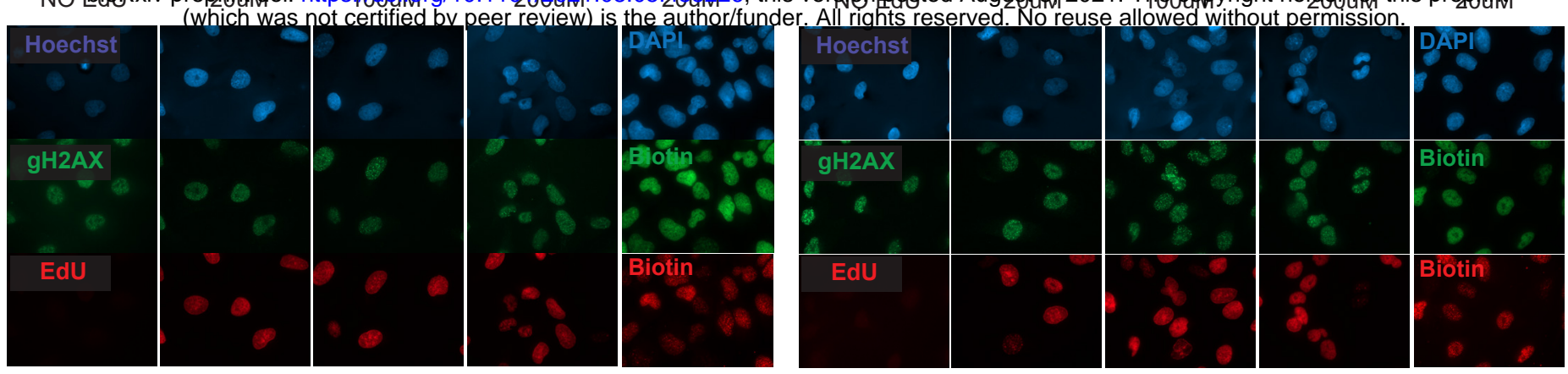

C)

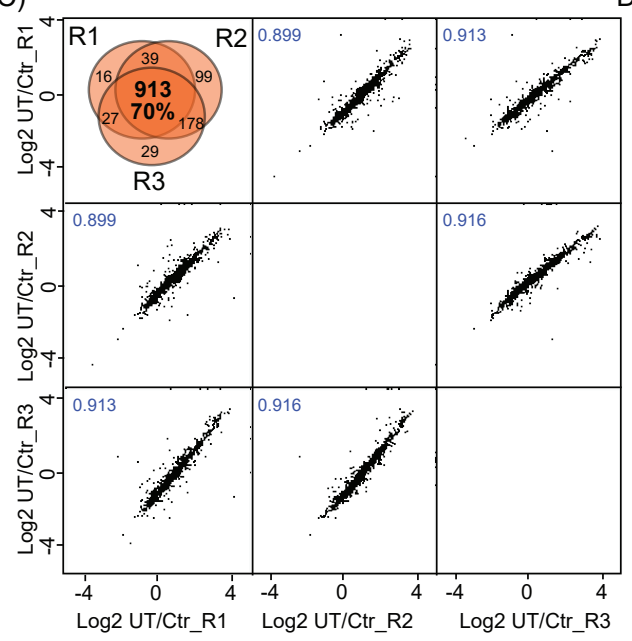

$\mathrm{F}$

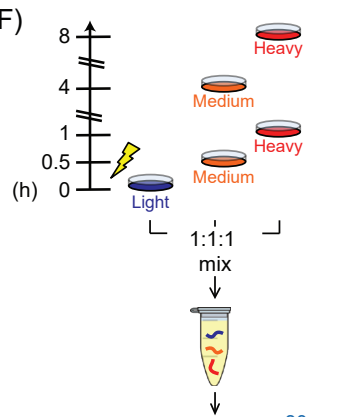

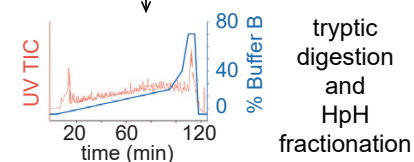

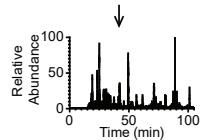

MS analysis
D)

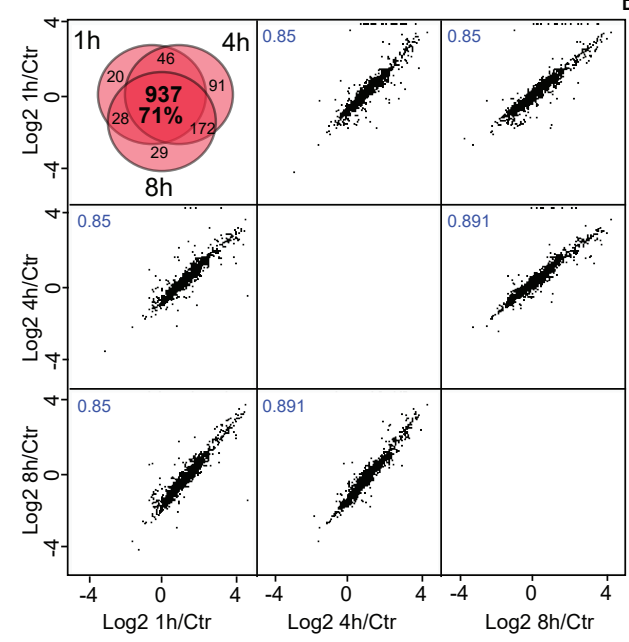

E)
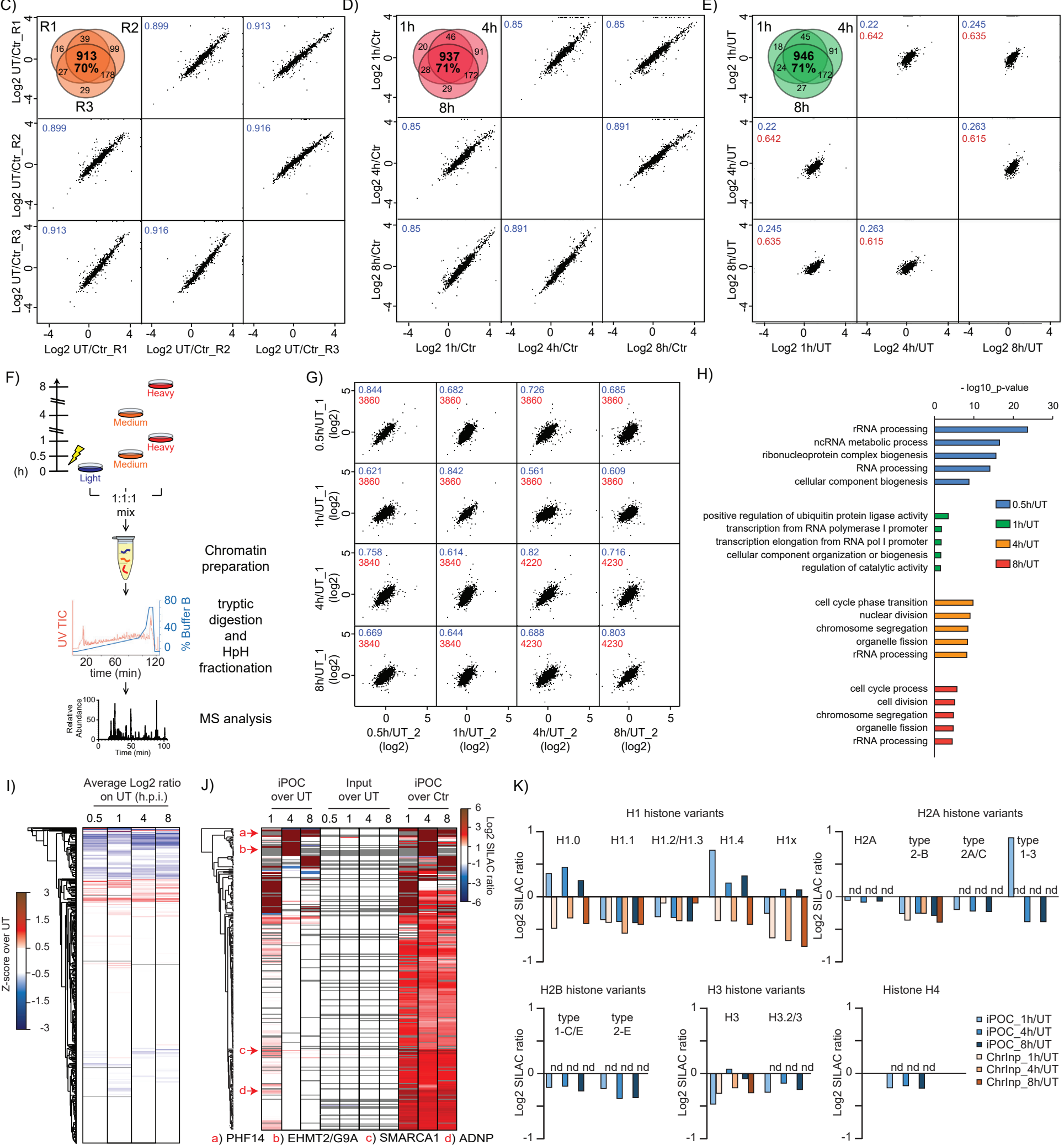

G)

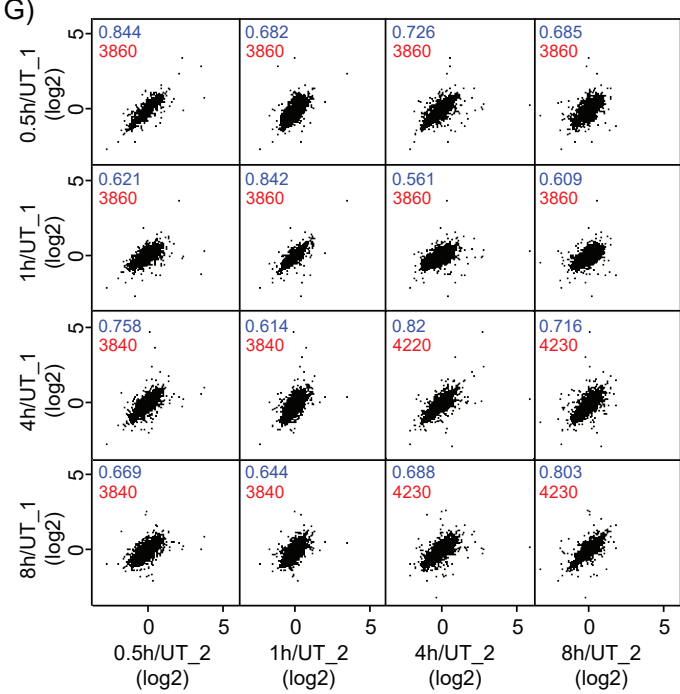

H)

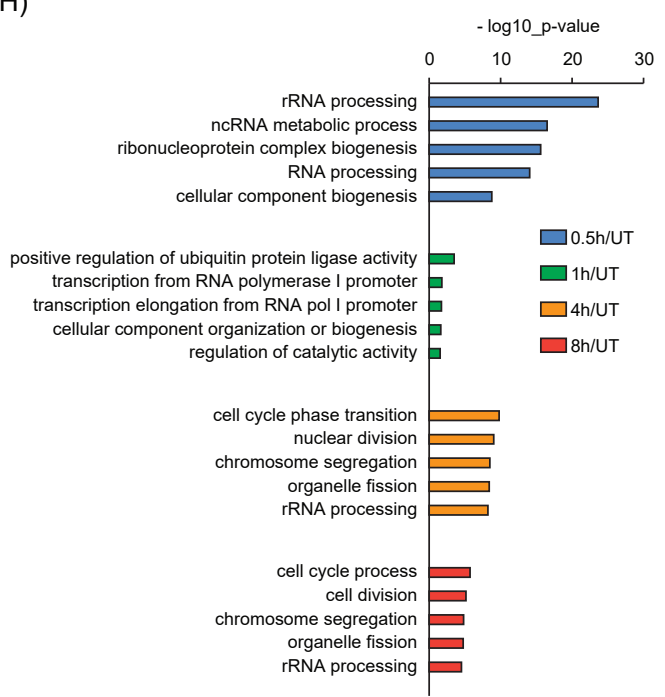

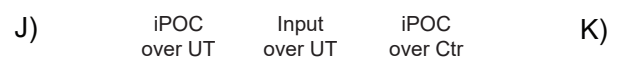
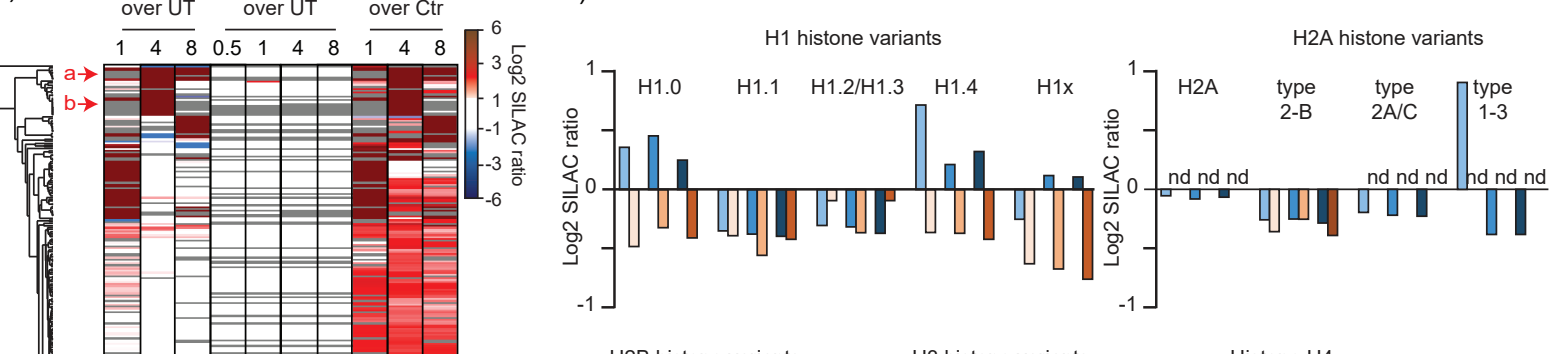

H2B histone variants

$\mathrm{H} 3$ histone variants

Histone H4
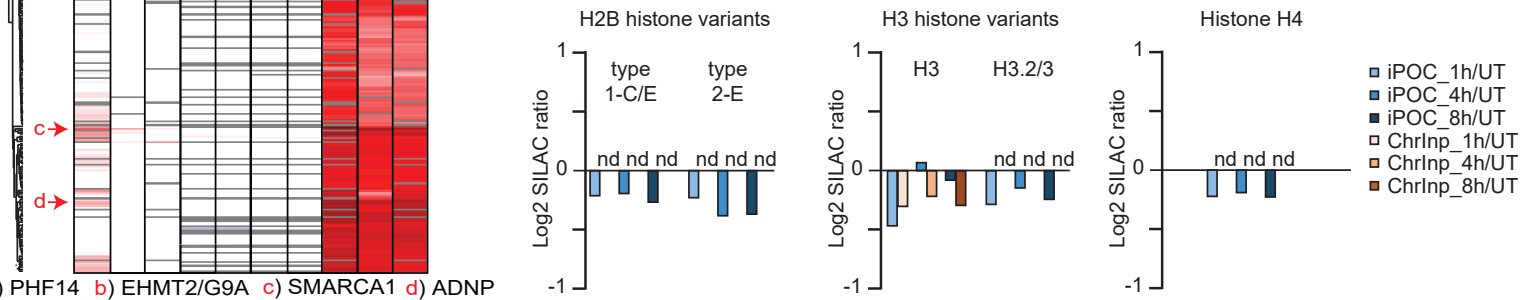

윰

के एपाएए

พั) 
A)
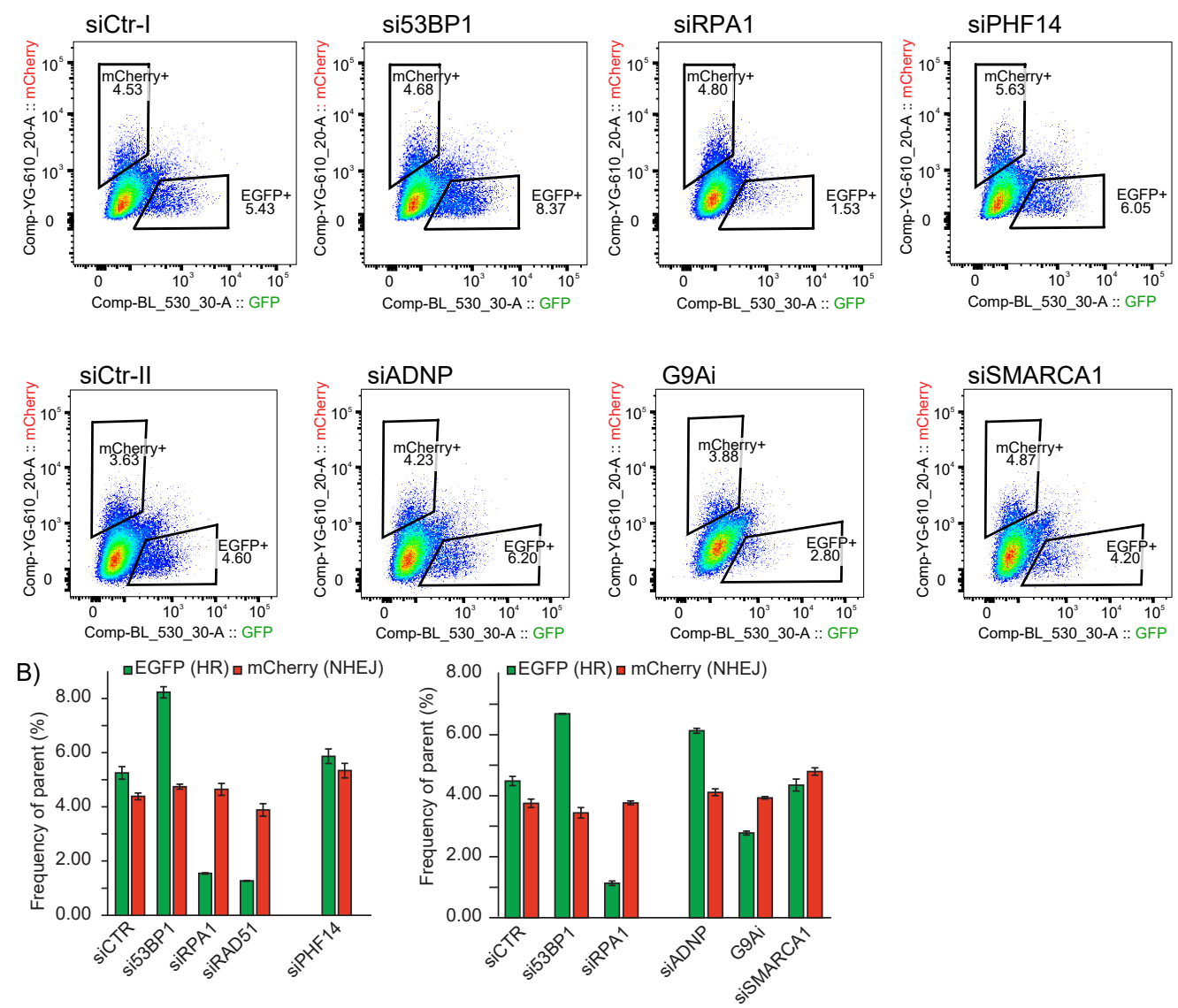

C)
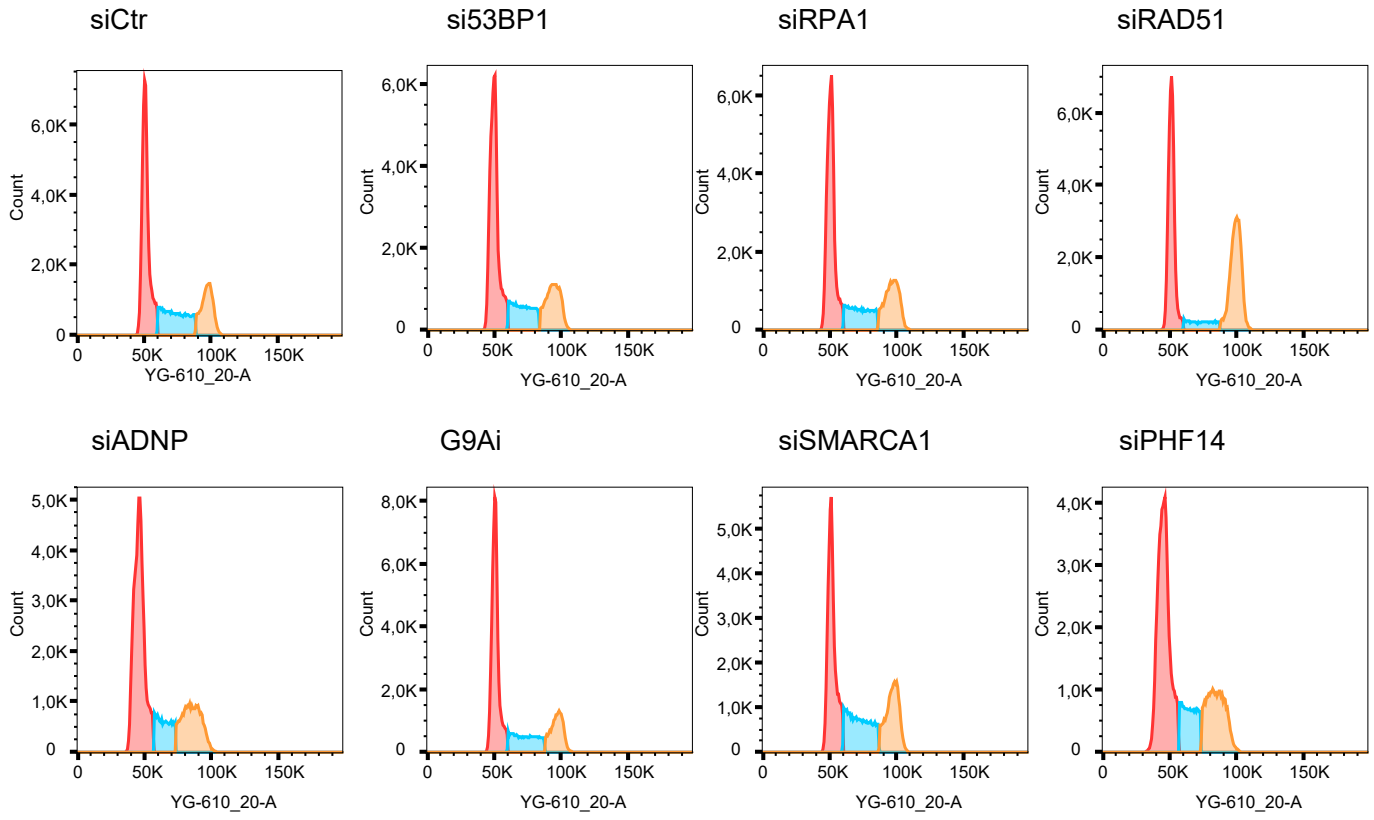

SiPHF14

D)
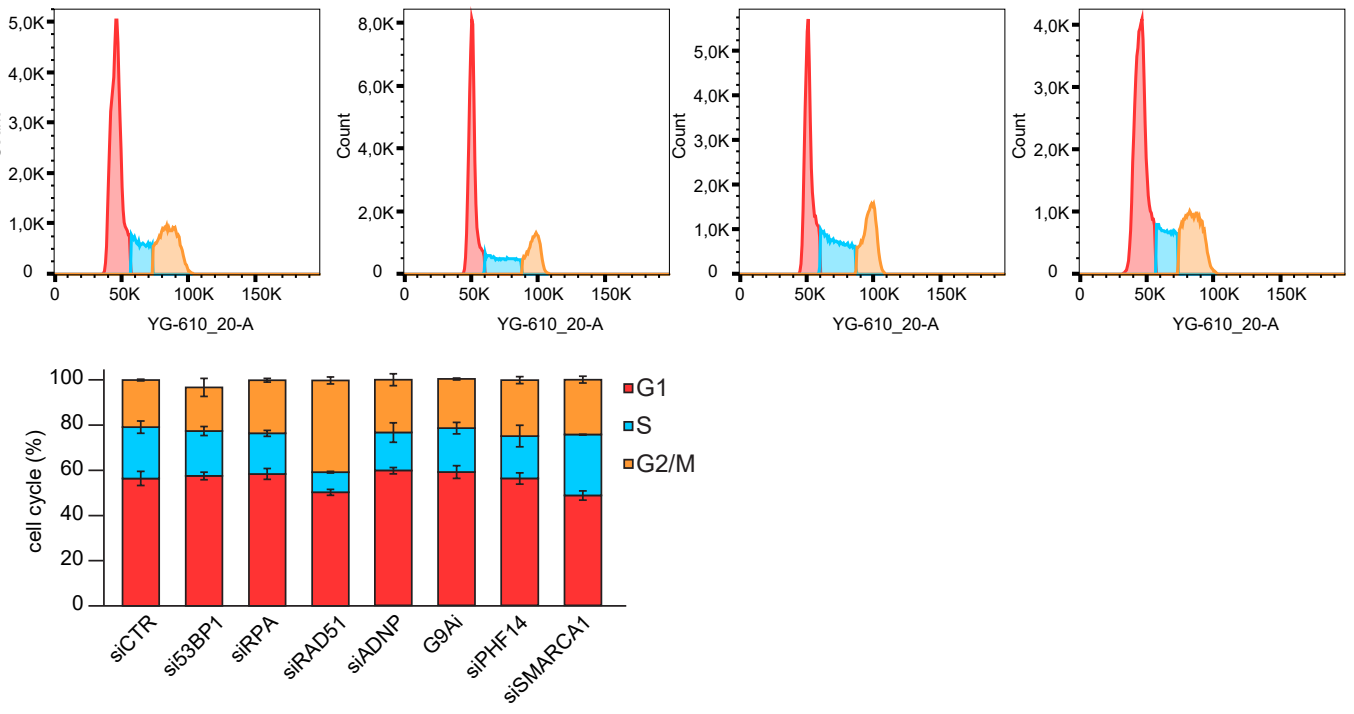
bioRxiv preprint doi: https://doi.org/10.1101/2021.08.05.455226; this version posted August 5, 2021. The copyright holder for this preprint

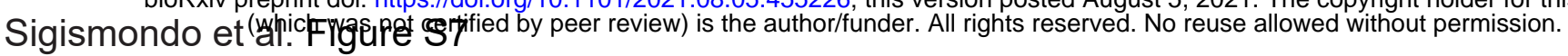
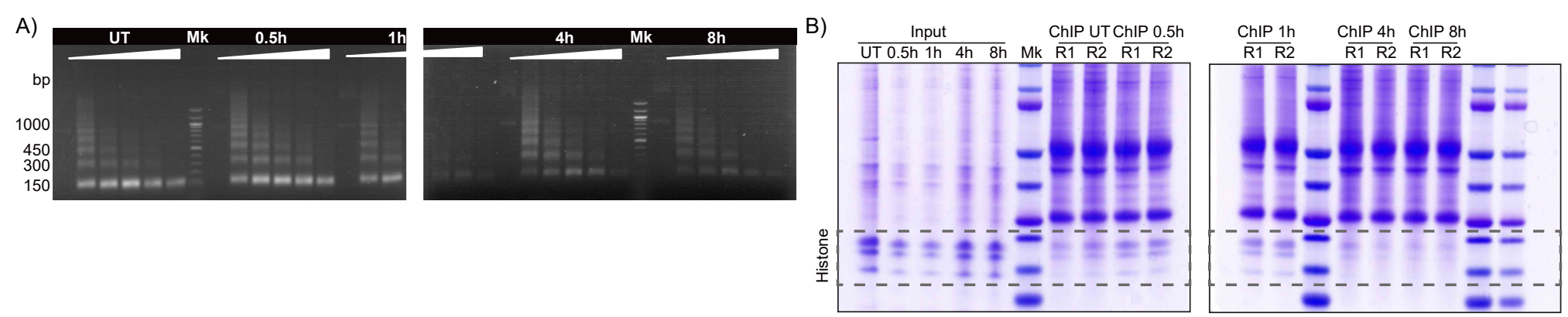

C)
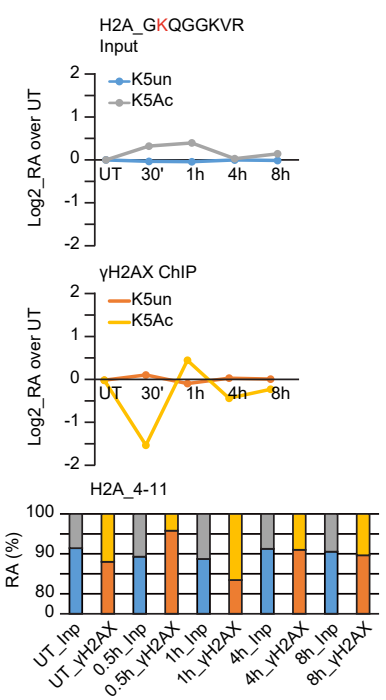

D)
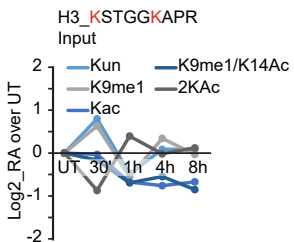

$2 \stackrel{\mathrm{YH} 2 \mathrm{AX} \text { ChIP }}{\mathrm{K} \text { Kun }}-\mathrm{K} 9 \mathrm{me} 1 / \mathrm{K} 14 \mathrm{Ac}$
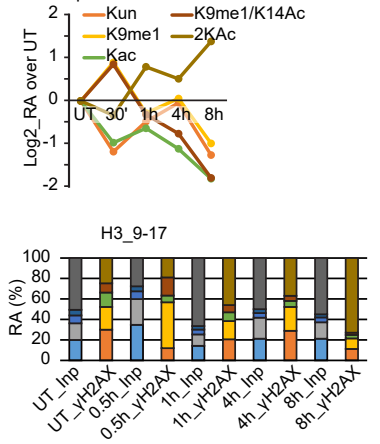

E)

H4_GKGGKGLGKGGAKR
Input
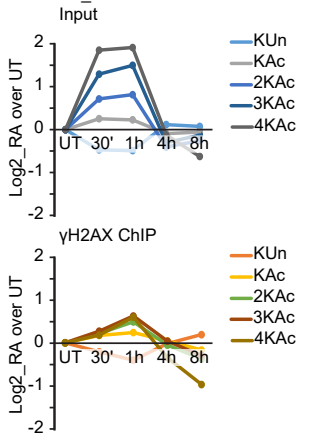

H4_4-17

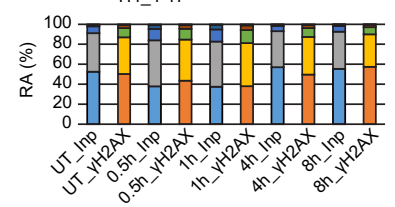

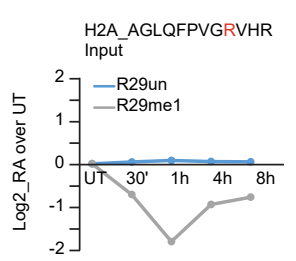

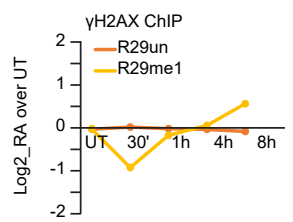

H2A_21-32
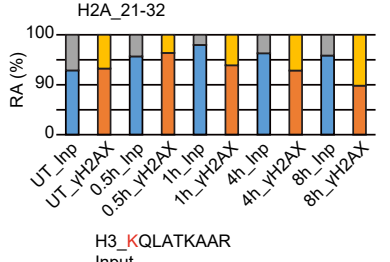

Input
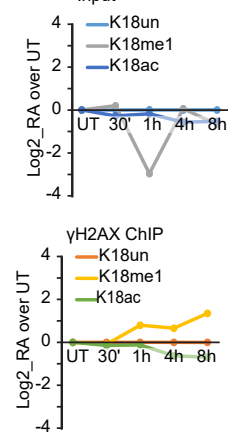

H3_18-26

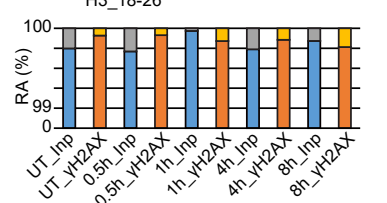

H4_DAVTYTEHAKR

Input

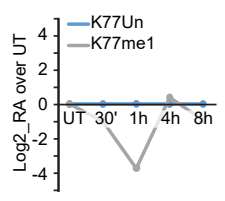

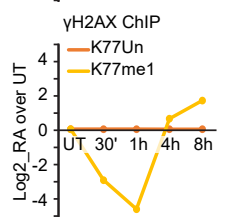

H4_68-78

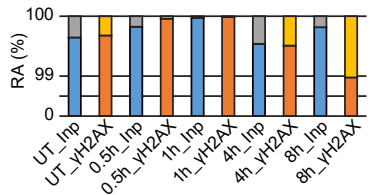

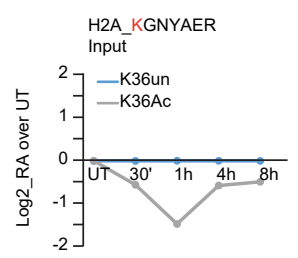

H2A_VTIAQGGVLPNIQAVLLPKKTESHHKAKGK
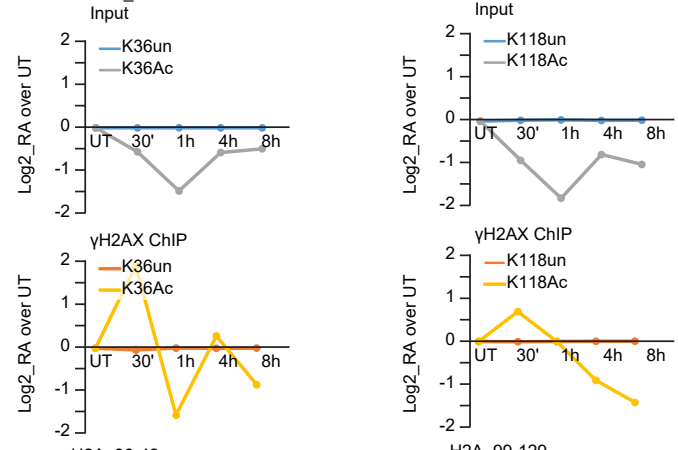

H2A_36-42
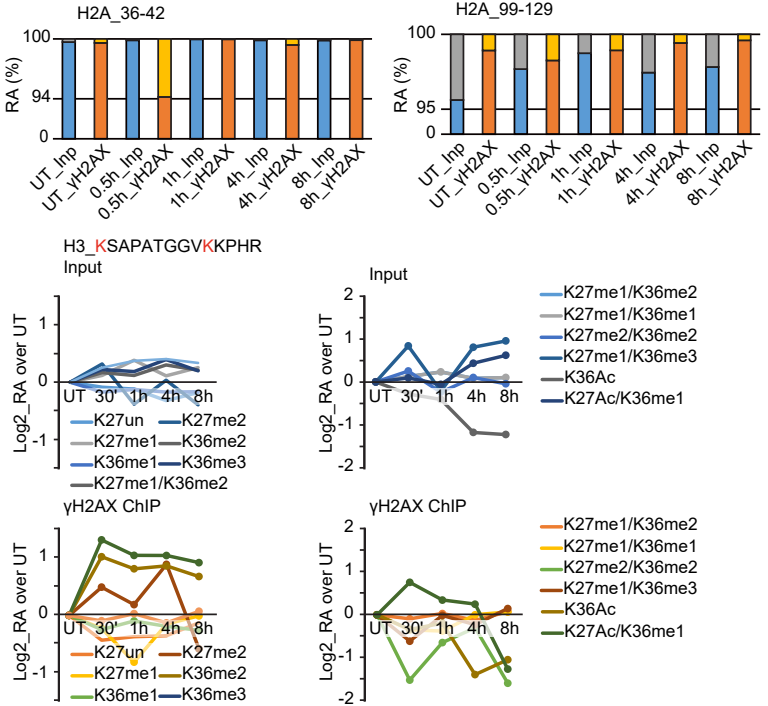

a H3_K27un a H3_K27me2/K36me2

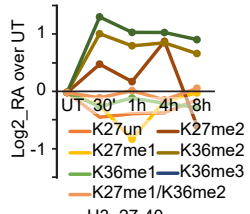

H3_27-40

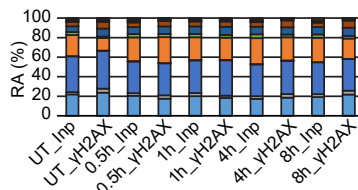

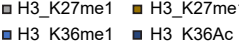

aH3_K27me2 $\square$ H3_K27Ac/K36me1

口 H3_K36me2

口 H3_K36me3

- H3_K27me $1 / \mathrm{K} 36 \mathrm{me} 2$

口 H3_K27me1/K36me1
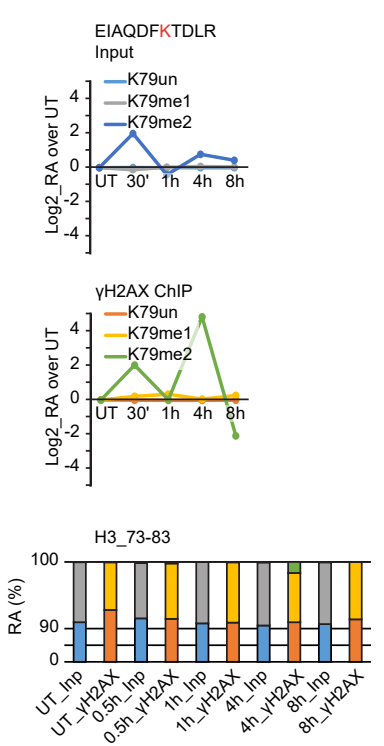